University of San Diego

Digital USD

Theses

Theses and Dissertations

Winter 1-31-2021

\title{
Otolith microchemistry reveals low habitat connectivity of California killifish (Fundulus parvipinnis) across a range of spatial scales
}

Lisa Robison

University of San Diego

Follow this and additional works at: https://digital.sandiego.edu/theses

Part of the Analytical Chemistry Commons, Marine Biology Commons, and the Terrestrial and Aquatic Ecology Commons

\section{Digital USD Citation}

Robison, Lisa, "Otolith microchemistry reveals low habitat connectivity of California killifish (Fundulus parvipinnis) across a range of spatial scales" (2021). Theses. 50.

https://digital.sandiego.edu/theses/50

This Thesis: Open Access is brought to you for free and open access by the Theses and Dissertations at Digital USD. It has been accepted for inclusion in Theses by an authorized administrator of Digital USD. For more information, please contact digital@sandiego.edu. 
San Diego

Otolith microchemistry reveals low habitat connectivity of California killifish (Fundulus parvipinnis) across a range of spatial scales

A thesis submitted in partial satisfaction of the requirements for the degree of

Master of Science in Environmental and Ocean Sciences

$$
\text { by }
$$

Lisa Catherine Robison

Thesis Committee

Dr. Drew Talley, Ph.D., Chair

Dr. Steven Searcy, Ph.D.

Dr. Andrew Thompson, Ph.D. 
The thesis of Lisa Catherine Robison is approved by:

Dr. Drew Talley, Ph.D., Chair

University of San Diego

Dr. Steven Searcy, Ph.D.

University of San Diego

Dr. Andrew Thompson, Ph.D.

Southwest Fisheries Science Center

University of San Diego

San Diego

2021 
(C) 2021 Lisa Catherine Robison 


\section{DEDICATION}

To my grandparents, Kay and Les Robison and my Popo, Soon Yin Kwan Chan. 


\section{ACKNOWLEDGMENTS}

First and foremost, I would like to thank my committee chair, Dr. Drew Talley, for inviting me to the EOSC graduate program, his advice on the design and execution of this study, and overall insight and support throughout my graduate studies. Drew, your mentorship, humor, and compassion over the past three years has been greatly appreciated. I have learned many things from you, about science and more, and I will always be grateful for your lessons about connectivity in all ways in life.

To my other committee members, Dr. Steven Searcy and Dr. Andrew Thompson, a sincere thank you for your expertise, guidance, and feedback on this manuscript. Steve, I appreciate you letting me pop my head into your office to ask questions, and your encouragement and technical expertise on labwork and fieldwork made it possible for me to analyze as many sampling locations as I did. Andrew, thank you for your enthusiasm about my research, valuable insight, and assistance with data analysis. The data analysis portion of my thesis was made possible by the afternoon you spent going over my code line by line with me.

Thank you to Ruan Hattingh and Dr. James Day at Scripps Institution of Oceanography's Isotope Geochemistry Laboratory for allowing me to use the ThermoFisher iCAP ICP-MS, for helping me to run sample preparation and sample analysis in their laboratory, and for their assistance with ICP-MS data analysis. I would also like to thank Dr. Dovi Kacev for his help with my multivariate statistical analysis, and for being the best biostatistics professor I've had. 
A big thank you to the many volunteers that helped me collect Killifish during my fieldwork: Justin McCullough, Marisol Shin, Alexander Blanco, Caitlynn Birch, Jackson Ingram, Helen Le, Lauren Robison, Patrick Levin, Thalia Rossette, Thomas Alchermes. I would also like to thank Chloe Van Grootheest at California State University at Long Beach for allowing me to join her sampling at Seal Beach National Wildlife Refuge, for teaching me how to seine for wetland fish, and for helping me to collect samples in Anaheim Bay.

Financial support for this research was provided by the American Killifish Association and the EOSC Department at University of San Diego. Thank you for your contributions that made this research possible.

To all of my friends, fellow graduate students, and the EOSC Department professors and staff at University of San Diego, thank you for your contributions to my research over the past three years. To my wonderful cohort, Caitlynn Birch, Rachel Steinberg, Gabriela Yamhure, and Marisol Shin, I feel lucky to have gone through graduate school with you all and I truly would not have been able to do it without your friendship. Thank you to the Talley Lab, Katie Robinson-Filipp, Emily Parks, and Marisol Shin for being great lab buddies during long hours of labwork together. I would especially like to thank my roommate and one of my best friends, Helen Le, for being my \#1 fieldwork buddy and for her tremendous help behind the scenes, including many hours of late night science talks.

To my boyfriend Patrick, I can’t thank you enough for your support and unwavering confidence in me from the very beginning. From helping me edit my application essay to getting our boots stuck in the mud while installing minnow 
traps in Vener Pond, to providing excellent feedback when I was practicing for my defense, I couldn’t have done this without you. Thank you for being my best friend and biggest supporter.

Finally, I wish to thank my wonderful family for their endless support, love, and encouragement. To my Mom and Dad; Connie and Alan, thank you for being my inspiration for my education and career; and for the many science summer camps and family trips to the ocean as a kid. To my sister Lauren and my brother Lucas, I'm lucky to have you both in my life and celebrating this achievement wouldn't be the same without your encouragement along the way. 


\section{TABLE OF CONTENTS}

ACKNOWLEDGEMENTS.............................................

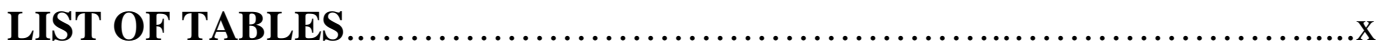

LIST OF FIGURES...................................................

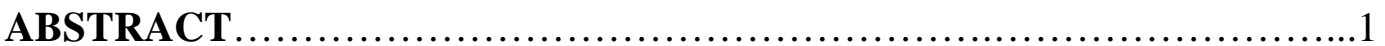

\section{CHAPTER 1: Introduction}

1.1 Introduction....................................................

1.1.1 Southern California Estuaries..............................3

1.1.2 Habitat Connectivity of Estuarine Fishes....................6

1.1.3 Otolith Microchemistry...............................9

1.1.4 Life History of California killifish (Fundulus parvipinnis)..15

1.2 Research Objectives............................................20

1.3 Statement of Hypotheses....................................21

\section{CHAPTER 2: Otolith microchemistry reveals low habitat connectivity of}

California killifish (Fundulus parvipinnis) across a range of spatial scales

2.1 Introduction..................................................22

2.2 Materials and Methods........................................26

2.2.1 Study System.....................................26

2.2.2 Fish Collection and Otolith Dissection....................28

2.2.3 Bulk Inductively Coupled Plasma Mass Spectrometry (ICP-

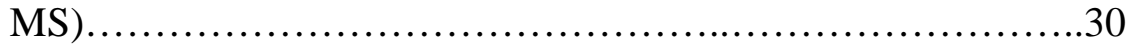

2.2.4 Statistical Analyses....................................37

2.3 Results..................................................... 40

2.3.1 ICP-MS Trace Elemental Analysis.......................40

2.3.2 Inter-Bay Analysis.................................40

2.3.2.1 Discriminant Function Analysis (DFA)..........40

2.3.2.2 Permutational Multivariate ANOVA

(PERMANOVA) ..................................41

2.3.2.3 Mantel Test.................................41

2.3.3 Intra-Bay Analysis..................................42 
2.3.3.1 Mission Bay......................................42

2.3.3.2 San Diego Bay.....................................43

2.3.3.3 Anaheim Bay.....................................43

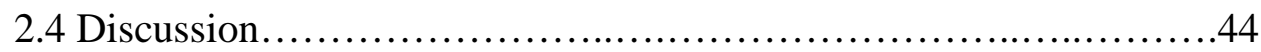

2.4.1 Otolith Microchemical Analysis.............................44

2.4.2 Mission Bay.............................................53

2.4.3 San Diego Bay .........................................54

2.4.4 Anaheim Bay..........................................54

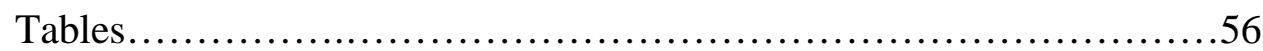

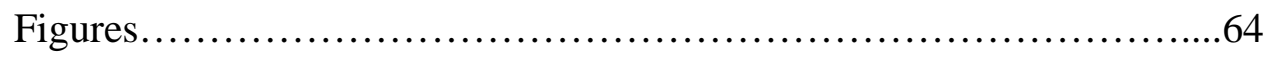

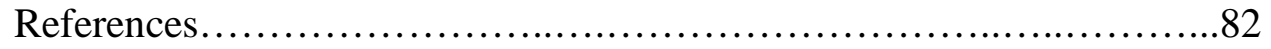

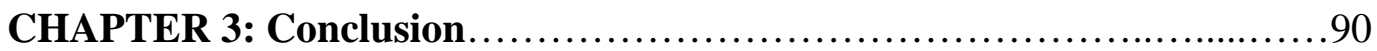

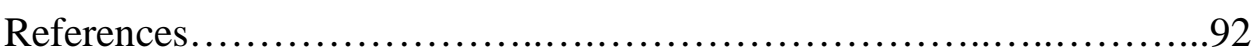

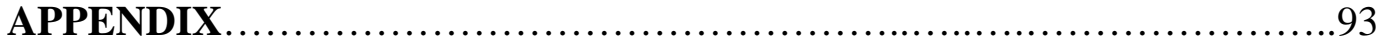




\section{LIST OF TABLES}

Table 2.1 106 adult California killifish (Fundulus parvipinnis) collected from ten sites across three estuaries (Mission Bay, San Diego Bay, and Anaheim Bay). Round of ICP-MS analysis, fish standard length size range, and number of fish per site utilized for bulk otolith microchemical analysis are included............56

Table 2.2 Distance $(\mathrm{km})$ between the GPS locations of the ten collection sites obtained from Google Earth Pro’s Ruler tool, Imagery Date = 17 Nov2018. When necessary, total distance was calculated by combining multiple line segments to fit the shape of the estuary..... 57

Table 2.3 Elemental Concentrations of External Standards (FEBS-1, CS, and $\mathrm{TAB}$ ) reported in units of ppm...

Table 2.4 Classification success matrix based on linear discriminant function analysis of 106 otolith signatures (from all 10 collection sites) analyzed by bulk ICP-MS

Table 2.5 Results of the PERMANOVA tests comparing the difference in mean concentration of each metal among all 10 collection sites. Significance codes: 0

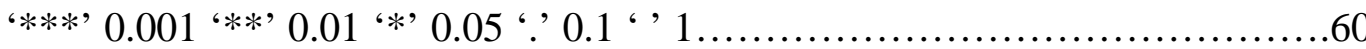

Table 2.6 P-values from Pairwise PERMANOVA tests. $\mathrm{P}-$ values of 96 pairwise comparisons of the 10 sites to determine which sites are statistically different based on otolith trace metal signature. 43/45 pairwise comparisons were 
statistically significant with a $\mathrm{p}-$ value $\leq 0.05(\alpha=0.05)$. Significant pairwise comparisons are denoted by an asterisk*

Table 2.7 Classification success matrix based on linear discriminant function analysis of 36 otolith signatures from three sites in Mission Bay, CA (MB1, MB2,

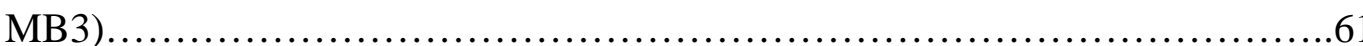

Table 2.8 Results of the PERMANOVA test comparing the difference in mean concentration of each metal among three sites in Mission Bay, CA (MB1, MB2,

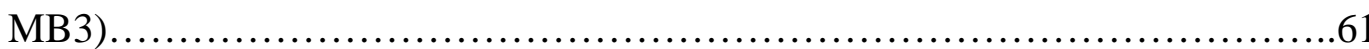

Table 2.9 P-values from Pairwise PERMANOVA test of mean metal concentration among three sites in Mission Bay, CA (MB1, MB2, MB3).

Significant pairwise comparisons are denoted by an asterisk*

Table 2.10 Classification success matrix based on linear discriminant function analysis of 40 otolith signatures from four sites in San Diego Bay, CA (SDB1,

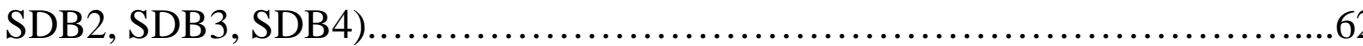

Table 2.11 Results of the PERMANOVA test comparing the difference in mean concentration of each metal among four sites in San Diego Bay, CA (SDB1,

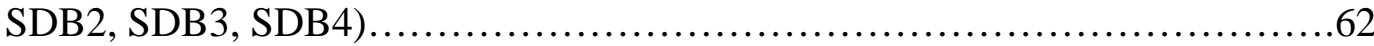

Table 2.12 P-values from Pairwise PERMANOVA test of mean metal concentration among four sites in San Diego Bay, CA (SDB1, SDB2, SDB3, SDB4). Significant pairwise comparisons are denoted by an asterisk*... 
Table 2.13 Classification success matrix based on linear discriminant function analysis of 30 otolith signatures from three sites in Anaheim Bay, CA (AB1, AB2,

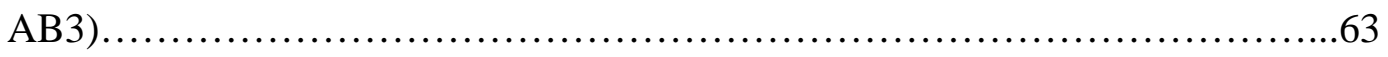

Table 2.14 Results of the PERMANOVA test comparing the difference in mean concentration of each metal among three sites in Anaheim Bay, CA (AB1, AB2, AB3). ..........................................................63

Table 2.15 P-values from Pairwise PERMANOVA test of mean metal concentration among three sites in Anaheim Bay, CA (AB1, AB2, AB3). Significant pairwise comparisons are denoted by an asterisk* ................63 


\section{LIST OF FIGURES}

Figure 2.1 Map of the 10 collection sites in Southern California, USA, where adult California killifish (Fundulus parvipinnis) were collected for otolith microelemental analysis. Estuarine systems are abbreviated as follows: Anaheim Bay $=$ AB, Mission Bay = MB, San Diego Bay $=$ SDB. Within each bay, sites are numbered numerically from north to south (e.g., AB1, AB2, AB3). Fundulus parvipinnis were collected from these sites using seine nets and baited minnow traps from July 10-August 10, 2018.

Figure 2.2 Map of the Mission Bay study site, characterized by wetland habitat type, according to the U.S. Fish and Wildlife Service, National Wetlands Inventory data accessed online in May 2018. Fish collection sites are numbered numerically from north to south as follows: MB1 = Kendall Frost Marsh Reserve, MB2 = Tecolote Creek, MB3 = Smiley Lagoon

Figure 2.3 Map of the San Diego Bay study site, characterized by wetland habitat type, according to the U.S. Fish and Wildlife Service, National Wetlands Inventory data accessed online in May 2018. Fish collection sites numbered numerically from north to south as follows: SDB1= Vener Pond, Sweetwater Marsh, SDB2 $=$ J Street Marsh, SDB3 $=$ Emory Channel, SDB4 $=$ Former Salt

Pond 10A . .66

Figure 2.4 Map of the Anaheim Bay study site, characterized by wetland habitat type, according to the U.S. Fish and Wildlife Service, National Wetlands 
Inventory data accessed online in May 2018. Fish collection sites numbered numerically from north to south as follows: $\mathrm{AB} 1=2 \mathrm{~A}, \mathrm{AB} 2=2 \mathrm{~N}, \mathrm{AB} 3=4 \mathrm{~N} \ldots .67$

Figure 2.5 Histograms of the 12 trace metals to check for normality of distribution across all 10 sites (MB1, MB2, MB3, SDB1, SDB2, SDB3, SDB4, AB1, AB2, AB3). Signatures from all 106 otoliths were combined..............68

Figure 2.6 Mean element concentrations (in ppm) in F. parvipinnis otoliths across all 10 sites. Note the differences in y-axis ranges between metals. On the xaxis, the fish collection sites are ordered from north to south (left to right) along the Southern California coast. No data indicates that a metal was not detected...69

Figure 2.7 Linear discriminant function analysis scores of element:Ca ratios in 106 otoliths of adult F. parvipinnis, by site, collected during summer 2018 at ten sites in Southern California. The axes of this plot are linear discriminants (LD1 and LD2) that described, on average, $63 \%$ of the differences among collection

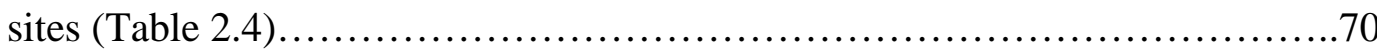

Figure 2.8 Linear discriminant function analysis scores of element:Ca ratios in 106 otoliths of adult F. parvipinnis, by element. Signatures are from all 10 collection sites. Elements in the top and right of the plot (Sr, Li, Mg) furthest from the center of the plot are driving the differences in trace metal results between fish capture sites. 
Figure 2.9 Linear discriminant function analysis scores of element:Ca ratios in 106 otoliths of adult F parvipinnis, by both element and collection site.

Signatures from all 10 collection sites...................................72

Figure 2.10 Linear discriminant function analysis scores of element:Ca ratios in 36 otoliths of adult F. parvipinnis from Mission Bay sites (MB1, MB2, MB3), by

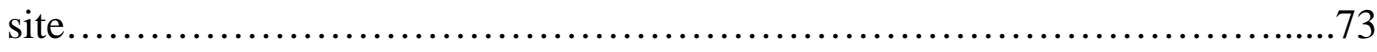

Figure 2.11 Linear discriminant function analysis scores of element:Ca ratios in 36 otoliths of adult F. parvipinnis from Mission Bay sites (MB1, MB2, MB3), by element. .74

Figure 2.12 Linear discriminant function analysis scores of element:Ca ratios in 36 otoliths of adult F. parvipinnis from Mission Bay sites (MB1, MB2, MB3), by both site and element. .75

Figure 2.13 Linear discriminant function analysis scores of element:Ca ratios in 36 otoliths of adult F parvipinnis from San Diego Bay sites (SDB1, SDB2, SDB3, SDB4), by site...........................................76

Figure 2.14 Linear discriminant function analysis scores of element:Ca ratios in 36 otoliths of adult F parvipinnis from San Diego Bay sites (SDB1, SDB2, SDB3, SDB4), by element...................................... 77

Figure 2.15 Linear discriminant function analysis scores of element:Ca ratios in 36 otoliths of adult F parvipinnis from San Diego Bay sites (SDB1, SDB2, SDB3, SDB4), by both site and element. 
Figure 2.16 Linear discriminant function analysis scores of element:Ca ratios in 36 otoliths of adult $F$. parvipinnis from Anaheim Bay sites (AB1, AB2, AB3), by site. ............................................................. 79

Figure 2.17 Linear discriminant function analysis scores of element:Ca ratios in 36 otoliths of adult $F$. parvipinnis from Anaheim Bay sites (AB1, AB2, AB3), by element.

Figure 2.18 Linear discriminant function analysis scores of element:Ca ratios in 36 otoliths of adult $F$. parvipinnis from Anaheim Bay sites (AB1, AB2, AB3), by both site and element. 


\begin{abstract}
As wetlands face continued fragmentation worldwide, an understanding of habitat connectivity and how fishes that rely on these environments is imperative to conduct effective marine management. Site fidelity and habitat connectivity are vital measures of the interdependence of fish populations living in neighboring marshes (or in regions of a single marsh).
\end{abstract}

Here, we examine the habitat connectivity, site fidelity, and movement of California killifish (Fundulus parvipinnis) within and among three estuaries in Southern California through otolith microelemental analysis. Assessing the site fidelity of estuarine fishes is important to determine the level of connectivity between spatially distinct populations within a bay and between adjacent bays.

Otolith microchemical analysis of $F$. parvipinnis successfully distinguished capture locations from as close as $2.89 \mathrm{~km}$ apart to as far as $184 \mathrm{~km}$ apart in San Diego Bay, Mission Bay, and Anaheim Bay. We found no relationship between distance among sites and our ability to distinguish them. Our results suggest populations of F. parvipinnis in Southern California have high site fidelity with low levels of population connectivity on both small and large spatial scales.

Specifically, Pairwise Permutational MANOVA (PERMANOVA) found 43/45 pairwise comparisons were statistically significant. Discriminant function analysis of otolith trace metal concentrations correctly classified, on average, 63.5\% of F parvipinnis to their collection site (DFA range: $20-100 \%$ ). When comparing intra-bay sites separately, the DFA classification success rate 
improved to an average of 79.9\%. DFA classification success rates were $77.9 \%$, 85\%, and 76.7\% in Mission Bay, San Diego Bay and Anaheim Bay, respectively. As such, F. parvipinnis do not appear to move between marshes, even those that are only $5 \mathrm{~km}$ apart.

This study is the first to analyze the site fidelity of F. parvipinnis within and among these three estuaries, the first to study the otolith microchemistry of $F$. parvipinnis in Southern California, and one of the few to investigate the power of otolith microchemistry on such a small spatial scale (less than tens of kilometers) in Southern California.

Fundulus parvipinnis are an ecologically important species in Southern California wetlands, thus quantifying their habitat connectivity has implications for interactions with predators and prey, and expands the knowledge base for mitigation and restoration projects of marshes worldwide. Low habitat connectivity on both small and large spatial scales makes F. parvipinnis a potentially sensitive indicator species to elucidate the impacts of wetland fragmentation on species conservation. 


\section{CHAPTER 1: INTRODUCTION}

\subsection{Introduction}

\subsubsection{Southern California Estuaries}

Coastal wetlands are vital habitats for birds, fishes, invertebrates, insects, and plants (Wolanski 2009). The wide variety of estuarine habitats include tidal marshes, salt marshes, mudflats, oyster reefs, seagrass beds, and river deltas (Lafferty 2005). Estuaries are among the most productive and dynamic habitats in the world (Allen 2006).

Estuaries provide many important ecosystem functions, including: (1) nutrient cycling and food chain support such as primary production, decomposition, and transferring carbon; (2) improving water quality through hydrological and biological functions including detoxification of toxic substances and absorption of nutrients (3) shoreline protection through flood conveyance, sediment control, ground water discharge and recharge, buffering wave and storm energy; and, (4) habitat for fishes, invertebrates, birds, and mammals, most notably as highly productive nursery grounds for fishes, habitat for threatened and endangered species, and resting and feeding areas for migratory birds (Day 2013, Lafferty 2005). Despite these important ecosystem functions, 90 percent of the original coastal wetland habitat in Southern California has been lost to filling and dredging during the last century, and the remaining areas face increasing threats of fragmentation, invasive plant and animals, agricultural development, and anthropogenic disturbances (NOAA 1990). 
Southern California estuaries are mainly small and marine in composition, due to their location in an arid region with a Mediterranean climate and extensive damming and channelization upstream (Allen et al. 2006). Mediterranean climate is characterized by warm, dry summers and cool, wet winters. Compared to northern California, where estuaries are fed by large river systems and high levels of rainfall, estuaries in Southern California are fragmented with limited freshwater input from small rivers, (many of which are channelized and dammed), and low rainfall. Southern California systems are home to many estuarine resident and marine migrant fish species, and very few native freshwater (Thompson et al. 2010) and anadromous fish species (Lafferty 2005). Anaheim Bay, Newport Bay, and San Diego Bay exhibit larger habitat diversity and larger environmental gradients, with respect to temperature and salinity, especially during the few rainy winter months (Allen et al. 2006).

Estuarine fishes spend a portion, or the entirety of their life history stages in the protected marsh environment because despite extreme salinity gradients and resource competition, the marsh habitat provides coverage and protection from larger predators, and often increased food availability for larvae and juveniles compared to the open ocean (Day 2013). Coastal fishes that spawn in protected marshes and estuaries and travel back offshore to the open coast as adults are known as transient or migrant species; while those fishes that spend their entire life history in the marsh are known as resident species (Day 2013). Both migrant and resident fish species are estuarine-dependent, or at least 
estuarine-facultative, and are distinct from marine species, such as tunas, that are estuarine independent and spend their entire lifetime in the ocean.

Depending on their physiology and life history, individual fish species exhibit habitat preferences within Southern California estuaries. For example, the shallow tidal channels of salt marshes are dominated by California killifish (Fundulus parvipinnis) and longjaw mudsucker (Gillichthys mirabilis). Topsmelt (Atherinops affinis), striped mullet (Mugil cephalus), deepbody anchovy (Anchoa compressa), and slough anchovy (Anchoa delicatissima) occupy the main tidal channels, and the shallow benthic areas of mudflats are occupied primarily by five species of goby: arrow goby (Clevelandia ios), shadow goby (Acentrogobius nebulosus), cheekspot goby (Ilypnus gilberti), tidewater goby (Eucyclogobius newberryi) and yellowfin goby (Acanthogobius flavimanus) (Allen et al. 2002). Deeper estuarine channels are inhabited mainly by marine migrants, including black perch (Embiotoca jacksoni), spotted sand bass (Paralabrax maculatofasciatus), diamond turbot (Hypsopsetta guttulata), and juvenile California halibut (Paralichthys californicus), and by marine species such as round stingray (Urolophus halleri) and barred sand bass (Paralabrax nebulifer). Estuaries with eelgrass beds provide valuable habitat for bay-estuarine fish species such as bay pipefish (Syngnathus leptorhynchus), barred pipefish (Syngnathus auliscus), shiner perch (Cymatogaster aggregata), and giant kelpfish (Heterostichus rostratus) (Allen et al. 2002).

Southern California estuaries support abundant and unique fish assemblages and can serve as nursery habitats for at least one commercially 
important fish, the California halibut (Paralichthys californicus) (Kramer 1991, Fodrie and Mendoza 2006). Migrant fish species, such as the P. californicus, spend their juvenile stage in the shallow, protected waters of an estuary as a nursery where they do not need to compete with adults for food and then migrate back offshore as adults (Fodrie and Mendoza 2006).

\subsubsection{Habitat Connectivity of Estuarine Fishes}

The survival of estuarine fishes relies on the ability of estuarine environments to serve as an effective foraging, spawning, and nursery grounds for juvenile and adult fishes (Gillanders et al. 2003). Wetland resident fishes dominate Southern California estuaries, which serve as an important food source for other economically important fish species and higher trophic level species such as birds, thus making resident fishes vital to wetland food webs (McMahon et al. 2005).

One of the most abundant mid-trophic level estuarine fish in Southern California is the native California killifish (Fundulus parvipinnis). Fundulus parvipinnis are often the numerically dominant species in Southern California and Baja California wetland systems, accounting for $80 \%$ of the taxa in some systems (Talley 2000). Fundulus parvipinnis complete their entire life history, including the pelagic larvae stage, within the estuarine environment, and rarely venture to the open coast as adults (Watson 1992). Wetland resident fishes, such as the $F$. parvipinnis, are an integral part of wetland food webs (Madon et al. 2001), both as predator (Madon et al. 2001, McMahon et al. 2005, Vince et al. 1976) and prey 
(Fritz 1976), and by aiding in the transfer of nutrients and production off the marsh surface (Kneib 1997, Talley 2000).

Fundulus parvipinnis also serve in wetland food webs as an intermediate host for the transmission of one of the most common parasitic trematodes in Southern California and Baja California estuaries, Euhaplorchis californiensis (Shaw et al. 2010). Parasites can represent a substantial biomass and productivity in California and Baja California wetlands and can greatly affect wetland food web dynamics by increasing chain length and connectivity (Kuris et al. 2008).

One method to measure the habitat connectivity, movement, and habitat use of estuarine fishes is to study site fidelity. Site fidelity occurs when the observed area used by an individual is much smaller than the area that would be used if the individual's movements were random (Danielson and Swihart 1987). Here, site fidelity is defined as the tendency of an organism to stay in or habitually return to a particular area. If an estuarine fish exhibits high site fidelity, then it tends to remain in a certain marsh or certain section of a marsh and seldom travels between other marshes or to different bays. Site fidelity and habitat connectivity can be expressed as an inverse relationship; if a fish exhibits high site fidelity then there is low habitat connectivity because the fish is seldom traveling between and among different habitats (Green et al. 2012). However, if a fish exhibits low site fidelity, then it does travel between marshes in the same bay or to different bays, and thus exhibits higher habitat connectivity (Green et al. 2012). 
Quantifying the connectivity among habitats is vital because common species, such as F. parvipinnis, are important conservation targets and potentially sensitive indicator species of environmental perturbation. Due to extreme loss of wetland habitat over the past decades, the connectivity of estuarine habitats is potentially reduced in Southern California wetlands, thereby exacerbating the need to understand the movement patterns of dominant taxa in these systems.

Worldwide, understanding the habitat connectivity of estuarine fishes has significant implications for habitat conservation and the design of marine protected areas. Stable isotope analysis of common European coastal fish species found high levels of site fidelity and minimal inter-marsh connectivity, resulting in individual salt marshes operating as discrete habitats for fish assemblages (Green et al. 2012). Limited habitat connectivity has also been previously identified in estuarine fish ecology studies along the coastlines of South Africa (Childs et al. 2015), Australia (Waltham and Connolly 2006), California (i.e. Tijuana Estuary and San Dieguito Lagoon) (Kwak and Zedler 1997), and Portugal (Vinagre et al. 2011). A mark-recapture study of the mummichog (Fundulus heteroclitus), the most abundant resident estuarine fish on the Atlantic coast of the United States, also found high site fidelity and limited connectivity between closely related marshes (Teo and Able 2003). As areas of salt marsh worldwide are lost, whether juvenile and adult fishes display increased or decreased connectivity within that marsh and between adjacent marshes, will have important implications on the overall population and recovery after such habitat destruction (Green et al. 2012). 


\subsubsection{Otolith Microchemistry}

To elucidate connectivity of fishes and their movements between and among estuaries, we evaluated site fidelity of young adult F. parvipinnis.

Common methods to track fish movements include mark-recapture tagging, passive integrated transponder tags, acoustic tags, archival tags, trawling and net surveys, and visual surveys (Elsdon et al. 2008). While these methods provide valuable insight on fine--scale movements, they can lack the ability to record large--scale movements over the majority of the life of a fish, and can be cost prohibitive and time consuming.

A more comprehensive method to study both fine and large--scale movements and habitat use of teleost fishes is otolith microelemental analysis. Otoliths, or ear stones, are paired calcified structures located in the inner ear of fish that aid the fish in balance, orientation, and sound detection. Otoliths are composed of calcium carbonate, typically in the form of aragonite (Campana 1999). Trace metals in the surrounding water deposit into the calcium carbonate matrix of the otolith daily, creating daily layers (Ludsin 2006). These daily layers are thus a permanent record of the water chemistry in which the fish inhabited during corresponding periods of its life (Swearer 2003). 
Image 1. California killifish (Fundulus parvipinnis) sagittae otolith at 40x

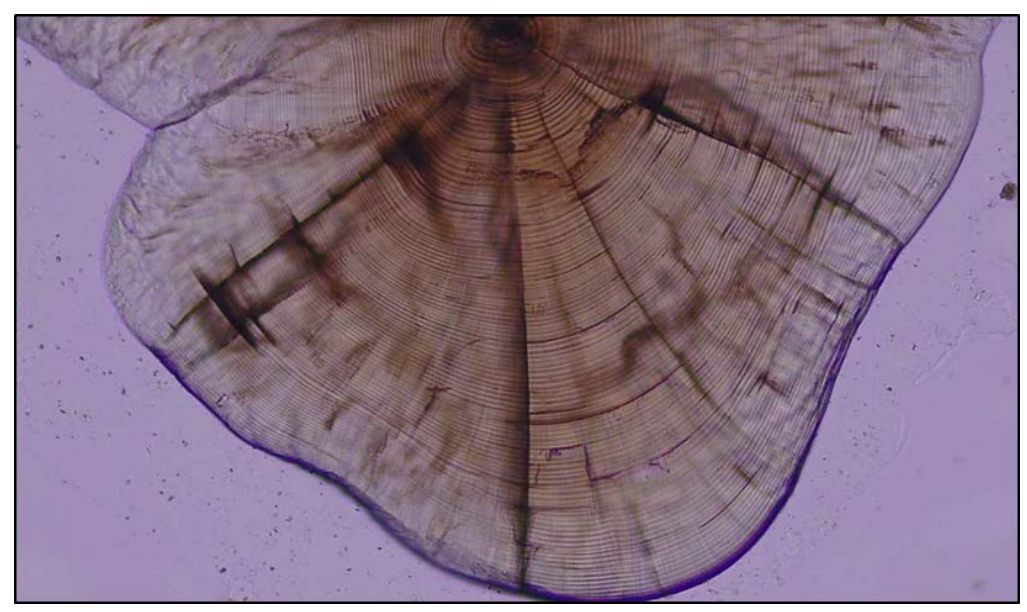

Elemental signatures reflect those of the surrounding water, along with a minimal amount reflecting diet, making otoliths natural, integrative tags of growth and environmental history (Campana 2000). To study the chemistry of fish otoliths, we can use otolith microelemental analysis to quantify the concentration of trace metals in the calcium carbonate structure of the otoliths of $F$. parvipinnis (Campana 1999).

Image 2. California killifish (Fundulus parvipinnis) otoliths at 10x. Lapilli, Asteriscii, and Sagittae (pictured left to right).

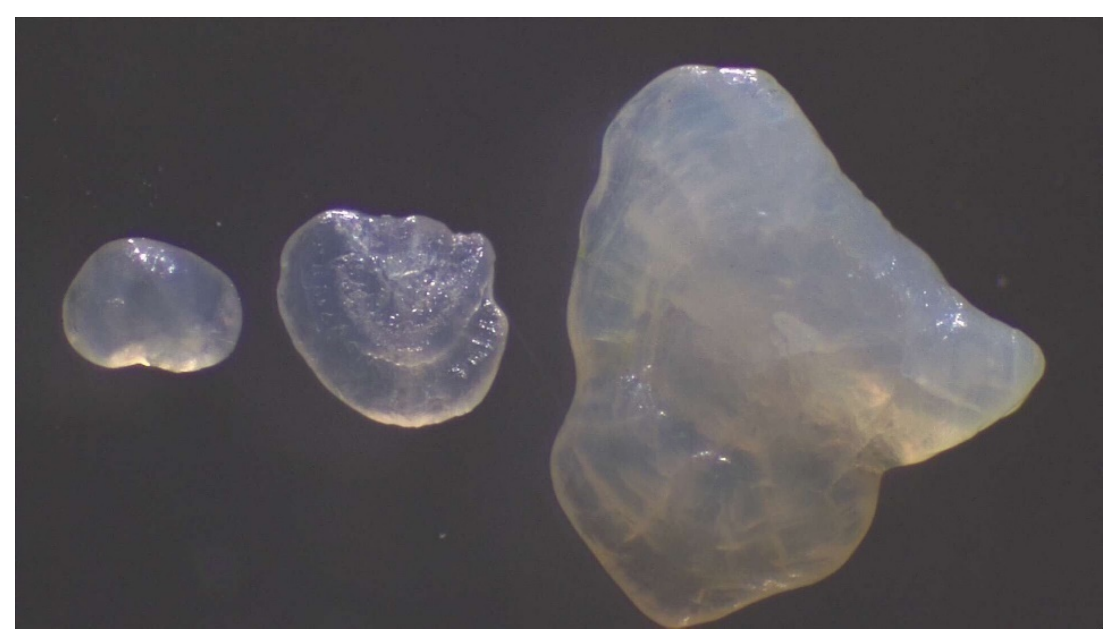


Otolith microelemental analysis uses an analytical chemistry technique known as Inductively Coupled Plasma Mass Spectrometry (ICP-MS) to analyze the concentration of alkali earth metals and other trace metals in otoliths. It can also be used to determine elemental concentrations in sediment, soil, rock samples, biological or organic samples (Wolf 2005). ICP-MS combines a high-temperature ICP (Inductively Coupled Plasma) source with a mass spectrometer. The ICP source converts the atoms of the elements in the sample to ions. These ions are then separated and detected by the mass spectrometer (Wolf 2005). ICP-MS can identify sub-populations of fish species (Forrester and Swearer 2002).

Bulk or solution-based inductively coupled plasma mass spectrometry (Bulk ICP-MS) digests the sample into a solution and analyzes the trace elemental composition as a whole (Campana 1999). Previous work found that concentrations of Sr and Ba vary with the temperature and salinity of water throughout an estuary or bay, and those elemental gradients are captured in otolith concentrations of teleost fish (Elsdon and Gillanders 2003). Thus, Sr and Ba, in particular, are the most useful elements for determining estuarine origin within fishes (Fodrie and Herzka 2008) and distinguishing different fishes (Swearer et al. 2003).

Laser Ablation ICP-MS (LA ICP-MS) examines otolith microchemistry on a finer temporal scale than bulk ICP-MS. LA ICP-MS take advantage of the chronological, annual growth rings recorded in an otolith and target a particular age or date range in an otolith ablated (sectioned) by a laser (Campana 1999). The 
advantage of LA ICP-MS, as compared to the bulk ICP-MS, is that LA ICP-MS can detect subtler migration and movement patterns on the scale of weeks, months, or years due to better sensitivity to non-physiologically regulated trace elements (Campana et al. 1997). Disadvantages of LA ICP-MS include the timeconsuming requirement that the otolith be sectioned by a laser to expose the growth sequence, the potential for contamination during the sectioning and polishing procedure, increased costs of analysis, and challenges in interpretation of subtler migration histories (Campana et al. 1997). In comparison, bulk ICP-MS digests the sample into a solution and analyzes the trace elemental composition as a whole, integrated signature over the entire lifetime of a fish.

Otolith microchemistry has been used in fisheries management for the past two decades to identify natal nursery grounds (Thorrold 1998, Bradbury et al. 2011), distinguish stocks (Campana 2000), study migration (Sturrock 2015, Walther and Limburg 2012), elucidate large-scale patterns of habitat connectivity (Gillanders 2005), utilize fish as environmental recorders (Arai 2007), study the life history of fish (Elsdon 2008), and protect endangered fish species (Sturrock 2015). However, this methodology has limitations and assumptions, and studies have typically assessed differences in otolith chemistry from locations separated by hundreds to thousands of kilometers. While past studies found otolith microchemistry to be an extremely valuable method to study habitat connectivity and site fidelity of estuarine fish on large spatial scales, the ability of this methodology to identify sub-populations on small spatial scales, specifically less than 10 kilometers apart, is largely unknown. 
We examine otolith microchemistry on a much smaller spatial scale than previous studies by comparing locations separated by from ones to tens of kilometers. The objective of this study is to distinguish sub-populations of $F$. parvipinnis within and among Mission Bay, San Diego Bay, and Anaheim Bay in Southern California.

We quantified the concentration of 12 trace elements in 106 F. parvipinnis sagittae otoliths: Li, Na, Mg, Ca, Mn, Cu, Zn, Sr, Cd, Sn, Ba, Pb. These elements were chosen based on their known incorporation into otoliths (Swearer et al. 2003, Forrester and Swearer 2002), due to these metals tending to exhibit the greatest variability in concentration between estuaries. We characterized the movement, habitat connectivity, and site fidelity of wetland fishes through otolith microchemistry analysis.

This project is the first to analyze the site fidelity of $F$. parvipinnis within and among these three estuaries, study the otolith microchemistry of the $F$. parvipinnis in Southern California, and one of the few to investigate the power of otolith microchemistry on such a small spatial scale (less than tens of kilometers) in Southern California. As Southern California continues wetland restoration efforts, effective restoration requires an understanding of how subpopulations of F. parvipinnis depend on these habitats are connected.

\section{Elemental deposition in otoliths}

Estuaries receive inputs of trace elements from a number of sources, and these habitats exhibit large variation in chemical composition. Distribution of 
elements in water is determined by a complex set of factors, including salinity, precipitation, evaporation, temperature, proximity to terrestrial sources, upwelling, tides, and the chemical composition of the underlying bedrock (Elsdon and Gillanders 2003, Elsdon et al. 2008).

Otolith $\mathrm{Sr}, \mathrm{Ba}$, and $\mathrm{Pb}$ to $\mathrm{Ca}$ ratios are deposited in proportion to their respective ratios in ambient waters (Bath et al. 2000, Milton and Chenery 2001, Swearer et al. 2003). As Sr and Ba appear to reflect environmental parameters, specifically temperature and salinity, either linearly or non-linearly, they are ideal tracers for tracking fish movement (Bath et al. 2000, Elsdon et al. 2008, Elsdon and Gillanders 2004). Water temperature and salinity have the largest impact on elemental variability for certain metals such as $\mathrm{Sr}$ and $\mathrm{Ba}$ (Elsdon and Gillanders 2003). The effect of temperature on otolith chemistry is likely due to both fish physiology and kinetic processes such as temperature impacting crystallography (Elsdon et al. 2008). Higher concentrations of Sr are associated with seawater and lower concentrations of Sr are associated with freshwater (Campana 1999, Elsdon et al. 2008, Doubleday et al. 2014). Higher concentrations of Sr are also associated with warmer water (Elsdon et al. 2008). Temperature has a varied effect on Ba, with studies showing both positive and neutral effects (Elsdon and Gillanders 2002).

In contrast to $\mathrm{Sr}$ and $\mathrm{Ba}$, the factors affecting concentration of other metals such as $\mathrm{Mn}, \mathrm{Mg}, \mathrm{Cu}, \mathrm{Zn}$, and $\mathrm{Li}$, is more complex because concentrations of these metals are increasingly controlled by fish physiology (Milton and Chenery 2001) and reduction-oxidation reactions in the sediments (Fodrie and Herzka 2008). Cu, 
$\mathrm{Mg}$, and $\mathrm{Zn}$ in otoliths are not thought to reflect water concentrations (Campana 1999, Milton and Chenery 2001), and thus these elements are less likely to reflect environmental parameters (Elsdon et al. 2008). $\mathrm{Cu}$ and $\mathrm{Pb}$ display a qualitatively similar concentration gradient to that observed in sediments: high levels in bays and lower levels on the open coast (Forrester and Swearer 2002).

The chemical fingerprint of an estuary is best described as a gradient, rather than a step change between multiple hydrological conditions and habitat types. Mn availability is dominated by reduction-oxidation reactions in the sediments and overlying water column (Fodrie and Herzka 2008). At the inner regions of embayments, more $\mathrm{Mn}$ is bioavailable for incorporation into otoliths because the net transport of dissolved $\mathrm{Mn}$ is to the water column (Hanson et al. 1993). At the outer regions of embayments, less $\mathrm{Mn}$ is bioavailable because tidal flow increases oxygenation in the water from constant mixing of sandy sediments (Fodrie and Herzka 2008).

\subsubsection{Life History of Fundulus parvipinnis}

Fundulus parvipinnis is a mid-trophic level species that is abundant in Southern California estuaries, and is thus a good model to help better understand the site fidelity of resident estuarine fishes. Fundulus parvipinnis live in eastern Pacific wetlands, ranging from Morro Bay, California, USA to Bahía Magdalena, Baja California, Mexico. The peak spawning season for F. parvipinnis is April to June during spring high tides at night, although the entire spawning season lasts until September (Fritz 1976). 
Fundulus parvipinnis have a very short pelagic larval duration of one to two weeks (Watson 1992), and do not appear to disperse during this short larval stage (Nordby 1982). The few available studies of F. parvipinnis larvae suggest they are retained in intertidal pools, small depressions, and shallow estuary creek habitats (Talley 2000) instead of subtidal or nearshore habitats (Nordby 1982). A study that sampled ichthyofauna of tidal creeks, subtidal channels, and nearshore habitats in Tijuana Estuary, CA over the course of one year captured over 21,000 larvae, only 2 of which were found to be F. parvipinnis (Nordby 1982).

Furthermore, these two F. parvipinnis larvae were found in the estuary creek, not in nearshore habitats nor open coast; strengthening the evidence that they do not disperse as larvae, because there are no observations of $F$. parvipinnis larvae in coastal waters. In addition, the same study collected over 50,000 fish eggs, none of which belonged to F. parvipinnis (Nordby 1982, Talley 2000). Therefore, F. parvipinnis larvae appear to remain on the intertidal marsh habitat, which their counterparts on the Atlantic coast of the United States, Fundulus heteroclitus, have also been found to do (Kneib 1993).

Fundulus parvipinnis typically live 12-18 months, reaching full adult size and reproductive age at 6-7 months old. Some adults have been found to live 2-3 years but that is very rare (pers. Obs. Talley 2000). Fritz 1976 found that spawning adults from Anaheim Bay that spawned in spring and caught in July were 48 to 78 millimeters in length, and those caught in August were 52 to 90 millimeters in length. There are 39 species in the genus Fundulus, and many species are extremely hardy and salt-tolerant (Froese and Pauly 2012). The high 
marsh habitats that Fundulus inhabit, specifically small intertidal pools and creeks, can experience salinity levels greater than $60 \mathrm{psu}$, which is 1.7 times more than the average salinity of seawater at $35 \mathrm{psu}$, and temperatures as high as $40^{\circ} \mathrm{C}$ (Rao 1975).

Image 3. California killifish (Fundulus parvipinnis) collected from San Diego Bay

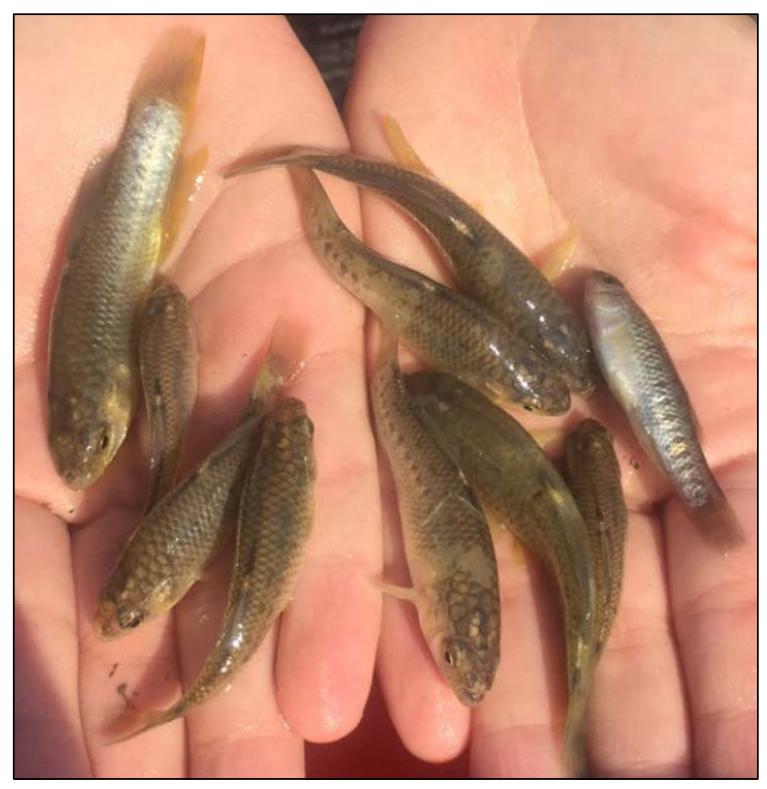

Life history and habitat fidelity studies of wetland fishes are vital for informing wetland restoration projects and wetland food web ecology. For example, F. parvipinnis also undergo tidal migrations, where during high tides they are able to move from subtidal channels to vegetated marsh to forage on insects and amphipods that would be unavailable during lower tides (Fritz 1976). Fundulus parvipinnis that conduct these tidal migrations to feed on the vegetated marsh were found to consume six times as much food as individuals restricted to foraging in creek habitats (West and Zedler 2000). Because salt marshes are 
important foraging grounds for fishes, wetland restoration projects were recommended to include protecting salt marsh habitats that are connected to tidal creeks and allow for adequate flooding (Madon et al. 2001).

Fundulus parvipinnis has been found to be the numerically dominant species in many Southern and Baja California wetland systems, accounting for $80 \%$ of the taxa in some systems (Talley 2000, Allen 2006). Fundulus parvipinnis complete its entire life history within the estuarine environment, and rarely venture to the open coast as adults (Watson 1992) or larvae (Nordby 1982). Adult F. parvipinnis exhibit high site fidelity on small spatial scales, as revealed through mark-recapture-release and stable isotope studies in Mission Bay (Talley 2000). Remarkably, F. parvipinnis were found to have low movement even between two sections of the Kendall Frost Marsh Reserve: a created and natural marsh, connected by a tidal creek, and otherwise separated by only $~ 10 \mathrm{~m}$ at high tide (Talley 2000).

A study of the population genetics between six populations of $F$. parvipinnis ranging from Santa Barbara to Baja California found high genetic divergence between populations that are separated by hundreds of kilometers and inferred that F. parvipinnis do not move between marshes on this large spatial scale (Bernardi and Talley 2000). A mark-recapture study found as many as 35\% of the F. parvipinnis tagged in the Kendall Frost marsh in Mission Bay were recovered one day later in the same marsh (Talley 2000). Therefore, $F$. parvipinnis seem to exhibit very high levels of site fidelity on both small (less than 10 kilometers apart) and large spatial scales (hundreds of kilometers apart). 
High site fidelity on both small and large spatial scales makes $F$. parvipinnis an important indicator species to study in Southern California that represents the potential effect of wetland fragmentation and wetland restoration on resident wetland fishes. Fundulus parvipinnis are an ecologically important species in Southern California wetlands, and their habitat connectivity has implications for their predators and prey species, and for mitigation and restoration projects in Southern California. 


\subsection{Research Objectives}

The objective of this study is to improve understanding of F. parvipinnis site fidelity and life history by examining the spatial variability of trace metals in $F$. parvipinnis otoliths.

\section{$\underline{\text { Research questions: }}$}

1. Do adult F. parvipinnis display site fidelity within and among three estuaries in Southern California: Mission Bay, San Diego Bay, and Anaheim Bay?

2. If so, at what spatial scale? Can otolith microchemistry distinguish adult $F$. parvipinnis site fidelity at small spatial scales (intra-marsh, $<10$ kilometers) or only at larger spatial scales (inter-marsh, >10 kilometers)?

If our research concludes that, based on otolith microchemistry, $F$. parvipinnis exhibit high site fidelity in an estuary, then wetland restoration efforts would likely only be locally beneficial. High site fidelity would suggest $F$. parvipinnis are not traveling throughout the entire estuary equally, and therefore, would be less impacted by wetland restoration to the head of the estuary if they only reside at the mouth of the estuary, for instance. However, if our research shows that F parvipinnis exhibit lower site fidelity in Mission Bay, San Diego Bay, and/or Anaheim Bay, then wetland restoration efforts in one section (for example: head, mouth, or body of the bay) would indeed affect $F$. parvipinnis throughout an entire estuary. 


\subsection{Statement of Hypotheses}

1. How do the trace metals in the otolith of adult $F$. parvipinnis differ at sites within each estuary (head, mouth, and body) and between different estuaries (Mission Bay versus San Diego Bay versus Anaheim Bay)?

$\mathrm{H}_{0}$ : There is no difference in otolith trace elemental analysis results within each estuary or between different estuaries.

$\mathrm{H}_{\mathrm{A}}$ : The otolith trace elemental analysis results differ between intra- and inter- estuary locations significantly enough to be able to distinguish site fidelity of adult $F$. parvipinnis. 


\section{CHAPTER 2:}

\section{Otolith microchemistry reveals low habitat connectivity of California killifish (Fundulus parvipinnis) across a range of spatial scales}

\subsection{Introduction}

Conservation and management of estuarine fishes hinges on an accurate assessment of fish location during different life history stages and their movement within and between estuaries. The ability to track movement patterns of fish with complex life cycles is required to determine the habitat value of certain bays and wetlands for larvae, juvenile, and adult fish (Forrester and Swearer 2002). Site fidelity is a useful metric for identifying and evaluating fish habitat requirements (e.g., Garwood et al. 2019), and measuring habitat connectivity and movement. Greater site fidelity could indicate better wetland habitat quality for fishes that remain in a particular section of the marsh, and temporal changes in the strength of site fidelity could denote decreases or increases in that habitat quality (Garwood et al. 2019).

Site fidelity and habitat connectivity have important implications for predicting the effect of local anthropogenic disturbances in Southern California estuaries. On the one hand, increased site fidelity and limited movement could mean these populations are particularly vulnerable to anthropogenic disturbances and slow to recover due to their reliance on local replenishment. On the other hand, high levels of dispersal could facilitate recovery to habitat perturbation.

Common methods to track and measure fish site fidelity and habitat connectivity include mark-recapture tagging, passive integrated transponder tags, 
acoustic tags, archival tags, trawling and net surveys, and visual surveys (Elsdon et al. 2008). While these methods provide valuable fine-scale movements, they can lack the ability to record large-scale movements over the majority of the life of a fish, and can be cost prohibitive and time consuming. A more comprehensive method to study both fine and large-scale movements and habitat use of teleost fishes is otolith microelemental analysis. All vertebrates have three, small calcium carbonate structures in each ear that aid in sensing gravity and movement called otoliths. Otoliths in fishes allow them to keep their balance and detect sound and water depth. Otoliths grow continuously during a fishes’ life, a few microns each day from hatch until death (Campana 1999). Because otoliths continuously accrete new calcium carbonate onto the external surface, daily concentric rings accumulate to form annual growth layers that we can use to age the fish and determine how long they spent in certain habitats. Thus, otoliths provide a high-resolution history of individual fish movements.

At least $90 \%$ of the chemical signatures recorded in the otoliths of teleost fishes is estimated to reflect the ambient water composition of these elements at the time of deposition, with the remaining $10 \%$ or less reflecting food uptake in diet (Walther and Thorrold 2006, Campana 1999). Therefore, otolith microchemistry creates "elemental fingerprints" by exploiting the variation in the chemical compositions of otoliths caused by environmental gradients in the water the fish inhabits throughout its life (Campana 1999, Swearer et al. 2003). Otolith microelemental analysis uses a powerful analytical chemistry technique known as Inductively Coupled Plasma Mass Spectrometry (ICP-MS) to analyze the 
concentration of alkali earth metals and other trace metals in otoliths and has been used to identify sub-populations of the fish species (Forrester and Swearer 2002). Otolith microchemistry has been used in fisheries management for the past two decades to identify natal nursery grounds (Thorrold 1998, Bradbury et al. 2011), distinguish stocks (Campana 2000), study migration (Sturrock 2015, Walther and Limburg 2012), elucidate large scale patterns of habitat connectivity (Gillanders 2005), utilize fish as environmental recorders (Arai 2007), study the life history of fish (Elsdon 2008), and protect endangered fish species (Sturrock 2015). However, this methodology has limitations and assumptions, and studies have typically assessed differences in otolith chemistry from locations separated by hundreds to thousands of kilometers. While past studies found otolith microchemistry to be an extremely valuable technique to study habitat connectivity and site fidelity of estuarine fish on large spatial scales, the efficacy of this methodology to identify sub-populations on small spatial scales, specifically less than 10 kilometers apart, is unknown.

Commercially important species and rarer species all depend on common species to maintain aspects of their populations (Connolly et al. 2014). One of the most common, mid-trophic level estuarine fish species in Southern California is the native California killifish (Fundulus parvipinnis). Fundulus parvipinnis is often the numerically dominant species in Southern and Baja California wetland systems, accounting for $80 \%$ of the fish taxa in some systems (Talley 2000). Fundulus parvipinnis complete their entire life history within estuarine environments, and rarely venture to the open coast as adults (Watson 1992). 
Fundulus parvipinnis have a very short pelagic larval duration of one to two weeks (Watson 1992), and do not appear to disperse during this short larval stage (Nordby 1982). Wetland resident fishes, such as F. parvipinnis, are an integral part of wetland food webs (Madon et al. 2001), both as predator (Madon et al. 2001, McMahon et al. 2005, Vince et al. 1976) and prey (Fritz 1976), and by aiding in the transfer of nutrients and production off the marsh surface (Kneib 1997, Talley 2000).

Potential high site fidelity on both small and large spatial scales makes $F$. parvipinnis an important indicator species to study in Southern California that represents the potential effect of wetland fragmentation and wetland restoration on resident wetland fishes. Fundulus parvipinnis are an ecologically important species in Southern California wetlands, and their habitat connectivity has implications for their predators and prey species, and for mitigation and restoration projects in Southern California.

We examine otolith microchemistry on a smaller spatial scale than previously studied for F. parvipinnis, and the majority of all other fishes, by comparing locations only two to ten kilometers apart. The primary objective of this study is to elucidate the degree of F. parvipinnis site fidelity within and among Mission Bay, San Diego Bay, and Anaheim Bay in Southern California. This project is the first to study the otolith microchemistry of $F$. parvipinnis in Southern California, one of the few to investigate the power of otolith microchemistry on such a small spatial scale (less than ten of kilometers) in 
Southern California, and the first to analyze the site fidelity of $F$. parvipinnis within and among these three estuaries.

\subsection{Materials and Methods}

\subsubsection{Study System}

This study was conducted in three bays in Southern California: Mission Bay (MB) (32.791276, -117.229831), San Diego Bay (SDB) (32.618664, 117.102571), and Anaheim Bay (AB) (33.742374, -118.080144) (Figure 2.1). Sampling locations within bays were chosen to provide both small-scale (intrabay) and large-scale (inter-bay) comparisons. AB lies in Orange County, CA, 132 kilometers from MB, and 147 kilometers from SDB (the latter two in San Diego County, CA). MB and SDB are separated by around $30 \mathrm{~km}$. These locations provided us with a range of spatial scales at which to study site-specific signatures.

SDB covers the largest total area $\left(545 \mathrm{~km}^{2}\right)$, MB the second largest (8.87

$\mathrm{km}^{2}$ ), and $\mathrm{AB}$ the smallest total area $\left(4.450 \mathrm{~km}^{2}\right)$ (U.S. Fish and Wildlife 2018). SDB has the largest estuarine and marine wetland area $\left(9.63 \mathrm{~km}^{2}\right.$ or $2 \%$ of its total area), $\mathrm{AB}$ the second most ( $2.61 \mathrm{~km}^{2}$ or $58 \%$ of its total area), and MB has the least $\left(0.62 \mathrm{~km}^{2}\right.$ or $7 \%$ of its total area) (U.S. Fish and Wildlife 2018). SDB is a natural and highly urbanized deepwater bay and harbor, with two river sources (Otay River and Sweetwater River). It exhibits seasonal hypersalinity (Largier et al. 1997) and consists of the broadest range of habitats among the studied bays 
and includes deep to shallow channels, mudflats, eelgrass beds, and salt marshes (Allen et al. 2006).

MB is a natural wetland that was heavily modified by dredging in the 1940s to create an urbanized bay for recreation and is now the largest manufactured aquatic park on the west coast of the U.S. (Dexter and Crooks 2000). MB has relatively high water exchange near the mouth, but the back bay has limited flushing and receives urban runoff from two creeks that serve as extremely limited freshwater input into MB (Rose Creek and Tecolote Creek) (Dexter and Crooks 2000). MB exhibits seasonal hypersalinity due to its complex topography, shallow basins, and Mediterranean climate with long dry summers; the head of MB at Tecolote Creek can become hypersaline as quickly as over a 2 month period (Largier et al. 1997).

AB samples were taken from Seal Beach National Wildlife Refuge, which is predominantly salt marsh connected by subtidal channels. Seal Beach National Wildlife Refuge is relatively undisturbed due to its location within the U.S. Naval Weapons Station and serves as a productive habitat for resident fishes and is an important stopover for many migratory birds (Allen et al. 2006).

To capture the range of environmental habitats within these estuaries, we attempted to collect fish from the front, middle, and back regions of each of the bays. However, despite repeated sampling attempts at six locations situated at the front of Mission Bay and San Diego Bay, we were unable to collect any F. parvipinnis from these locations, likely due to a lack of salt marsh habitat. In 
Anaheim Bay, we successfully sampled from the front, middle, and back regions of the bay (Figure 2.4).

Fish were collected from three locations within MB, three locations within $\mathrm{AB}$, and four locations within SDB, for 10 collection sites across three bays (Figure 2.1 and Table 2.1). MB3, Smiley Lagoon, is located at the mouth of the San Diego River, in Ocean Beach, as opposed to inside Mission Bay (Figure 2.2 and Table 2.1). However, for the sake of this study, we classified Smiley Lagoon as MB3 because this site was the closest to the front of Mission Bay as we found F. parvipinnis. The unique location of Smiley Lagoon, separated from MB by a jetty break at the mouth of the San Diego River, allows for the potential movement of fishes between San Diego River and MB, without having to cross the open ocean to enter MB.

\subsubsection{Fish Collection and Otolith Dissection}

\section{i. Fish Collection}

We collected adult F. parvipinnis from July 10 to August 10, 2018 (Table 2.1). Fundulus parvipinnis were collected at low tide using a beach seine, at all ten sites except SDB1. At SDB1, fish were collected using a minnow trap baited with cat food.

Fish collection was conducted in accordance with the following U.S. Fish and Wildlife permits: SDBNWR Research and Monitoring Special Use Permit \#SDB-18011 (Permit Holder = Lisa Robison), SBNWR Research and Monitoring Special Use Permit \#81683-18006SB (Permit Holder = Lisa Robison), CDFW 
2018 Scientific Collecting Permit $($ Permit Holder $=$ Dr. Theresa Talley and Dr. Drew Talley). All samples were brought back to the University of San Diego for processing; we measured standard length (SL), total length (TL), and wet weight. All $F$. parvipinnis were stored frozen at $-4^{\circ} \mathrm{C}$ before otolith dissection and preparation for chemical analyses.

Image 4. Seine fishing for Fundulus parvipinnis at Emory Channel in San Diego Bay.

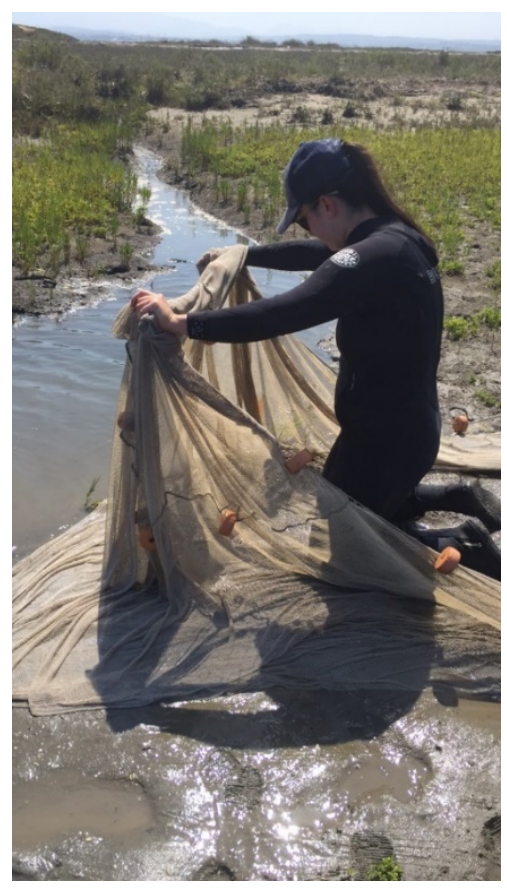

\section{ii. Size Class Analysis}

Fish collection was scheduled during the summer of 2018 to coincide with F. parvipinnis spawning season in April (Fritz 1975). Fish samples were collected within a one-month time frame in order to study fish of the same age and increase the probability of these samples being adults that hatched in the spring of 2018. Because Solution ICP-MS analyzes the composition of the otolith as an integrated record over a fish's entire lifetime, any temporal differences between sampling 
dates during this one-month period were largely integrated into the total, bulk signature (Campana 1999, Elsdon and Gillanders 2003). Due to the Mediterranean climate in Southern California, the environmental conditions were relatively stable during the sampling period, and there was no rainfall.

We collected a total of 406 F. parvipinnis ranging in standard length (SL) size from 25-60mm $(\mathrm{AB}$ mean $\mathrm{SL}=29.3 \mathrm{~mm}, \mathrm{MB}$ mean $\mathrm{SL}=48.78 \mathrm{~mm}, \mathrm{SDB}$ mean $\mathrm{SL}=44.7 \mathrm{~mm})$. Fundulus parvipinnis individuals ranging from $28-42 \mathrm{~mm}$ in July and $30-50 \mathrm{~mm}$ in August are considered early spawned young, hatched in the spring of the year they were caught (Fritz 1975). Fundulus parvipinnis spawning adults are fish of SL >42mm in July and SL >50mm in August (Fritz 1975). Our objective was to study adult F. parvipinnis that hatched in spring 2018, so we performed size class analysis to select 106 individuals that were 35-55mm SL for otolith microchemistry analysis (Table 2.1). On average, fish collected from AB were slightly smaller than from MB and SDB, with samples selected for ICP-MS from $\mathrm{AB}$ at $35-40 \mathrm{~mm}$, while $\mathrm{MB}$ and SDB fish were $40-55 \mathrm{~mm}$.

\section{iii. Otolith Dissection}

All six otoliths (two sagittal, two lapilli, and two asteriscii) from each fish were dissected and removed and stored dry in glass vials at room temperature at University of San Diego. Only the sagittal otoliths, commonly used for trace metal analysis and ageing (Campana 1999, Campana 2000), were used for this microchemistry study. One sagittae otolith was saved for future otolith ageing analyses, and the other sagittae was used in this study for trace elemental analysis. 


\subsubsection{Bulk Inductively Coupled Plasma Mass Spectrometry (ICP-MS)}

The concentrations of trace elements in the otolith samples were determined using solution (bulk) inductively coupled plasma mass spectrometry (ICP-MS). Solution ICP-MS sample analysis was conducted in two rounds at the Scripps Isotope Geochemistry Laboratory at Scripps Institution of Oceanography in La Jolla, CA. Round 1 was conducted on March 22, 2019 ( $\mathrm{n}=50$ otoliths) and Round 2 was conducted on November 1, 2019 ( $\mathrm{n}=56$ otoliths), for a total of 106 otoliths analyzed in this study. The following sample preparation, sample analysis, and data standardization were identical during both round of ICP-MS at Scripps Institution of Oceanography. The same instrument (ThermoFisher iCAP SQ ICP-MS instrument), stock solutions for sample preparation (nitric acid), internal reference standard (Indium), external standards (Crab Shell standard, FEBS-1 standard), glassware, pipets, and consumables were used for both rounds of ICP-MS.

\subsubsection{Sample Preparation}

To make the stock solution, first the otoliths and standards were weighed to within 0.00001 grams and transferred into individual clean and labelled $5 \mathrm{~mL}$ Teflon vessels. The lid and body of the Teflon vessels were labeled and then 0.5 $\mathrm{mL}$ of $15.7 \mathrm{M} \mathrm{TD} \mathrm{HNO}_{3}$ was added to each vessel to digest the sample. The Teflon vessels were then tightly capped and put on a hotplate at $140-150{ }^{\circ} \mathrm{C}$ for $>72$ hours. After $>72$ hours, the Teflon vessels were removed from hotplate and let cool to room temperature. Once cooled, they were tapped lightly on bench to 
get droplets form lid in to bottom, carefully uncapped, and placed back on to a hotplate in the evaporation chamber at $85^{\circ} \mathrm{C}$ to dry overnight.

Once the samples were dried, $0.5 \mathrm{~mL}$ of $\mathrm{TD}^{\mathrm{HNO}} 3,0.5 \mathrm{~mL}$ of the internal standard (1 ppm Indium (In) solution), and $1 \mathrm{~mL}$ of $\mathrm{MQ} \mathrm{H}_{2} \mathrm{O}$ were added to the Teflon vessels. The vessels were re-capped and placed back on to a hotplate in an evaporation chamber set at $90{ }^{\circ} \mathrm{C}$ to equilibrate overnight. Next, the vessels were removed from hotplate and let cool to room temperature.

To prepare the stock solution for analysis, $0.5 \mathrm{~mL}$ aliquot of each stock solution was pipette transferred into a clean, labelled $15 \mathrm{~mL}$ centrifuge tube. Both the body and cap of the centrifuge tube were labeled. Next, $4.5 \mathrm{~mL}$ of $2 \% \mathrm{HNO}_{3}$ was added to each $15 \mathrm{~mL}$ centrifuge tube containing the $0.5 \mathrm{~mL}$ stock solution, the lids of the centrifuge tubes were sealed, and the tube was inverted several times to ensure complete mixing of samples.

\subsubsection{Sample Analysis}

Otolith samples were run on a ThermoFisher iCAP QC ICP-MS equipped with a quartz concentric nebulizer with $0.4 \mathrm{~mL} \cdot \min -1$ sample consumption. The ICP-MS workflow method was established using Thermo Scientific ${ }^{\mathrm{TM}}$ Qtegra $^{\mathrm{TM}}$ Intelligent Scientific Data Solution (ISDS) Software. Elements analyzed were: ${ }^{7} \mathrm{Li},{ }^{23} \mathrm{Na},{ }^{25} \mathrm{Mg},{ }^{26} \mathrm{Mg},{ }^{39} \mathrm{~K},{ }^{43} \mathrm{Ca},{ }^{48} \mathrm{Ca},{ }^{47} \mathrm{Ti},{ }^{55} \mathrm{Mn},{ }^{65} \mathrm{Cu},{ }^{66} \mathrm{Zn},{ }^{86} \mathrm{Sr},{ }^{111} \mathrm{Cd}$,

${ }^{118} \mathrm{Sn},{ }^{137} \mathrm{Ba},{ }^{204} \mathrm{~Pb},{ }^{206} \mathrm{~Pb},{ }^{207} \mathrm{~Pb}$, and ${ }^{208} \mathrm{~Pb}$. All trace element concentrations were obtained in counts per second and converted to units of ppm relative to calibration 
curves. Data are also expressed relative to the concentration of calcium (shown as a ratio of $\left.\mathrm{X}:{ }^{43} \mathrm{Ca}\right)$.

To run ICP-MS sample analysis, the $15 \mathrm{~mL}$ centrifuge tubes containing the samples were placed in a 5x12 sample rack for the autosampler for the ThermoFisher iCAP QC ICP-MS. The samples in Round 1 of ICP-MS ( $\mathrm{n}=50$ otoliths) included: 50 otolith samples, 8 FEBS-1 external standards, 6 crab shell standards, 2 total analytical blanks, and 18 diluent blanks (2\% $\left.\mathrm{HNO}_{3}\right)$. The samples in the Round 2 of ICP-MS (n=56 otoliths) included: 56 otolith samples, 4 FEBS-1 external standards, 4 crab shell standards, 2 total analytical blanks, and 18 diluent blanks $\left(2 \% \mathrm{HNO}_{3}\right)$.

In Round 1 of ICP-MS, samples were run in blocks of 3-6 samples at a time, with $2 \% \mathrm{HNO}_{3}$, a diluent blank, run in-between each block of samples. In Round 2 of ICP-MS, samples were run in blocks of 6-10 samples at a time, with 2\% $\mathrm{HNO}_{3}$ run in-between each block. For both Round 1 and Round 2, otolith samples from each collection site were placed randomly in each rack, in order to avoid possible bias and instrument drift.

For both rounds of ICP-MS, a $50 \mathrm{~mL}$ centrifuge tube containing $40 \mathrm{~mL}$ of the $2 \% \mathrm{HNO}_{3}$, used for dilution of the stock solution, was put in the left most standard position in the autosampler for the duration of the analysis. Repeated analysis of the same $2 \% \mathrm{HNO}_{3}$ solution ( $n=18$ in Round 1 ICP-MS, and $n=9$ in Round 2) indicated good analytical reproducibility among sample blocks (see 2\% $\mathrm{HNO}_{3} \mathrm{RSD}$ in Table 2.2). 


\subsubsection{Data Standardization}

After sample analysis was completed, the data were downloaded to an Excel spreadsheet for standardization. The concentrations of elements in the sample were calculated using calibrations derived from one internal standard and two external standards that were analyzed at random along with the otoliths in the block of samples. The internal reference standard, Indium (In) was spiked into the stock solution during earlier sample preparation, as described above. Two types of external standards run through the ICP-MS along with the otoliths, and optimized to represent the low, medium, and high concentrations of elements expected in the otoliths. The two external standards were 1) Crab Shell standard and 2) FEBS-1 standard.

A Scripps Isotope Geochemistry Laboratory in-house crab shell (CS) standard (Cancer productus) was used as an external standard in this study for all 14 elements: Li, Na, Mg, K, Ca, Ti, Mn, Cu, Zn, Sr, Cd, Sn, Ba, Pb (Table 2.2), and which have been assessed for concentration using calibration curves. FEBS-1 is an otolith Certified Reference Material (CRM) for trace elemental analysis produced by the National Research Council Canada. FEBS-1 is a saggital otolith reference material procured from red snapper (Lutjanus campechanus). Certified reference values are based on unweighted mean results from data submitted by collaborating laboratories (Sturgeon et al. 2005). For ICP-MS analysis, Sturgeon et al. 2005 reported FEBS-1 certified reference values for seven elements (Ba, Ca, Li, Mg, Mn, Na and Sr). Sturgeon et al. (2005) also reported FEBS-1 reference values for ICP-MS of three elements (Cd, $\mathrm{Cu}, \mathrm{Pb}$ ), 
referred to by the National Research Council Canada as "information values"1. This study used the average of the range of information values that National Research Council Canada provided for each metal: $\mathrm{Cd}(1.4-3.2 \mu \mathrm{g} / \mathrm{kg}), \mathrm{Cu}(4.2$ $-6.8 \mathrm{mg} / \mathrm{kg})$, and $\mathrm{Pb}(0.40-0.77 \mathrm{mg} / \mathrm{kg})$. FEBS-1 was used as an external standard in this study for the following 10 elements: $\mathrm{Li}, \mathrm{Na}, \mathrm{Mg}, \mathrm{Ca}, \mathrm{Mn}, \mathrm{Cu}, \mathrm{Sr}$, Cd, Ba, $\mathrm{Pb}$ (Table 2.2).

The raw elemental concentrations from the ThermoFisher iCAP SQ ICPMS were standardized by first correcting by the diluent blank solution, $2 \% \mathrm{HNO}_{3}$. The average of the $2 \% \mathrm{HNO}_{3}$ diluent blank samples ( $\mathrm{n}=18$ in Round 1 ICP-MS, and $n=9$ in Round 2) was subtracted from the concentration of each metal. Second, we corrected the data by the internal standard, Indium, by dividing the elemental concentration by the product of the average elemental concentration of Indium (Round $1=7617928$ CPS) and Round $2=12056467$ CPS) and the elemental concentration. Third, we corrected the data by the otolith weigh (g). We multiplied the weight of each otolith by dividing the elemental concentration by the product of the weight of the otolith (g) and the weight correction value (Round 1 weight correction value $=0.0001$; Round 2 weight correction value $=0.0005)$. We repeated these data correction steps for all metals in both rounds of ICP-MS, to calculate the concentrations of each metal in ppm. For data correction, we took the average concentration of all four isotope of $\mathrm{Pb}\left({ }^{204} \mathrm{~Pb},{ }^{206} \mathrm{~Pb},{ }^{207} \mathrm{~Pb},{ }^{208} \mathrm{~Pb}\right)$ and calculated one "Total_Pb" value.

\footnotetext{
${ }^{1}$ Sturgeon et al. 2005 was unable to certify these CRM information values for these elements because of the large component of uncertainty contributed by homogeneity, but these information values are still extremely valuable as a CRM for ICP-MS studies.
} 
The limits of detection (LOD, mean concentration of total analytical blank $+3 \mathrm{x} \mathrm{SD}$ ) of this method were (in ppm): ${ }^{7} \mathrm{Li}=0.006,{ }^{23} \mathrm{Na}=4.2, \mathrm{Mg}=9.9,{ }^{39} \mathrm{~K}=$ 0.4, $\mathrm{Ca}=300,{ }^{47} \mathrm{Ti}=24.5,{ }^{55} \mathrm{Mn}=0.00004,{ }^{65} \mathrm{Cu}=0.07,{ }^{66} \mathrm{Zn}=3.6,{ }^{86} \mathrm{Sr}=5.1$, $\left.{ }^{111} \mathrm{Cd}=0.1,{ }^{118} \mathrm{Sn}=1.1,{ }^{137} \mathrm{Ba}=0.1,{ }^{204} \mathrm{~Pb}=0.0003\right)$. The limits of quantification (LOQ) of this method were (in ppm): ${ }^{7} \mathrm{Li}=0.01,{ }^{23} \mathrm{Na}=10, \mathrm{Mg}=20,{ }^{39} \mathrm{~K}=1$, Ca $=500,{ }^{47} \mathrm{Ti}=50,{ }^{55} \mathrm{Mn}=0.0001,{ }^{65} \mathrm{Cu}=0.2,{ }^{66} \mathrm{Zn}=9,{ }^{86} \mathrm{Sr}=12,{ }^{111} \mathrm{Cd}=0.3$, $\left.{ }^{118} \mathrm{Sn}=2.5,{ }^{137} \mathrm{Ba}=0.3,{ }^{204} \mathrm{~Pb}=0.0009\right)$.

All elemental concentrations were above the detection limit. However, negative values for elemental concentrations signify that the elemental concentration was lower than the diluent blank $\left(2 \% \mathrm{HNO}_{3}\right)$, which is the maximum possible blank. Negative values are thus below the level of quantification and were removed from the data. ${ }^{47} \mathrm{Ti}$ concentration was found to be below the diluent value and therefore below the level of quantification, so ${ }^{47} \mathrm{Ti}$ was removed from the dataset. ${ }^{39} \mathrm{~K}$ was also removed from the statistical analysis.

FEBS-1 RSD was quite high in Round 2 of ICP-MS, but we attribute this higher RSD to a function of weighing error at these low masses (Table 2.2). During ICP-MS sample preparation, we recognize the possibility of weighing errors when weighing otoliths of such small size (Round 1 mean otolith weight from $=0.76 \mathrm{mg}$, Round 2 mean otolith weight $=0.53 \mathrm{mg}$, MB mean otolith weight $=0.86 \mathrm{mg}$, SDB mean otolith weight $=0.69 \mathrm{mg}, \mathrm{AB}$ mean otolith weight $=0.30 \mathrm{mg}$ ). For example, the 30 Anaheim Bay fish that were run during Round 2 ICP-MS were 35-40 mm in SL and had a mean otolith weight of $0.30 \mathrm{mg}$. Thus, 
assuming a $10 \%$ weighing error on $0.30 \mathrm{mg}$ would lead to major improvement in RSD.

Notwithstanding, in real terms, these RSDs, estimated from FEBS-1 lead to the following uncertainties on the 53 otoliths ran in Round 2 ICP-MS (in ppm): $\mathrm{Li}=0.29+/-0.09, \mathrm{Na}=2110+/-680, \mathrm{Mg}=24+/-6, \mathrm{~K}=730+/-140, \mathrm{Ca}=$ $300,000+/-40,000, \mathrm{Mn}=1.9+/-0.2, \mathrm{Cu}=0.52+/-0.12, \mathrm{Zn}=15.7+/-0.9, \mathrm{Sr}=$ $3500+/-390, \mathrm{Cd}=0.93+/-0.09, \mathrm{Sn}=3.00+/-0.35, \mathrm{Ba}=6.6+/-1.1, \mathrm{~Pb}=0.051$ +/- 0.008. However, the variations observed in the otolith samples exceed these uncertainties.

\subsubsection{Statistical Analyses}

All statistical tests were performed using R v 4.0.1 (R Core Team, 2020). All plots of statistical analysis and Figure 2.1 were produced using R package ‘ggplot2’ (v 4.0.1.; Wickham 2016). All trace element concentrations were reported in units of ppm and expressed relative to the concentration of calcium (shown as a ratio of $\mathrm{X}:{ }^{43} \mathrm{Ca}$ ). We reported the ICP-MS trace elemental analysis results for 12 metals: Li, Na, Mg, Ca, Mn, Cu, Zn, Sr, Cd, Sn, Ba, Pb. We combined ${ }^{25} \mathrm{Mg}$ and ${ }^{26} \mathrm{Mg}$ into “Total_Mg” and combined ${ }^{204} \mathrm{~Pb},{ }^{206} \mathrm{~Pb},{ }^{207} \mathrm{~Pb}$, and ${ }^{208} \mathrm{~Pb}$ into “Total_Pb”.

We first examined the distribution of the 12 elements to check for normality, before using these data in four multivariate statistical tests: 1 ) Discriminant Function Analysis, 2) Permutational Multivariate ANOVA, 3) Pairwise Permutational MANOVA, 4) Mantel test. Plotting the distribution of all 
12 trace metal concentrations across all 10 sites (Figure 2.5), and the distribution of metal concentrations for each bay individually (Appendix A), we found the distribution of all metals to be normal except for $\mathrm{Pb}$ and $\mathrm{Cd}$. Pd and $\mathrm{Cd}$ were zero-inflated and thus unfit for the following four multivariate statistical tests, so these two metals were removed from the dataset.

To assess the ability of otolith microchemistry to distinguish between capture locations on both small and large spatial scales, we first performed linear Discriminant Function Analysis (DFA) using R package 'MASS' (v 4.0.1.; Venables and Ripley 2002) to determine if the otolith trace elemental signatures could accurately predict which fish came from which site. Linear DFA is a supervised, multivariate classification technique (Quinn and Keough 2002). DFA maximally separates collection sites using a weighted linear combination of the 12 element concentrations in otoliths (canonical factors) and then assigns fish to a collection site based on their proximity to the centroid of each site within an estuary (the intersection of the means of $n$ canonical factors, in this case $n=2$ ) (Swearer et al. 2003). We generated models that used all 12 predictor variables (elemental concentrations) to assign 106 F. parvipinnis samples to the 10 collection sites.

Next, we ran a Permutation Multivariate ANOVA (PERMANOVA), using the function 'Adonis’ within the R package 'vegan' (v 4.0.1.; Oksanen et al. 2019), to compare the difference in mean concentration of each metal among all 10 sites. To determine which specific group means were driving the differences in the PERMANOVA's significant results, we ran a multi-level pairwise 
comparison, using R package ‘RVAideMemoire’ (v 4.0.1.; Hervé and Hervé 2020) (analogous to the univariate Post-hoc Tukey’s Test). Our objective was to find which of the pairwise comparisons were statistically significant. We repeated the DFA, PERMANOVA, and Pairwise PERMANOVA tests for each bay individually, and for all 10 sites combined. Because our goal was to evaluate the overall degree of connectivity rather than the connectivity of any particular pair of sites, we did not implement a Bonferroni correction to p-values.

To test if the distance between our collection sites influenced the ability of the Pairwise PERMANOVA to tell the sites apart based on differences in otolith microchemistry, we ran a Mantel test (Legendre and Fortin 2010). The Mantel test examined the correlation between two matrices - in this case geographic distance between pairs of sites and F-values from the PERMANOVA (Quinn and Keough 2002). 


\subsection{Results}

\subsubsection{ICP-MS Trace Elemental Analysis}

Otolith microchemical analysis of $F$. parvipinnis significantly

distinguished capture locations at both small $(<10 \mathrm{~km})$ and large $(>10 \mathrm{~km})$ spatial scales in San Diego Bay, Mission Bay, and Anaheim Bay. When comparing the 10 study sites, pairwise permutational MANOVA found 43/45 pairwise comparisons were statistically significant $(\mathrm{p}<0.05)$ (Table 2.6).

Discriminant function analysis of otolith trace metal concentrations correctly classified, on average, $63.5 \%$ of $F$. parvipinnis to the collection site (DFA range: 20-100\%; Table 2.3). When comparing intra-bay sites separately, the DFA classification success rate improved to an average of $79.9 \%$. Mission Bay-only had a DFA classification success of 77.9\% (Table 2.7), San Diego Bay-only had 85\% success (Table 2.10), and Anaheim Bay-only had 76.7\% success (Table 2.13). The ten collection sites exhibited a range of trace metal concentrations in F. parvipinnis otoliths (Figure 2.6).

\subsubsection{Inter-Bay Analysis}

\subsubsection{Discriminant Function Analysis (DFA) Results}

To evaluate the success of each discriminant model in assigning fish to their site of origin, we compared the number of fish we caught from each site to the number of fish that the DFA model correctly predicted to have originated from that site (Swearer et al. 2003). DFA, on average, accurately classified 63.5\% of fish to their collection site (Table 2.4). We plotted the inter-bay DFA results 
graphically by site (Figure 2.9), by element (Figure 2.10), and by both site and element (Figure 2.11). Otolith signatures from SDB3, SDB4, AB1, and AB2 could be distinguished from all other sites with a higher accuracy than the average (Table 2.4, Figure 2.4).

DFA models found Sr, Mg, and Li to be the most useful elements in distinguishing among sub-populations in this study (Figure 2.10). We found the three Anaheim Bay sites to be distinguishable from the three Mission Bay sites and the four San Diego Bay sites (Figure 2.9). In particular, SDB3 exhibited a significantly different signature than the other three sites in San Diego Bay (Figure 2.9).

\subsubsection{Permutational Multivariate ANOVA (PERMANOVA)}

The PERMANOVA analyses revealed that there were strong differences in otolith chemistry among sites $(p=0.001, \alpha=0.05)$ (Table 2.5).

The Pairwise Permutational MANOVA (PERMANOVA) found 43/45 pairwise comparisons were statistically significant with a $\mathrm{p}^{-}$-value $\leq 0.05$ (Table 2.6). Only two pairwise comparisons, $\mathrm{AB} 1$ vs $\mathrm{AB} 2(p=0.166)$ and $\mathrm{AB} 3$ vs MB3 (the sites closest to the open ocean) ( $p=0.0706$ ) were not statistically significant.

\subsubsection{Mantel Test}

There was no indication that geographic distance affected the strength of chemical difference between pairs of sites (Table 2.2; Mantel test $\mathrm{r}=0.02759 p=$ 
0.568). This suggests that geographic distance, per se, did not induce significant relationship between sampling locations.

\subsubsection{Intra-Bay Analysis}

To test the differences in otolith microchemistry within each bay separately, we repeated the DFA, PERMANOVA, and Pairwise PERMANOVA tests for each bay individually. When each bay was analyzed individually, the pairwise PERMANOVA test discriminated between every site within a bay with the exception of $\mathrm{AB} 1 \mathrm{vs} \mathrm{AB} 2$.

At the smallest spatial scale this study explored (2.15-4.19 km, Table 2.3.), six of the seven comparison of intra-bay sites were different from one another (AB1/AB3: $p=0.0036^{*}$; AB2/AB3: $p=0.0077^{*}$; MB1/MB2: $p=$ 0.0167*; SDB2/SDB3: $p=0.0012 *$; SDB2/SDB4: $p=0.0077 *$ SDB3/SDB4: $p=$ 0.0012*). The smallest spatial scale that DFA could discern was between AB2 and AB3 that are separated by only $2.89 \mathrm{~km}$.

\subsubsection{Mission Bay}

Considering Mission Bay-only, the DFA, on average, accurately classified 77.9\% of fish to their collection site (Table 2.7). DFA found Sr and Mg to be the most useful elements in distinguishing Mission Bay sites (Figure 2.11). PERMANOVA found a significant difference among Mission Bay sites ( $p=$ 0.001) (Table 2.8). Pairwise PERMANOVA could distinguish between all pairwise site comparisons in Mission Bay (Table 2.9). 


\subsubsection{San Diego Bay}

Considering San Diego Bay-only, the DFA, on average, accurately classified 85\% of fish to their collection site (Table 2.10). DFA found $\mathrm{Zn}, \mathrm{Mn}, \mathrm{Sr}$, Sn, and Li to be the most useful elements in distinguishing between San Diego Bay sites (Figure 2.14). PERMANOVA found a significant difference among San Diego Bay sites $(p=0.001)$ (Table 2.11). Pairwise PERMANOVA could distinguish between all pairwise site comparisons in San Diego Bay (Table 2.12).

\subsubsection{Anaheim Bay}

Considering Anaheim Bay-only, the DFA, on average, accurately classified 76.7\% of fish to their collection site (Table 2.13). DFA found Mg, Mn, Sr, Sn, and Li to be the most useful elements in distinguishing Anaheim Bay sites (Figure 17). PERMANOVA found a significant difference among Anaheim Bay sites $(p=0.031)$ (Table 2.14). The only pairwise site comparison in Anaheim Bay that the Pairwise PERMANOVA could not distinguish was between AB1 and AB2. The pairwise PERMANOVA could distinguish all other pairwise comparisons between Anaheim Bay sites (Table 2.15). 


\subsection{Discussion}

\subsubsection{Otolith Microchemical Analysis}

Otolith microchemistry distinguished collection sites even at small spatial scales

Otolith microchemistry successfully distinguished intra-bay capture locations even on spatial scales of less than $5 \mathrm{~km}$, and the ability to discriminate was not related to distance between sites. This suggests that few if any adult $F$. parvipinnis move between these marshes, even those quite close to each other.

Our findings support previous research that large bays such as Mission Bay and San Diego Bay impart discrete otolith signatures of fish inhabiting different zones along the long-axes of the bays (Fodrie and Mendoza 2006). We were unable to collect any F. parvipinnis at the front or middle of San Diego Bay, and at the front of Mission Bay, so our samples were only from the back of San Diego Bay and the middle and back of Mission Bay, and yet we were still able to distinguish fish among locations within these two bays (Table 2.8, Table 2.11). These fish were likely $4-5$ months old at time of capture, meaning they had been residents long enough to record local conditions in their otoliths (Fodrie and Levin 2008, Elsdon and Gillanders 2003).

We conclude the majority of individuals from these intra-bay locations did not mix, even within the back of San Diego Bay where there is the most potential habitat to support increased movement between sites or within Anaheim Bay where there is continuous marsh between sites. In Anaheim Bay, we were able to collect $F$. parvipinnis from the front, middle, and back of Seal Beach 
National Wildlife Refuge, and found significant differences in otolith signatures along the long-axes of this bay as well (Table 2.14).

Comparable otolith microchemistry studies have typically focused on California halibut (Paralichthys californicus), a commercially important fish species in the Southern California Bight (SCB). Paralichthys californicus use bays and open coasts as juvenile nursery habitats and then migrate offshore in the SCB as adults (Fodrie and Mendoza 2006). Juvenile halibut exhibited very localized movement, generally migrating $<10 \mathrm{~km}$ from nurseries in bays to subadult populations in nearby coastal areas (Fodrie and Levin 2008). Therefore, juvenile halibut from adjacent sites were likely to receive recruits from similar sources, effectively limiting connectivity during this phase of their life history and producing higher numbers of adults located near the large embayments where they had originated (Fodrie and Levin 2008, López-Duarte et al. 2012).

Otolith microchemistry accurately predicts fish residency

Otolith microchemistry successfully distinguished capture locations at both small $(<10 \mathrm{~km})$ and large $(10-200 \mathrm{~km})$ spatial scales across three bays in Southern California. The distance between the collection sites did not affect our ability to tell the sites apart.

This study demonstrated similar DFA classification accuracy to other otolith microchemistry studies, despite previous work comparing signatures of sites further apart (Forrester and Swearer 2002, Fodrie and Herzka 2008). Our 
results are comparable to previous Laser Ablation ICP-MS (LA ICP-MS) studies, which examines otolith microchemistry on an even finer temporal scale than the bulk ICP-MS method performed here. For example, an investigation of the contribution of juvenile $P$. californicus habitats to adult populations by comparing nine protected, semi-enclosed bay nurseries (one of which was Anaheim Bay) to shallow, open coast in Southern California, found 83\% accuracy using $\mathrm{Cu}$ and $\mathrm{Pb}$ (Forrester and Swearer 2002). Another study used LA ICP-MS to examine smaller scale, intra-embayment variability to reconstruct movement of $P$. californicus in Southern California (Fodrie and Herzka 2008). In that experiment, LA ICP-MS analyzed Mn and Sr concentrations between two sites along the exposed coast (La Jolla and Imperial Beach) and four embayments (inner and outer Mission Bay, and inner and outer San Diego Bay), and achieved an average of 63\% accuracy (MB: 83\%; SDB: 44\%; Inner: 91\%; Outer: 41\%) (Fodrie and Herzka 2008).

Here, we provide the first bulk otolith microchemistry data for this important mid-trophic level, estuarine resident fish species. Our data supports and expands on previous work using Bulk ICP-MS to compare otolith signatures of five species from Carpinteria Marsh, Alamitos Bay, and Anaheim Bay: a midwater-dwelling smelt (Atherinops affinis), two benthic gobies (Clevelandia ios and Ilypnus gilberti), and two flatfish (Paralichthys californicus and Hypsopsetta guttulata) (Swearer et al. 2003). With 93.5\% accuracy, Sr and Ba signatures assigned fish to their site of origin (Swearer et al. 2003). However, testing for temporal stability of otolith signatures between spring and autumn 1996 in one of 
the sites, Carpinteria Marsh, revealed elemental signatures were not consistent between seasons within the same year. Also, when comparing the five fish species, elemental fingerprints proved to be similar between closely related species (two benthic gobies and the two flatfish) but dissimilar between distantly (phylogenetically and ecologically) related species (Swearer et al. 2003). Such studies suggest otolith elemental fingerprints may be temporally variable (Gillanders 2005, Patterson et al. 2004, Forrester and Swearer 2002) and species specific (Swearer et al. 2003, Gillanders and Kingsford 2003). Therefore, this study demonstrates the success of otolith microchemistry to accurately predict fish residency, even when only comparing sub-populations of one species at a time, and from a single sampling event, instead of multiple sampling events over the course of a year.

F. parvipinnis exhibit high site fidelity and low habitat connectivity among ten sites in Southern California

Our findings expand on previous evidence that $F$. parvipinnis display high site fidelity on both small (Talley 2000) and large (Bernardi and Talley 2000) spatial and temporal scales. For example, otolith microchemical analysis of $F$. parvipinnis collected from separate arms of San Quintin Bay in Baja California, Mexico in 2002 found fish at this bay also exhibited distinct chemical fingerprints and concluded high site fidelity (C. DiBacco and D. Talley pers. comm.). 
Furthermore, high site fidelity and low habitat connectivity fit the life history strategy of $F$. parvipinnis. Shallow, intertidal creeks are used extensively by F. parvipinnis, especially by juveniles, where these first-order creeks provide them a nursey habitat (Desmond et al. 2000). These first-order creeks serve as conduits for fishes moving onto the marsh surface at high tide (Desmond et al. 2000). Their life history strategy is to remain on the salt marsh, in the shallow creeks, rather than risk predation by birds or larger fish in the seagrass beds, or deeper channels, known as higher order creeks (Talley 2000). Fundulus parvipinnis exhibit a strong negative relationship with both depth and creek order, with higher numbers of small individuals occurring in low order creeks (Desmond et al. 2000).

By remaining on the marsh surface, F. parvipinnis avoid getting pulled out to sea by tidal flushing following large rain events. In addition, predation risk increases as water depth increases and fish size decreases (Talley 2000), which promotes use of shallow habitat by these small resident fish. Mission Bay and San Diego Bay house small, fragmented marsh habitats that are separated by very large, deep water sections of bay (Figure 2.2, Figure 3). Therefore, low habitat connectivity of F. parvipinnis is not surprising, and is in fact supported by their life history strategy, because moving between these study sites would require traveling across very deep channels or between fragmented marsh, thus increasing their predation risk. Additionally, F. parvipinnis appear well adapted physiologically to handle these extreme intertidal creek conditions (salinity levels 
greater than 60 psu and temperatures as high as $40^{\circ} \mathrm{C}$ ), which we conclude has likely given them a competitive advantage in this environment.

The F. parvipinnis we studied ranged in standard length from $25-60 \mathrm{~mm}$ $(\mathrm{AB}$ mean $\mathrm{SL}=29.3 \mathrm{~mm}, \mathrm{MB}$ mean $\mathrm{SL}=48.78 \mathrm{~mm}, \mathrm{SDB}$ mean $\mathrm{SL}=44.7 \mathrm{~mm})$, most likely making them early spawned young, hatched in the spring of the year they were caught, but they may have been spawning adults from the previous year (Fritz 1975).

We found Sr, Mg, Mn, and Li to be the most useful metals in distinguishing interbay and intra-bay collection sites

Currently, there is a limited understanding of the mechanisms regulating trace metal deposition in fish otoliths. Water has been determined to be the major source of trace metals incorporated into fish otoliths (Milton and Chenery 2001, Walther and Thorrold 2006, Bath et al. 2000). Other factors such diet, physiology, growth rates, and ontogenetic effects can also contribute to elemental deposition in otoliths but play a much smaller role compared to water (Walther and Thorrold 2006). Previous work suggests $\mathrm{Sr}, \mathrm{Ba}$, and $\mathrm{Pb}$ incorporation in otoliths is primarily a function of the ambient water chemistry of the environment the fish inhabits (Bath et al. 2000, Walther and Thorrold 2006, Campana 1999). Water sources contributed $83 \%$ of $\mathrm{Sr}$ and $98 \%$ of Ba in otoliths formed in spiked seawater (Walther and Thorrold 2006). Our results support the consensus that water chemistry is the dominant factor controlling the uptake of $\mathrm{Sr}$ and $\mathrm{Ba}$ in $\mathrm{F}$. 
parvipinnis otoliths because the fish we analyzed were of a similar age and thus otolith elemental differences are unlikely to be a result of ontogenetic effects. Within San Diego Bay, there is a nearly linear gradient in Mn seawater concentration from the mouth $(<1 \mathrm{ppb})$ to the head $(>30 \mathrm{ppb})$ (Fodrie and Herzka 2008). Mission Bay had similar Mn otolith concentrations as Anaheim Bay, but San Diego Bay displayed an increase in Mn otolith signature at SDB1 (Figure 6). Our four sampling locations in San Diego Bay were all located in the middle and back region (Figure 2.3), so we were unable to test Mn levels at the mouth of the bay.

$\mathrm{Cu}$ and $\mathrm{Pb}$ display a qualitatively similar concentration gradient to that observed in sediments: high levels in bays and lower levels on the open coast (Forrester and Swearer 2002). We found elevated levels of $\mathrm{Cu}$ and $\mathrm{Pb}$ at MB3 compared to the other nine sites in our study (Figure 6). We did not sample any site on the open coast but MB3 receives the most tidal influence and is the most marine in composition, so the fact that MB3 had higher $\mathrm{Cu}$ and $\mathrm{Pb}$ than the other nine sites was initially surprising. We hypothesize that higher $\mathrm{Cu}$ and $\mathrm{Pb}$ at $\mathrm{MB} 3$ is due to the input from the San Diego River drainage basin and anthropogenic runoff.

Understanding the mechanisms responsible for elemental deposition in otoliths is not required to utilize otoliths as natural tracers of fish movement and connectivity. Nevertheless, our data contributes to the growing literature concluding that several metals are most responsible for differences in signatures among sites. When comparing all ten study sites, DFA models found Sr, Mg, and 
Li to be the most useful elements in distinguishing among sub-populations, supporting previous work in estuarine ICP-MS studies (Swearer et al. 2003, Fodrie and Herzka 2008, Gillanders and Kingsford 2000) (Figure 2.10).

Implications for wetland restoration, conservation, and management

Fundulus parvipinnis is an important component of wetland food webs, making the results of this study useful for informing wetland restoration and management in Southern California. Most habitat connectivity studies using otolith microchemistry focus on transient fish species (Elsdon et al. 2008), but here we demonstrated that for a resident fish species that spends its entire lifetime within estuaries, otolith microchemistry is a useful tool for assessing habitat connectivity.

High site fidelity and low habitat connectivity have important implications for predicting the effect of local anthropogenic disturbances in Southern California estuaries. Increased site fidelity and limited movement could mean these populations are particularly vulnerable to anthropogenic disturbances and slow to recover due to their reliance on local replenishment. Broadly, fish species that display high site fidelity can be susceptible to regional overfishing and local stressors, such as anoxia, chemical spills, or habitat destruction (McGrath and Austin 2009).

Fundulus parvipinnis are a common, abundant species in Southern California estuaries that are given little attention in most estuarine ecology 
studies. Aside from a few physiological studies of F. parvipinnis that explored their unique ability to withstand extremely salty habitats, studies of estuarine fish ecology tend to focus on commercially important species like the California halibut, or rare fish species for conservation efforts. We value the importance of investigating the habitat connectivity of common fish species because the nature of their commonness makes them essential in wetland food webs. Commercially important species and rarer species all often depend on abundant species to maintain aspects of their diversity (Connolly et al. 2014).

The fact that these common species remain common over time, means their traits are successful in that environment (Connolly et al. 2014). The tidal migrations of $F$. parvipinnis makes them a vital vector for transferring energy and nutrients off the marsh surface, which directly affects their predators and prey (Kneib 1997, Talley 2000). Truly understanding the habitat connectivity of $F$. parvipinnis necessitates understanding not only how individual F. parvipinnis relate to each other and identifying which traits have made them so successful in certain habitats, but how this resident fish is connected to the rest of the wetland food web.

Many rare species rely on positive interactions with common species (Frimpong 2018). By focusing on individual species conservation and defaulting to protecting physical habitats of rare or declining species, we miss the opportunity to study species interactions and better understand the importance of positive interdependence among species (Frimpong 2018). By investigating the habitat connectivity of a common wetland resident fish in this study, our findings 
contribute to ecological studies that protect rare species by protecting the common species that serve as their hosts.

\subsubsection{Mission Bay}

In Mission Bay, there are two primary wetland habitats large enough to sustain sub-populations of F. parvipinnis: Kendall Frost Marsh (MB1) and Tecolote Creek marsh (MB2), the two sites we were able to collect samples from. Significant differences in elemental signatures indicate F. parvipinnis are rarely traveling between Kendall Frost Marsh and Tecolote Creek marsh (Table 2.9), supporting observed high site fidelity at these marshes in Mission Bay (Talley 2000).

Smiley Lagoon (MB3) is not located in Mission Bay, but directly south of Mission Bay, separated by a breakwater at Ocean Beach, where the San Diego River mouth empties to the ocean (Figure 2.2). Due to Smiley Lagoon's proximity to the open coast and increased tidal flushing at this site, the fact that DFA found Sr and Mg to be the most useful elements in distinguishing Mission Bay sites (Figure 2.11) is to be expected because Sr strongly associates with water temperature and salinity. As expected, F. parvipinnis does not appear to be moving between the inner reaches of Mission Bay at Kendall Frost or Tecolote Creek and Smiley Lagoon in Ocean Beach, which would require them to venture into the deep channel in the inlet and then across the jetty to reach Smiley Lagoon. Fundulus parvipinnis rarely venture to the open coast as adults (Watson 1992). 


\subsubsection{San Diego Bay}

San Diego Bay had the strongest site differences in otolith microchemistry of the three intra-bay analyses. The DFA, on average, accurately classified 85\% of fish within San Diego Bay-only (Table 2.10). All four San Diego Bay sites are located towards the back of the bay because despite numerous sampling attempts, we were unable to collect $F$. parvipinnis from the mouth or middle region of San Diego Bay (Figure 2.2). Therefore, we conclude that even within the back of San Diego Bay, F. parvipinnis are not frequently moving between Vener Pond (SDB1), J-Street Marsh (SDB2), Emory Channel (SDB3), and Former Salt Pond 10A (SDB4). Zn, Mn, Sr, Sn, and Li were the most useful elements in distinguishing between San Diego Bay sites (Figure 2.14). Interestingly, Emory Channel (SDB3) appears to exhibit elevated levels of Sn compared to the other SDB sites.

\subsubsection{Anaheim Bay}

Within Seal Beach National Wildlife Refuge, site AB1 is an altered (tidally restricted) pond, and sites $\mathrm{AB} 2$ and $\mathrm{AB} 3$ are natural marsh habitat. Only two of the 45 pairwise comparisons did not differ significantly enough to distinguish using the Pairwise PERMANOVA test (AB1/AB2: $p=0.1660$; AB3/MB3: $p=0.0706)$. One of these comparisons, AB1 vs AB2, suggests increased habitat connectivity (lower site fidelity) between these adjacent sites in Seal Beach National Wildlife Refuge. This inability to distinguish between these sites may be due to their proximity to each other (AB1 and AB2 are the closest 
sites examined, only $2.15 \mathrm{~km}$ apart). Another explanation is that similar elemental signatures between $\mathrm{AB} 1$ and $\mathrm{AB} 2$ are a result of similar ambient water chemistry at these two sites. Another possibility is that the fish collected from AB were slightly smaller than from MB and SDB, with samples selected for ICP-MS from $\mathrm{AB}$ at $35-40 \mathrm{~mm}$, while $\mathrm{MB}$ and $\mathrm{SDB}$ fish were $40-55 \mathrm{~mm}$. Smaller $\mathrm{AB}$ fish had slightly smaller otoliths than MB or SDB, so increased possibility of AB otolith weighing errors during ICP-MS sample preparation at these smaller weights.

The other comparison that the Pairwise PERMANOVA did not distinguish, AB3 vs MB3, is most likely due to similar environmental and hydrological conditions between these two sites. AB3 and MB3 are the closest to the bay mouth and receive the most tidal flushing, compared to the other eight sites in our study system that rarely receive tidal flushing. Therefore, we believe similarities in elemental deposition between fish caught in $\mathrm{AB} 3$ and MB3 are due to similarities in their proximity to the ocean and increased marine influence. 


\section{TABLES}

Table 2.1106 adult California killifish (Fundulus parvipinnis) collected from ten sites across three estuaries in southern California (Mission Bay, San Diego Bay, and Anaheim Bay). Round of ICP-MS analysis, fish standard length size range, and number of fish per site utilized for bulk otolith microchemical analysis are included.

\begin{tabular}{|c|c|c|c|c|c|c|c|}
\hline Location & $\begin{array}{l}\text { Site } \\
\text { Name }\end{array}$ & Description & GPS Location & $\begin{array}{l}\text { Date of } \\
\text { Fish } \\
\text { Collection }\end{array}$ & $\begin{array}{c}\text { ICP-MS } \\
\text { Round } \\
\#\end{array}$ & \#Fish/Site & $\begin{array}{l}\text { Fish } \\
\text { Standard } \\
\text { Length } \\
\text { (SL) }\end{array}$ \\
\hline \multirow{3}{*}{$\begin{array}{l}\text { Mission } \\
\text { Bay (MB) }\end{array}$} & MB1 & $\begin{array}{l}\text { Kendall Frost Marsh } \\
\text { Reserve }\end{array}$ & $\begin{array}{l}\text { 32.791276, - } \\
117.229831\end{array}$ & $\begin{array}{l}\text { July 28, } \\
2018\end{array}$ & $\begin{array}{c}\text { Round } 1 \\
(n=10) \text {, } \\
\text { Round } 2 \\
(n=3)\end{array}$ & $\mathrm{n}=13$ & \multirow{3}{*}{$40-55 \mathrm{~mm}$} \\
\hline & MB2 & Tecolote Creek & $\begin{array}{l}32.770661,- \\
117.208473\end{array}$ & $\begin{array}{l}\text { July 18, } \\
2018\end{array}$ & $\begin{array}{c}\text { Round } 1 \\
(n=10), \\
\text { Round } 2 \\
(n=3)\end{array}$ & $\mathrm{n}=13$ & \\
\hline & MB3 & $\begin{array}{l}\text { Smiley Lagoon, } \\
\text { Ocean Beach }\end{array}$ & $\begin{array}{l}\text { 32.754939, - } \\
117.247745\end{array}$ & $\begin{array}{l}\text { August 10, } \\
2018\end{array}$ & $\begin{array}{l}\text { Round } \\
2\end{array}$ & $\mathrm{n}=10$ & \\
\hline \multirow{4}{*}{$\begin{array}{l}\text { San Diego } \\
\text { Bay (SDB) }\end{array}$} & SDB1 & $\begin{array}{l}\text { Vener Pond, } \\
\text { Sweetwater Marsh, } \\
\text { San Diego Bay } \\
\text { National Wildlife } \\
\text { Refuge } \\
\end{array}$ & $\begin{array}{l}\text { 32.639085, - } \\
117.110066\end{array}$ & $\begin{array}{l}\text { August 6, } \\
2018\end{array}$ & Round 1 & $\mathrm{n}=10$ & \multirow{4}{*}{$40-55 \mathrm{~mm}$} \\
\hline & SDB2 & $\begin{array}{l}\text { J Street Marsh, San } \\
\text { Diego Bay National } \\
\text { Wildlife Refuge }\end{array}$ & $\begin{array}{l}\text { 32.618664, - } \\
117.102571\end{array}$ & $\begin{array}{c}\text { August } 1 \text {, } \\
2018\end{array}$ & Round 1 & $\mathrm{n}=10$ & \\
\hline & SDB3 & $\begin{array}{l}\text { Emory Channel, San } \\
\text { Diego Bay National } \\
\text { Wildlife Refuge }\end{array}$ & $\begin{array}{l}32.607391,- \\
117.129968\end{array}$ & $\begin{array}{c}\text { August 1, } \\
2018\end{array}$ & Round 2 & $\mathrm{n}=10$ & \\
\hline & SDB4 & $\begin{array}{l}\text { Former Salt Pond } \\
\text { 10A, San Diego Bay } \\
\text { National Wildlife } \\
\text { Refuge }\end{array}$ & $\begin{array}{l}32.591963,- \\
117.122283\end{array}$ & $\begin{array}{l}\text { August 3, } \\
2018\end{array}$ & Round 1 & $\mathrm{n}=10$ & \\
\hline \multirow{3}{*}{$\begin{array}{l}\text { Anaheim } \\
\text { Bay (AB) }\end{array}$} & AB1 & $\begin{array}{l}\text { 2A, Seal Beach } \\
\text { National Wildlife } \\
\text { Refuge }\end{array}$ & $\begin{array}{l}\text { 33.748998, - } \\
118.076022\end{array}$ & $\begin{array}{l}\text { July 16, } \\
2018\end{array}$ & Round 2 & $\mathrm{n}=10$ & \multirow{3}{*}{$35-40 \mathrm{~mm}$} \\
\hline & $\mathrm{AB} 2$ & $\begin{array}{l}\text { 2N, Seal Beach } \\
\text { National Wildlife } \\
\text { Refuge }\end{array}$ & $\begin{array}{l}33.742374,- \\
118.080144\end{array}$ & $\begin{array}{l}\text { July 17, } \\
2018\end{array}$ & Round 2 & $\mathrm{n}=10$ & \\
\hline & AB3 & $\begin{array}{l}\text { 4N, Seal Beach } \\
\text { National Wildlife } \\
\text { Refuge }\end{array}$ & $\begin{array}{l}33.730592,- \\
118.071939\end{array}$ & $\begin{array}{l}\text { July 12, } \\
2018\end{array}$ & Round 2 & $\mathrm{n}=10$ & \\
\hline
\end{tabular}


Table 2.2 Distance between the GPS locations of the ten fish collection sites (in km), obtained from Google Earth Pro's Ruler tool, Imagery Date $=17$ Nov2018. When necessary, total distance was calculated by combining multiple line segments to fit the shape of the estuary.

\begin{tabular}{|c|c|c|c|c|c|c|c|c|c|}
\hline & AB_1 & AB_2 & AB_3 & MB_1 & MB_2 & MB_3 & SDB_1 & SDB_2 & SDB_3 \\
\hline AB_2 & 2.15 & & & & & & & & \\
\hline AB_3 & 4.00 & 2.89 & & & & & & & \\
\hline MB_1 & 152.89 & 150.74 & 148.89 & & & & & & \\
\hline MB_2 & 156.17 & 154.02 & 152.17 & 3.95 & & & & & \\
\hline MB_3 & 150.31 & 148.16 & 146.31 & 9.15 & 12.19 & & & & \\
\hline SDB_1 & 180.66 & 178.51 & 176.66 & 38.97 & 32.92 & 36.20 & & & \\
\hline SDB_2 & 181.59 & 179.44 & 177.59 & 44.21 & 38.16 & 37.53 & 5.24 & & \\
\hline SDB_3 & 182.25 & 180.10 & 178.25 & 44.91 & 38.86 & 38.67 & 5.94 & 3.21 & \\
\hline SDB_4 & 184.19 & 182.04 & 180.19 & 51.03 & 44.98 & 40.49 & 12.06 & 4.19 & 3.25 \\
\hline
\end{tabular}


Table 2.3 Elemental Concentrations of External Standards (FEBS-1, CS, and TAB) reported in units of ppm. FEBS-1 expected values include both certified quantity values (C) and information values (I) from National Research Council Canada (Sturgeon et al. 2005). After standardizing the otolith data by the crab shell (CS) standard, this table reports how the FEBS-1 observed values from this study compare to the FEBS- 1 standard expected values from the National Research Council Canada. Cells highlighted in blue show the expected values per standard, per element. Cells highlighted in light gray (Round 1 ICP-MS) and dark gray (Round 2 ICP-MS) show the observed values per standard, per element. 


\begin{tabular}{|c|c|c|c|c|c|c|c|c|c|c|c|c|c|c|c|}
\hline \multicolumn{16}{|c|}{ Elemental Concentrations of External Standards (FEBS-1, CS, and TAB) reported in units of ppm } \\
\hline$\underline{y}$ & 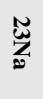 & $\mathfrak{y}_{\substack{n \\
\text { and }}}$ & 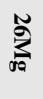 & 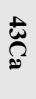 & $\stackrel{\infty}{\infty}$ & 崩 & ֻ̆ & : & 象 & $\vec{\Xi}$ & 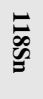 & Ш్త్ర & 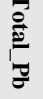 & 氞高 & \\
\hline 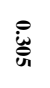 & 勈 & 葛 & 蓜 & 遌 & 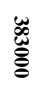 & 总 & 舁 & $\frac{z}{s}$ & 总 & $\tilde{\omega}$ & $\underset{s}{z}$ & 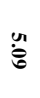 & 总 & 仓曾 & 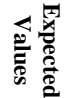 \\
\hline$\stackrel{+}{\infty}$ & 嵒 & 怘 & 良 & 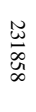 & 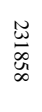 & ज̆ & $\stackrel{+}{\infty}$ & in & $\begin{array}{l}\text { 岁 } \\
\text { g. }\end{array}$ & Бे & 悹 & 甚曾 & 胥 & 可 & 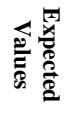 \\
\hline$\stackrel{\circlearrowright}{\varpi}$ & 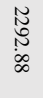 & $\underset{w}{\tilde{\omega}}$ & 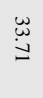 & 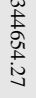 & 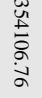 & 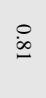 & $\tilde{\omega}$ & 惢 & 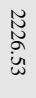 & i & $\overrightarrow{\tilde{\tilde{N}}}$ & 品 & के & 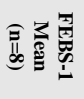 & \\
\hline ¿̊. & 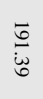 & 芯 & $\underset{\sim}{\tilde{N}}$ & 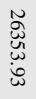 & 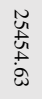 & ì & ï & $\vec{\infty}$ & 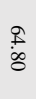 & $\underset{\sim}{\stackrel{\mathcal{W}}{N}}$ & : & 该 & 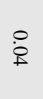 & 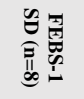 & \\
\hline$\stackrel{0}{\circ}$ & $\stackrel{\infty}{\circ}$ & $\begin{array}{l}\omega \\
\stackrel{\sigma}{\circ}\end{array}$ & $\begin{array}{l}\mathscr{\sigma} \\
\text { o }\end{array}$ & œ & فे & 缹 & ڤ & $\begin{array}{l}\text { No } \\
\text { वे }\end{array}$ & ă & 㤅 & ळे & ڤे & ஃ & 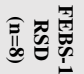 & 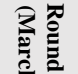 \\
\hline$\stackrel{+}{\stackrel{\leftrightarrow}{\circ}}$ & 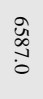 & 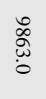 & 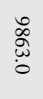 & 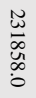 & 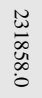 & $\ddot{g}$ & $\stackrel{+}{\dot{\infty}}$ & in & 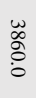 & 宮 & ì & $\dot{\omega}$ & i & 言量 & 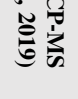 \\
\hline$\dot{f}$ & 岕 & 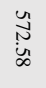 & 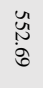 & 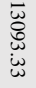 & 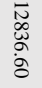 & $\dot{\nexists}$ & 氙 & $\overrightarrow{\dot{\omega}}$ & 岕 & 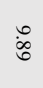 & $\dot{\dot{\rho}}$ & $\overrightarrow{\dot{\infty}}$ & $\stackrel{\dot{\omega}}{.}$ & 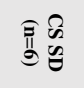 & \\
\hline$\stackrel{\infty}{\circ}$ & o & ஃ & \& & \& & : & वे & 峞 & సै & ๘口 & œ & $\begin{array}{l}\frac{1}{0} \\
\text { aे }\end{array}$ & 策 & 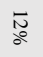 & 衰苟 & \\
\hline : & 总 & : & : & ذँ⿱ & 递 & : & : & : & : & 这 & : & 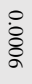 & : & 焉胥苞 & \\
\hline$\stackrel{0}{\dot{H}}$ & 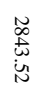 & 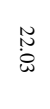 & $\underset{\substack{\tilde{W} \\
\infty}}{\tilde{N}}$ & 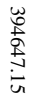 & 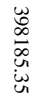 & : & 芯 & 8 & 惫 & N & : & $\begin{array}{ccc}\pi \\
\ddagger\end{array}$ & in & 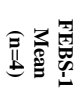 & \\
\hline$\stackrel{\dot{L}}{\dot{L}}$ & $\begin{array}{l}\stackrel{0}{0} \\
\stackrel{0}{8}\end{array}$ & : & $\dot{\theta}$ & 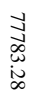 & 䍔 & : & 悹 & ळ. & 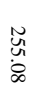 & 잉 & :े & : & $\dot{\dot{\omega}}$ & 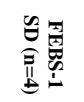 & \\
\hline 嵌 & 崖 & 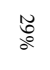 & 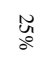 & 产 & ज़ & $\vec{\circ}$ & 永 & 壳 & ت. & 范 & స్ّ & ذّ & 销 & 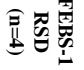 & Z \\
\hline 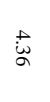 & $\begin{array}{l}\text { 䅰 } \\
\text { ○े }\end{array}$ & 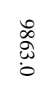 & 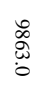 & 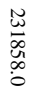 & 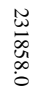 & 崩 & \& & 息 & 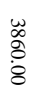 & 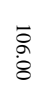 & ì & $\begin{array}{l}\infty \\
\vdots \\
\omega\end{array}$ & 总 & 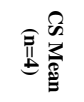 & 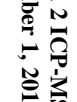 \\
\hline ì & 呄 & 总 & $\begin{array}{l}\text { 勇 } \\
\text { S. }\end{array}$ & "ृ & 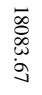 & 号 & $\dot{d}$ & $\overrightarrow{\dot{\sigma}}$ & 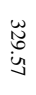 & $\begin{array}{l}0 \\
i \\
i \\
+1\end{array}$ & ¿্口 & : & ¿े & 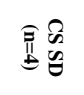 & \\
\hline ğ & دे & ğ & 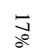 & $\bar{\circ}$ & $\stackrel{\circ}{\circ}$ & مे & ஃ & g̊ & ஃ̊ & ஃ & 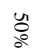 & aे & $\begin{array}{ll}\mathrm{Gg} \\
\text { gी }\end{array}$ & 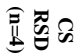 & \\
\hline 递 & 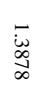 & 恿 & 总 & 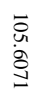 & 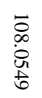 & : & 离 & 范 & 岕 & : & $\begin{array}{l}\text { 岕 } \\
\text { g }\end{array}$ & 选 & : & 恶胥蛋 & \\
\hline
\end{tabular}


Table 2.4 Classification success matrix based on linear discriminant function analysis of 106 otolith signatures (from all 10 collection sites) analyzed by bulk ICP-MS.

\begin{tabular}{|c|c|c|c|c|c|c|c|c|c|c|c|}
\hline Site & AB1 & AB2 & AB3 & MB1 & MB2 & MB3 & SDB1 & SDB2 & SDB3 & SDB4 & Average \\
\hline $\begin{array}{c}\% \\
\text { Accuracy }\end{array}$ & $80 \%$ & $80 \%$ & $20 \%$ & $61.5 \%$ & $53.9 \%$ & $60 \%$ & $60 \%$ & $50 \%$ & $100 \%$ & $70 \%$ & $63.5 \%$ \\
\hline
\end{tabular}

Table 2.5 Results of the PERMANOVA test comparing the difference in mean concentration of each metal among all 10 collection sites. Significance codes: 0 ‘***’ $0.001^{\text {‘**’ }} 0.01^{\text {‘*’ }} 0.05$ ‘’ 0.1 '’ 1 .

\begin{tabular}{|l|c|c|c|c|c|c|}
\hline & Df & SumOfSqs & R2 & F & $\operatorname{Pr}(>\mathrm{F})$ & \\
\hline bay_site & 9 & 428 & 0.407 & 7.33 & 0.001 & *** \\
\hline Residual & 96 & 622 & 0.593 & & & \\
\hline Total & 105 & 1050 & 1 & & & \\
\hline
\end{tabular}

Table 2.6 $P$-values from Pairwise PERMANOVA test. $P$-values of 96 pairwise comparisons of the 10 sites based on otolith trace metal signature. 43/45 pairwise comparisons were statistically significant with a $p$-value $\leq 0.05(\alpha=0.05)$.

Significant pairwise comparisons are denoted by an asterisk*

\begin{tabular}{|c|c|c|c|c|c|c|c|c|c|}
\hline & AB_1 & AB_2 & AB_3 & MB_1 & MB_2 & MB_3 & SDB_1 & SDB_2 & SDB_3 \\
\hline AB_2 & 0.1660 & & & & & & & & \\
\hline AB_3 & $0.0036^{*}$ & $0.0077^{*}$ & & & & & & & \\
\hline MB_1 & $0.0012^{*}$ & $0.0012^{*}$ & $0.0012^{*}$ & & & & & & \\
\hline MB_2 & $0.0012^{*}$ & $0.0012^{*}$ & $0.0012^{*}$ & $0.0167^{*}$ & & & & & \\
\hline MB_3 & $0.0012^{*}$ & $0.0058^{*}$ & 0.0706 & $0.0012^{*}$ & $0.0012^{*}$ & & & & \\
\hline SDB_1 & $0.0012^{*}$ & $0.0012^{*}$ & $0.0012^{*}$ & $0.0012^{*}$ & $0.0012^{*}$ & $0.0012^{*}$ & & & \\
\hline SDB_2 & $0.0012^{*}$ & $0.0012^{*}$ & $0.0012^{*}$ & $0.0012^{*}$ & $0.0161^{*}$ & $0.0012^{*}$ & $0.0012^{*}$ & & \\
\hline SDB_3 & $0.0012^{*}$ & $0.0012^{*}$ & $0.0012^{*}$ & $0.0036^{*}$ & $0.0012^{*}$ & $0.0012^{*}$ & $0.0012^{*}$ & $0.0012^{*}$ & \\
\hline SDB_4 & $0.0012^{*}$ & $0.0012^{*}$ & $0.0012^{*}$ & $0.0012^{*}$ & $0.0012^{*}$ & $0.0012^{*}$ & $0.0012^{*}$ & $0.0077^{*}$ & $0.0012^{*}$ \\
\hline
\end{tabular}


Table 2.7 Classification success matrix based on linear discriminant function analysis of 36 otolith signatures from three sites in Mission Bay, CA (MB1, MB2, MB3).

\begin{tabular}{|c|c|c|c|c|}
\hline Site & MB1 & MB2 & MB3 & Average \\
\hline $\begin{array}{c}\text { Percent } \\
\text { Accuracy }\end{array}$ & $76.9 \%$ & $76.9 \%$ & $80.0 \%$ & $77.9 \%$ \\
\hline
\end{tabular}

Table 2.8 Results of the PERMANOVA test comparing the difference in mean concentration of each metal among three sites in Mission Bay, CA (MB1, MB2, MB3). Significance codes: 0 ‘***’ $0.001^{\text {‘**’ }} 0.01^{\text {‘*’ }} 0.05$ ‘’ $0.1^{\text {‘ ’ }} 1$.

\begin{tabular}{|c|c|c|c|c|c|c|c|}
\hline $\mathrm{a}=0.05$ & Df & SumOfSqs & MeanSqs & F.Model & R2 & $\operatorname{Pr}(>\mathrm{F})$ & \\
\hline bay_site & 2 & 87.9 & 43.9 & 5.53 & 0.251 & 0.001 & $* * *$ \\
\cline { 2 - 9 } Residual & 33 & 262 & 7.94 & & 0.749 & & \\
\hline Total & 35 & 350 & & & 1.00 & & \\
\hline
\end{tabular}

Table 2.9 P-values from Pairwise PERMANOVA test of mean metal concentration among three sites in Mission Bay, CA (MB1, MB2, MB3). Significant pairwise comparisons are denoted by an asterisk ${ }^{*}$.

\begin{tabular}{|c|c|c|}
\hline & MB_1 & MB_2 \\
\hline MB_2 & $0.0170^{*}$ & \\
\hline MB_3 & $0.0015^{*}$ & $0.0015^{*}$ \\
\hline
\end{tabular}


Table 2.10 Classification success matrix based on linear discriminant function analysis of 40 otolith signatures from four sites in San Diego Bay, CA (SDB1, SDB2, SDB3, SDB4).

\begin{tabular}{|c|c|c|c|c|c|}
\hline Site & SDB1 & SDB2 & SDB3 & SDB4 & Average \\
\hline $\begin{array}{c}\text { Percent } \\
\text { Accuracy }\end{array}$ & $80 \%$ & $80 \%$ & $100 \%$ & $80 \%$ & $85 \%$ \\
\hline
\end{tabular}

Table 2.11 Results of the PERMANOVA test comparing the difference in mean concentration of each metal among four sites in San Diego Bay, CA (SDB1, SDB2, SDB3, SDB4). Significance codes: 0 ' $* * *$ ’ $0.001^{\text {'**' }} 0.01^{\text {‘ }}$ ’ 0.05 '? 0.1 ' 1 .

\begin{tabular}{|c|c|c|c|c|c|c|c|}
\hline $\mathrm{a}=0.05$ & Df & SumOfSqs & MeanSqs & F.Model & $\mathrm{R} 2$ & $\operatorname{Pr}(>\mathrm{F})$ & \\
\hline bay_site & 3 & 146 & 48.6 & 7.160 & 0.374 & 0.001 & $* * *$ \\
\hline Residual & 36 & 244 & 6.79 & & 0.626 & & \\
\hline Total & 39 & 390 & & & 1.00 & & \\
\hline
\end{tabular}

Table 2.12 P-values from Pairwise PERMANOVA test of mean metal concentration among four sites in San Diego Bay, CA (SDB1, SDB2, SDB3, SDB4). Significant pairwise comparisons are denoted by an asterisk*

\begin{tabular}{|c|c|c|c|}
\hline & SDB_1 & SDB_2 & SDB_3 \\
\hline SDB_2 & $0.0012^{*}$ & & \\
\hline SDB_3 & $0.0012^{*}$ & $0.0012^{*}$ & \\
\hline SDB_1 & $0.0012^{*}$ & $0.0030^{*}$ & $0.0012^{*}$ \\
\hline
\end{tabular}


Table 2.13 Classification success matrix based on linear discriminant function analysis of 30 otolith signatures from three sites in Anaheim Bay, CA (AB1, AB2, AB3).

\begin{tabular}{|c|c|c|c|c|}
\hline Site & AB1 & AB2 & AB3 & Average \\
\hline $\begin{array}{c}\text { Percent } \\
\text { Accuracy }\end{array}$ & $80 \%$ & $70 \%$ & $80 \%$ & $76.7 \%$ \\
\hline
\end{tabular}

Table 2.14 Results of the PERMANOVA test comparing the difference in mean concentration of each metal among three sites in Anaheim Bay, CA (AB1, AB2, AB3).

\begin{tabular}{|c|c|c|c|c|c|c|c|}
\hline $\mathrm{a}=0.05$ & Df & SumOfSqs & MeanSqs & F.Model & $\mathrm{R} 2$ & $\operatorname{Pr}(>\mathrm{F})$ & \\
\hline bay_site & 2 & 33.6 & 16.8 & 1.77 & 0.116 & 0.031 & $*$ \\
\hline Residual & 27 & 256 & 9.50 & & 0.884 & & \\
\hline Total & 29 & 290 & & & 1.00 & & \\
\hline
\end{tabular}

Table 2.15 P-values from Pairwise PERMANOVA test of mean metal concentration among three sites in Anaheim Bay, CA (AB1, AB2, AB3). Significant pairwise comparisons are denoted by an asterisk*.

\begin{tabular}{|c|c|c|}
\hline & AB_1 & AB_2 \\
\hline AB_2 & 0.189 & \\
\hline AB_3 & $0.015^{*}$ & $0.019^{*}$ \\
\hline
\end{tabular}




\section{FIGURES}

Figure 2.1 Map of the 10 collection sites in Southern California, USA, where adult California killifish (Fundulus parvipinnis) were collected for otolith microelemental analysis. Estuarine systems are numbered as follows: Anaheim Bay $=$ AB, Mission Bay $=$ MB, San Diego Bay $=$ SDB. Within each bay, sites are numbered numerically from north to south (e.g., AB1, AB2, AB3). Fundulus parvipinnis were collected from these sites using seine nets and baited minnow traps from July 10-August 10, 2018.

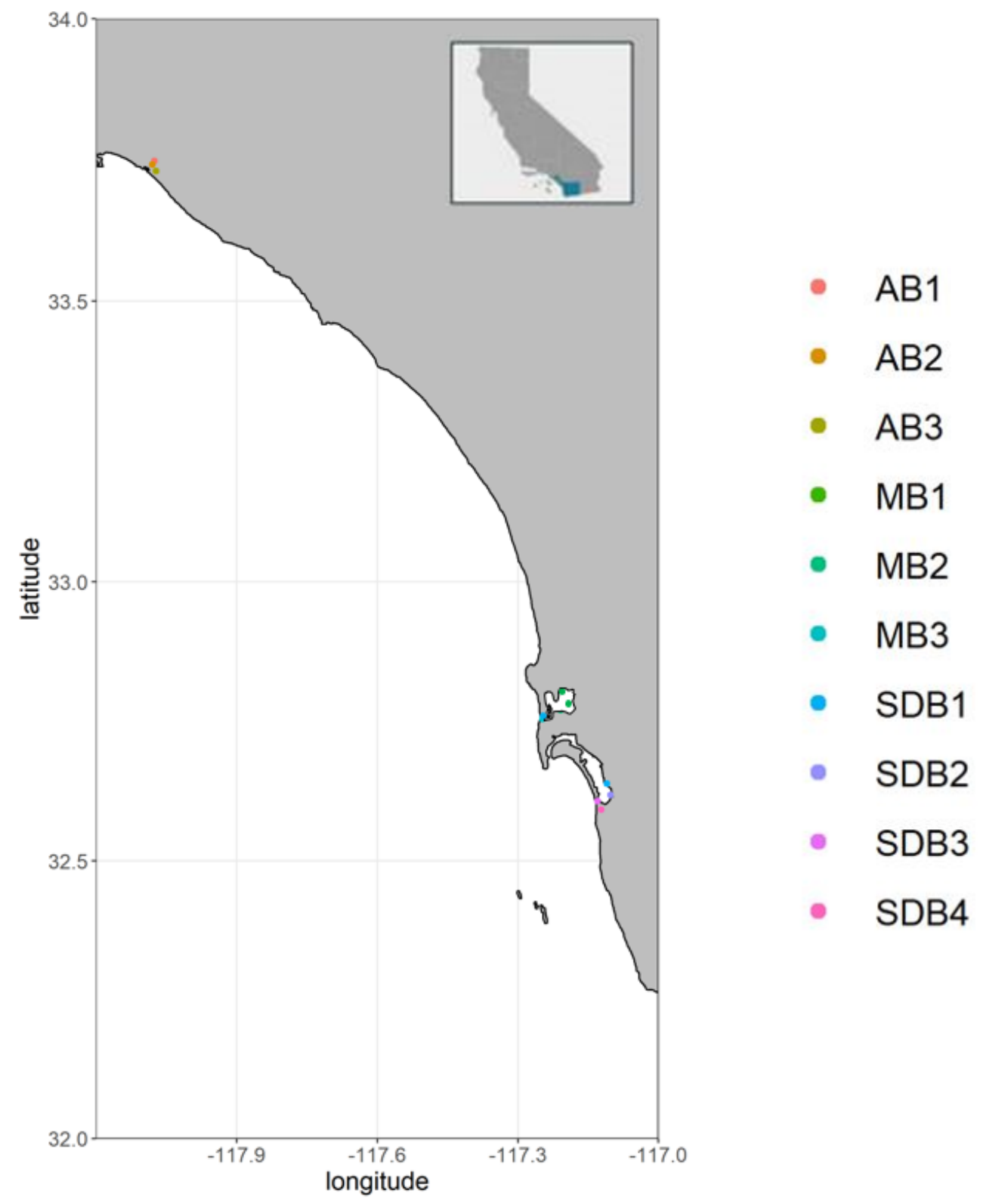


Figure 2.2 Map of the Mission Bay study site, characterized by wetland habitat type, according to the U.S. Fish and Wildlife Service, National Wetlands Inventory data accessed online in May 2018. Fish collection sites are numbered numerically from north to south as follows: MB1 = Kendall Frost Marsh Reserve, MB2 = Tecolote Creek, MB3 = Smiley Lagoon .

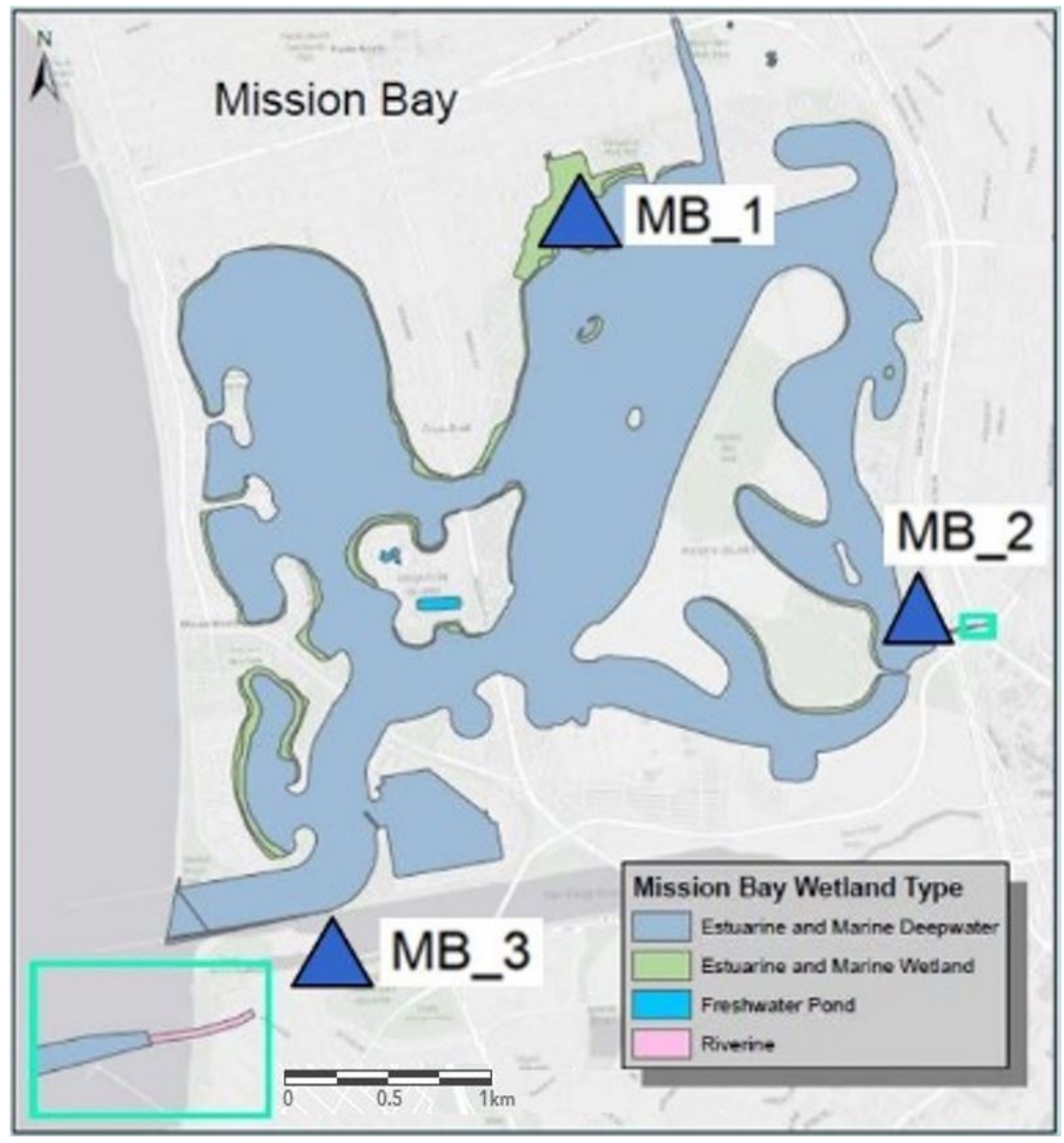


Figure 2.3 Map of the San Diego Bay study site, characterized by wetland habitat type, according to the U.S. Fish and Wildlife Service, National Wetlands Inventory data accessed online in May 2018. Fish collection sites are numbered numerically from north to south as follows: SDB1= Vener Pond, Sweetwater Marsh, SDB2 $=$ J Street Marsh, SDB3 = Emory Channel, SDB4 $=$ Former Salt Pond 10A.

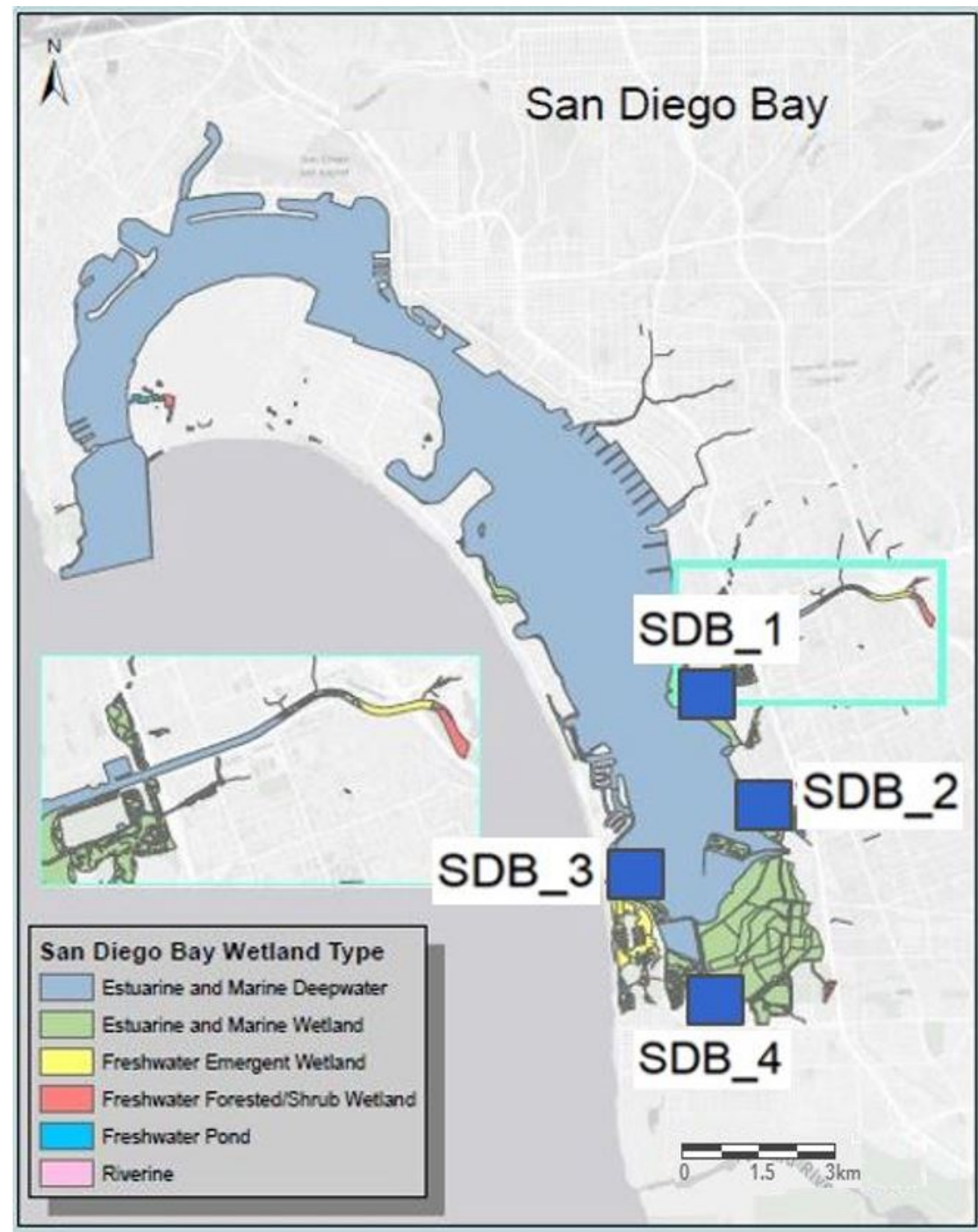


Figure 2.4 Map of the Anaheim Bay study site, characterized by wetland habitat type, according to the U.S. Fish and Wildlife Service, National Wetlands Inventory data accessed online in May 2018. Fish collection sites are numbered numerically from north to south as follows: $A B 1=2 A, A B 2=2 N, A B 3=4 N$.

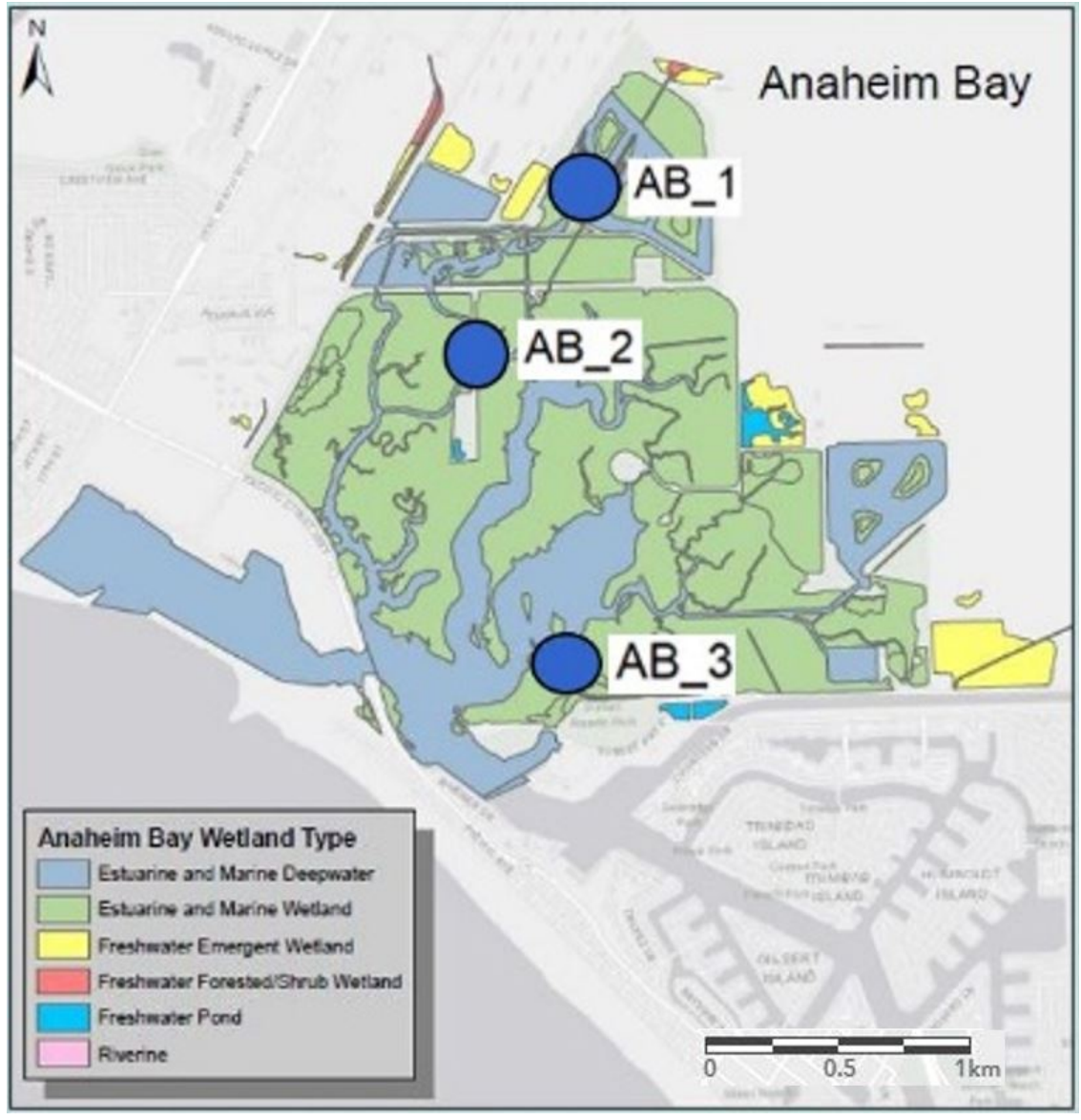


Figure 2.5 Histograms of the 12 trace metals to check for normality of distribution across all 10 sites (MB1, MB2, MB3, SDB1, SDB2, SDB3, SDB4, AB1, AB2, AB3). Signatures from all 106 otoliths were combined.

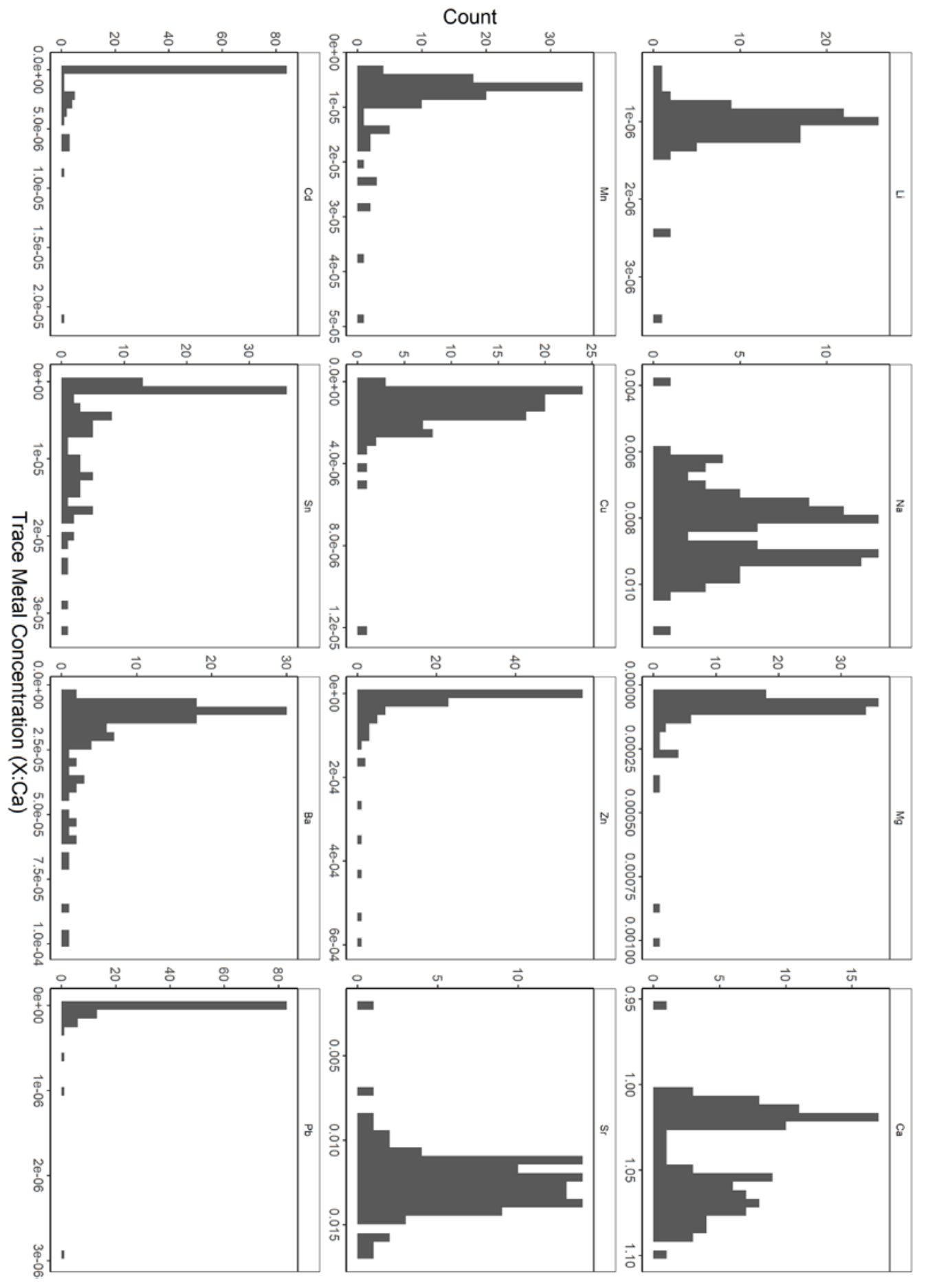


Figure 2.6 Mean element concentrations (in ppm) in Fundulus parvipinnis otoliths across all 10 sites. Note the differences in y-axis ranges between metals. On the $\mathrm{x}$ axis, the fish collection sites are ordered from north to south (left to right) along the Southern California coast. No data (ND) indicates non-detect of that metal.

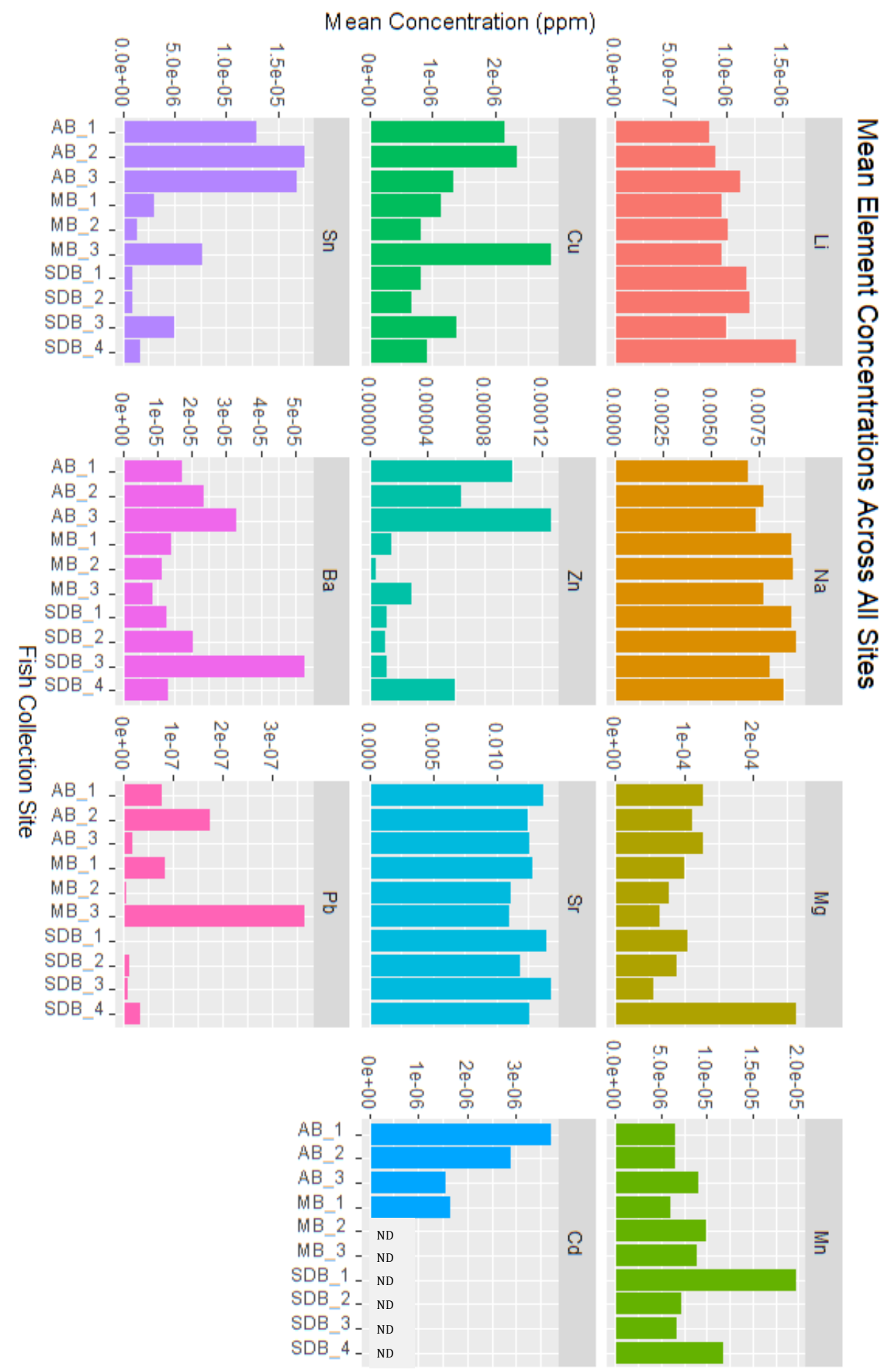


Figure 2.7 Linear discriminant function analysis scores of element:Ca ratios in 106 otoliths of adult Fundulus parvipinnis, by site, collected during summer 2018 at ten sites in Southern California. The axes of this plot are linear discriminants (LD1 and LD2) that described, on average, 63.5\% of the differences among collection sites (Table 2.4).

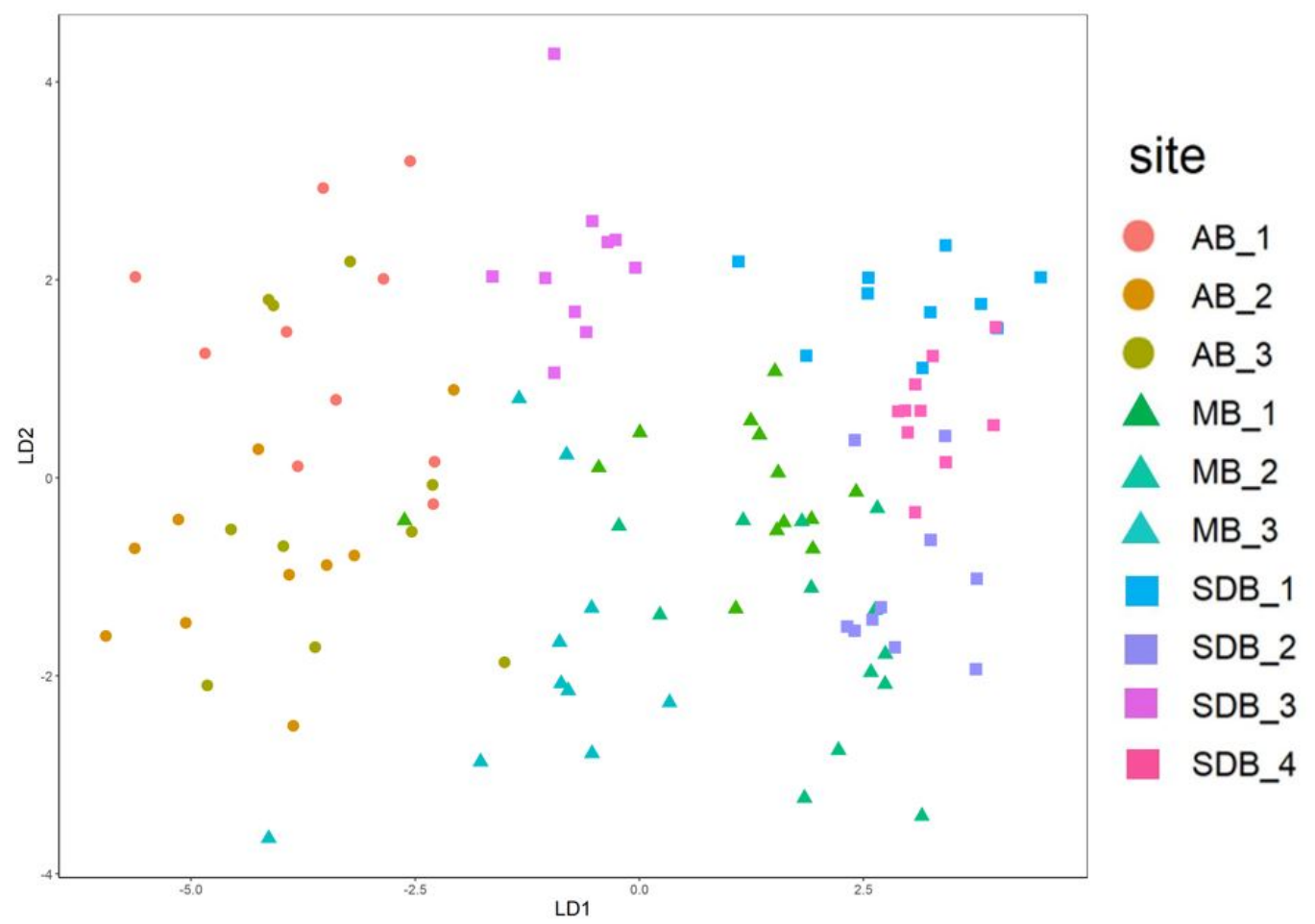


Figure 2.8 Linear discriminant function analysis scores of element:Ca ratios in 106 otoliths of adult Fundulus parvipinnis, by element. Signatures from all 10 collection sites. Elements in the top and right of the plot ( $\mathrm{Sr}, \mathrm{Li}, \mathrm{Mg}$ ) furthest from the center of the plot are driving the differences in trace metal results between fish capture sites.

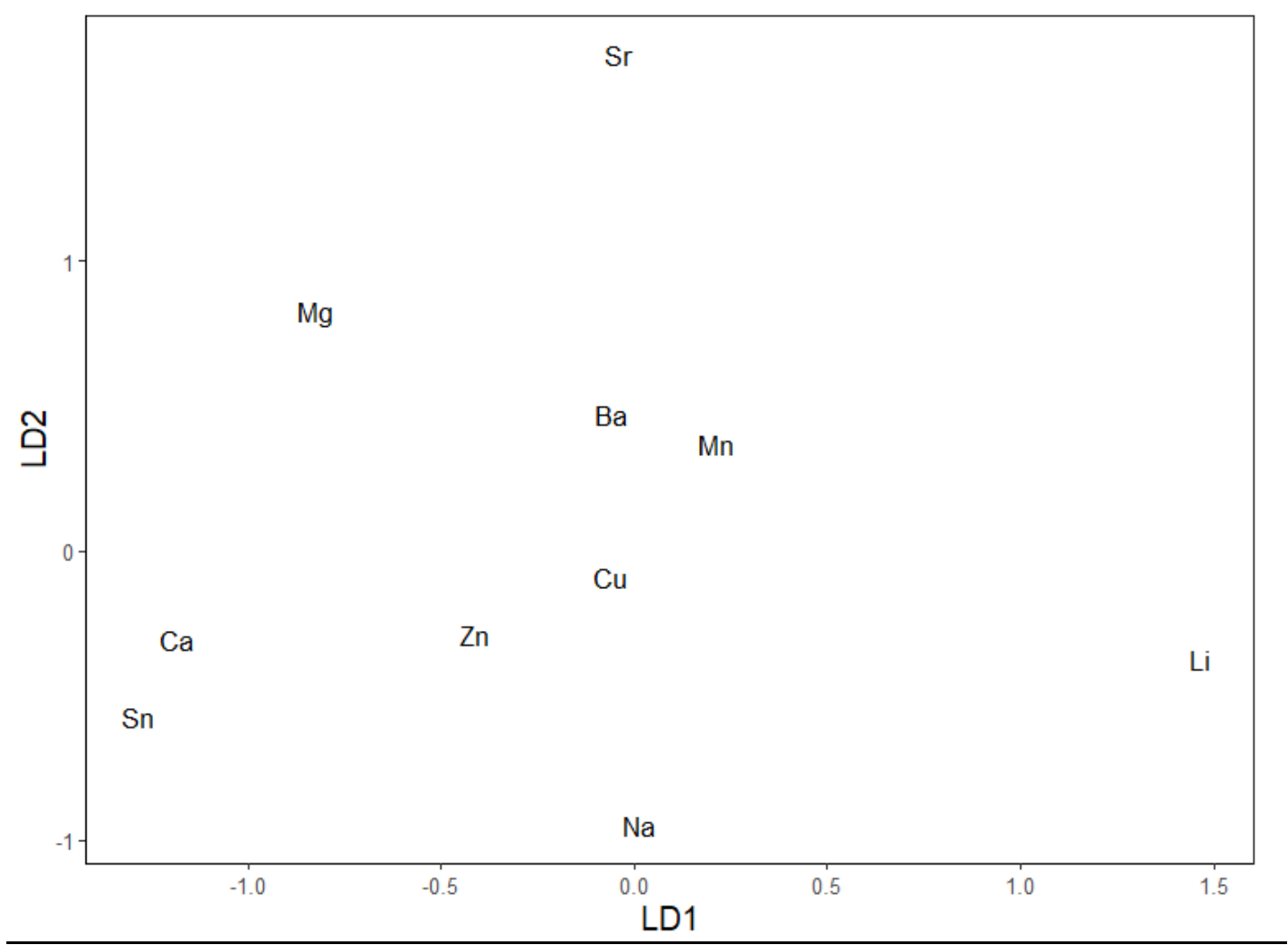


Figure 2.9 Linear discriminant function analysis scores of element:Ca ratios in 106 otoliths of adult Fundulus parvipinnis, by both element and collection site. Signatures from all 10 collection sites.

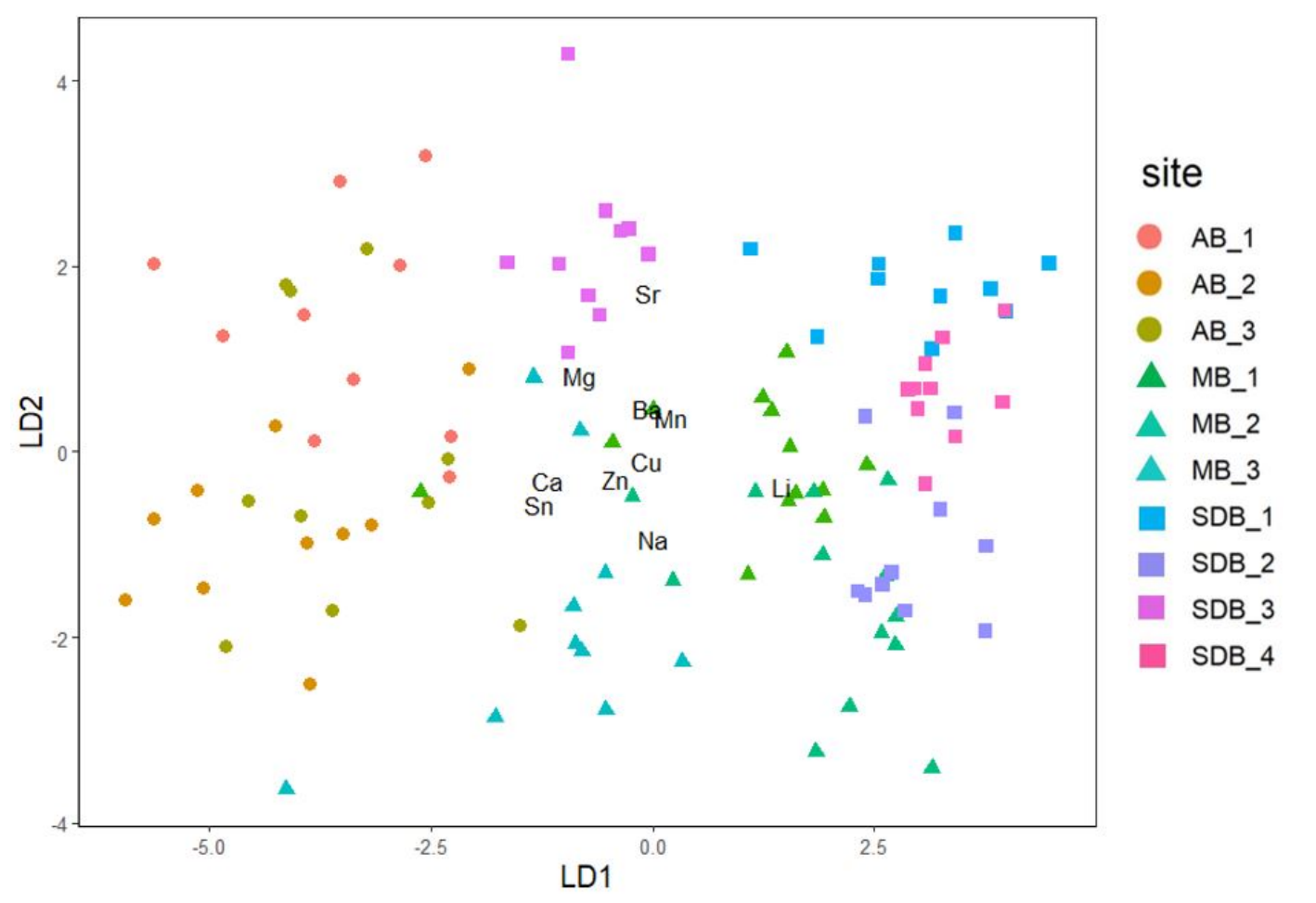


Figure 2.10 Linear discriminant function analysis scores of element:Ca ratios in 36 otoliths of adult Fundulus parvipinnis from Mission Bay sites (MB1, MB2, MB3), by site.

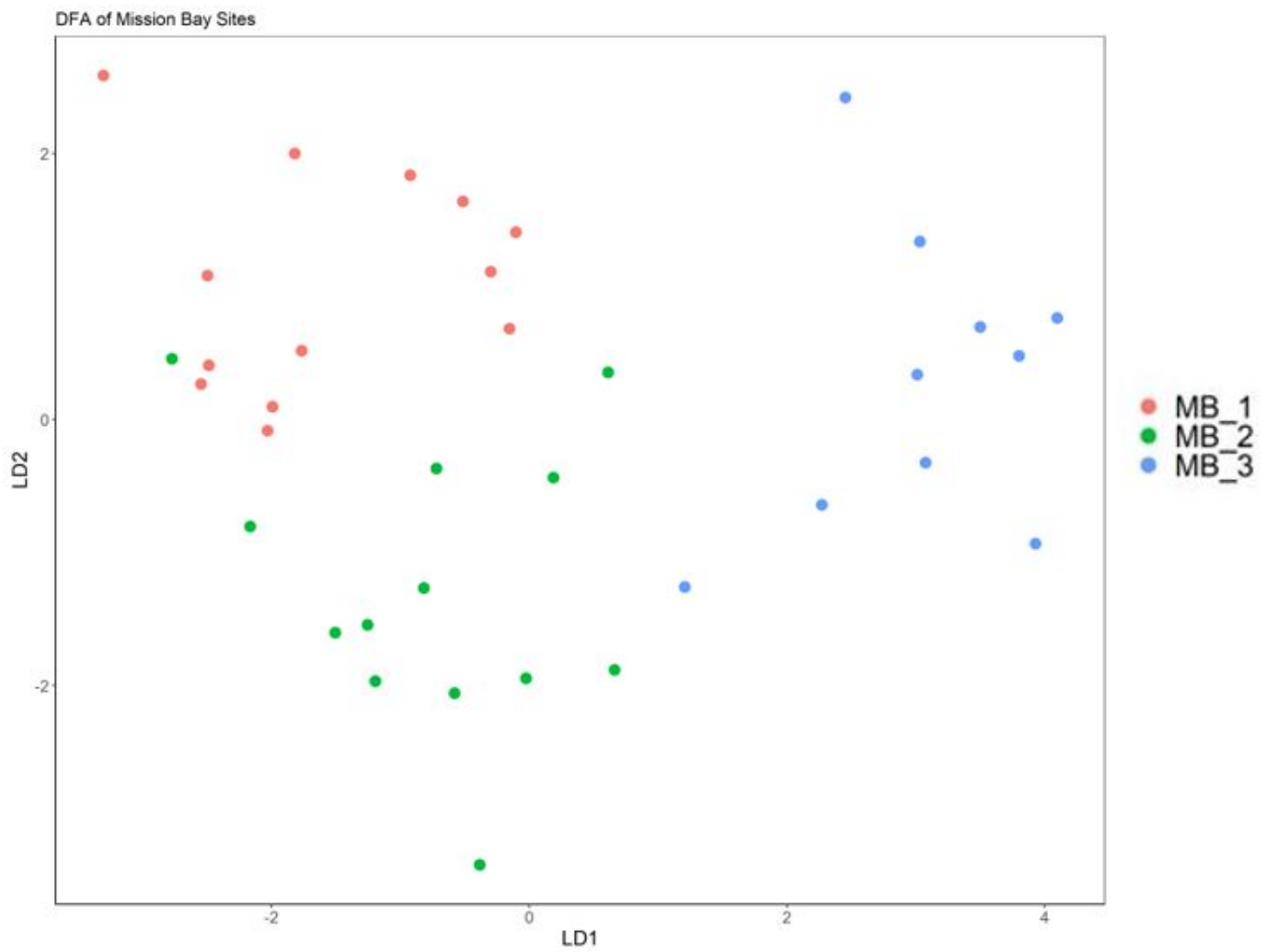


Figure 2.11 Linear discriminant function analysis scores of element:Ca ratios in 36 otoliths of adult Fundulus parvipinnis from Mission Bay sites (MB1, MB2, MB3), by element.

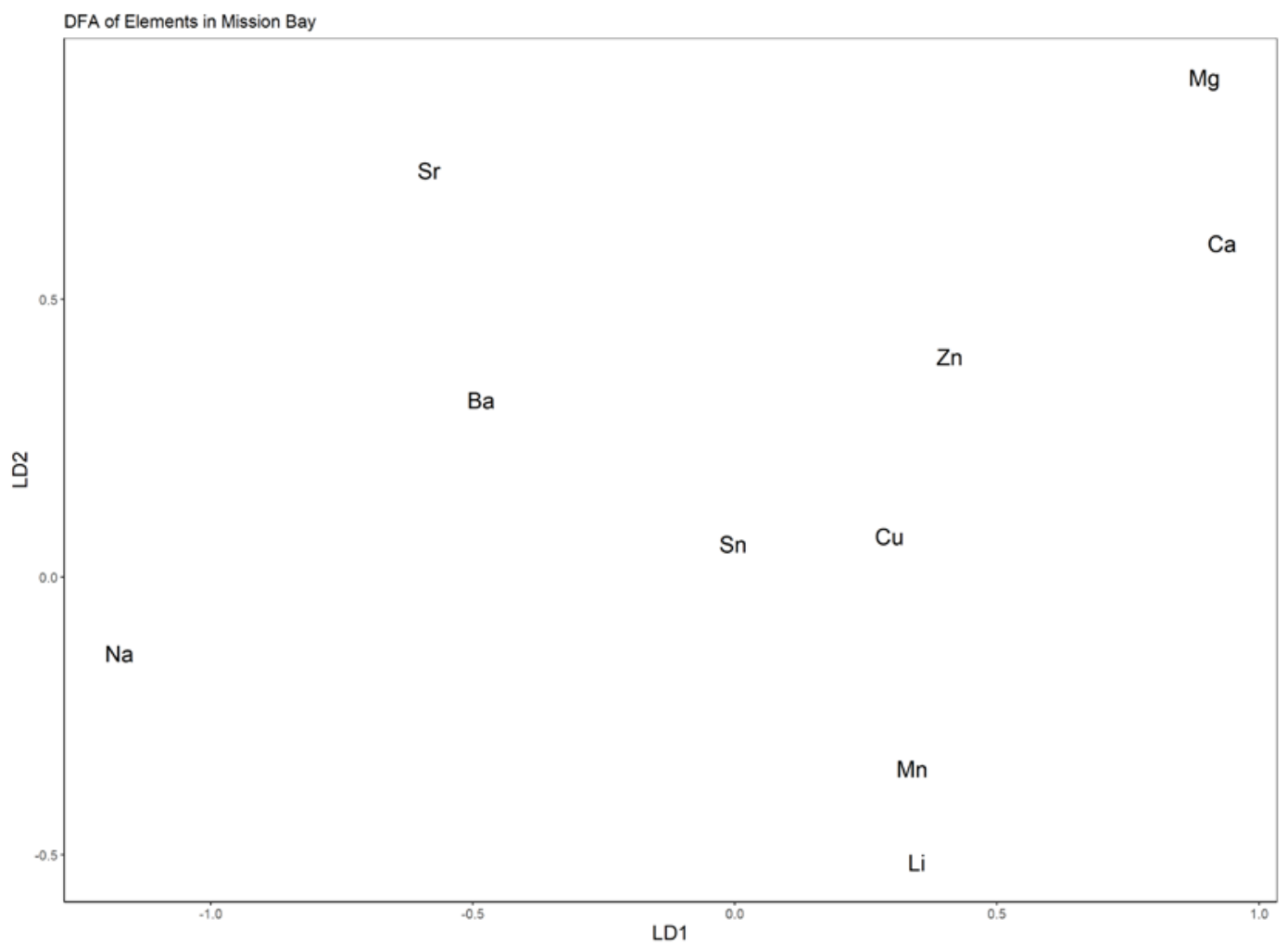


Figure 2.12 Linear discriminant function analysis scores of element:Ca ratios in 36 otoliths of adult Fundulus parvipinnis from Mission Bay sites (MB1, MB2, MB3), by both site and element.

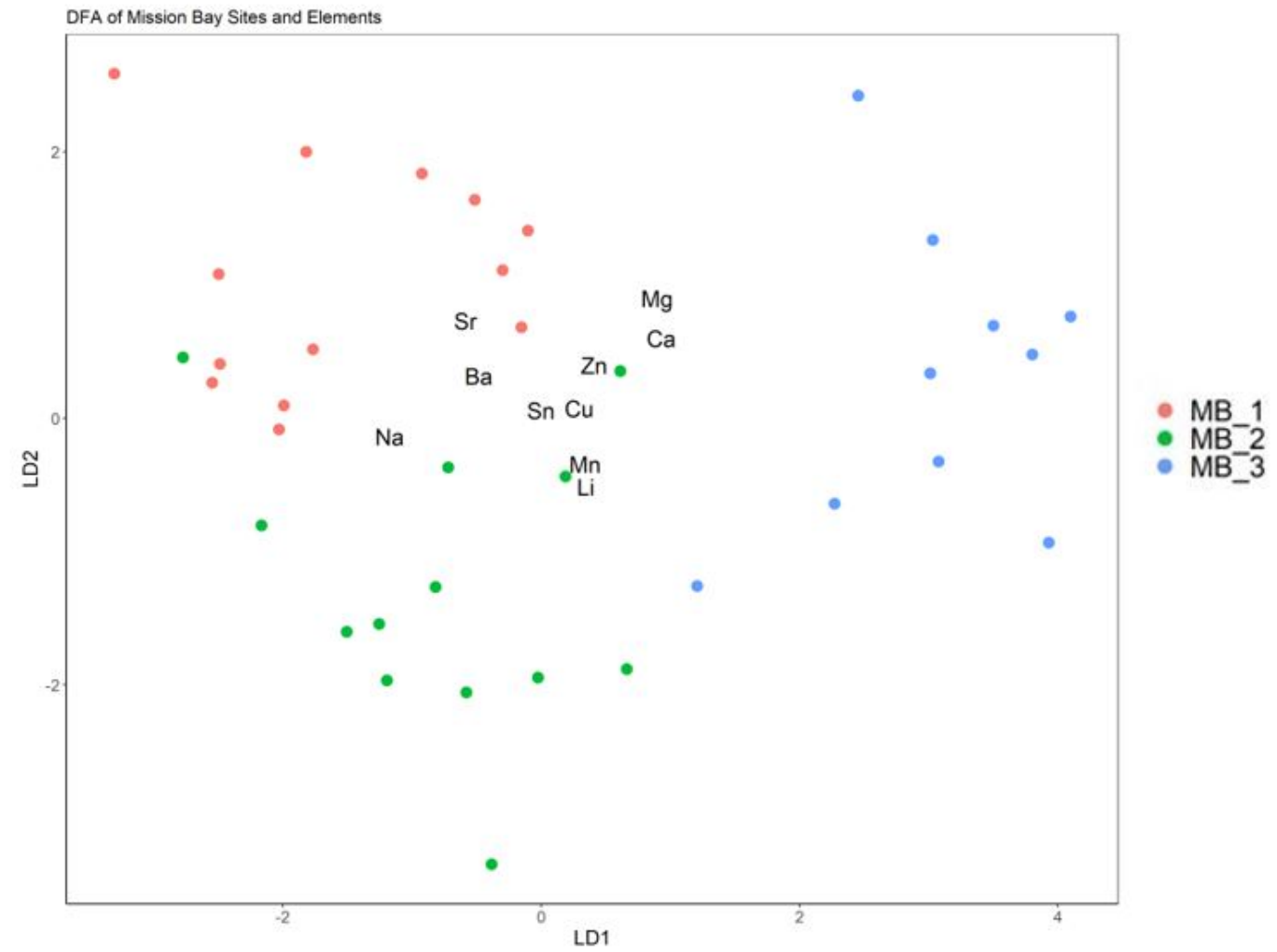


Figure 2.13 Linear discriminant function analysis scores of element:Ca ratios in 36 otoliths of adult Fundulus parvipinnis from San Diego Bay sites (SDB1, SDB2, SDB3, SDB4), by site.

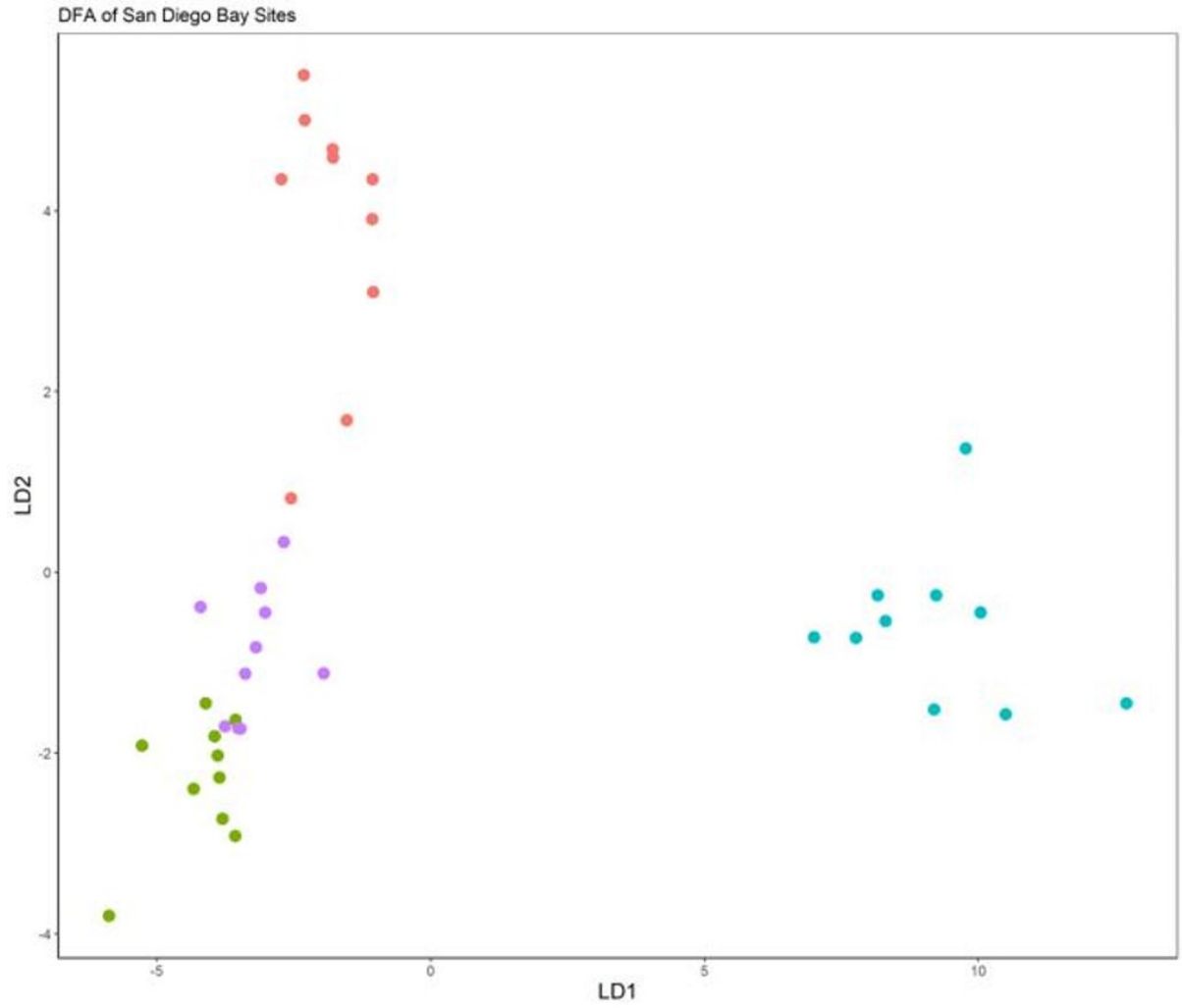

- SDB_1

- SDB_2

- $\mathrm{SDB}^{-3}$

- SDB_4

LD1 
Figure 2.14 Linear discriminant function analysis scores of element:Ca ratios in 36 otoliths of adult Fundulus parvipinnis from San Diego Bay sites (SDB1, SDB2, SDB3, SDB4), by element.

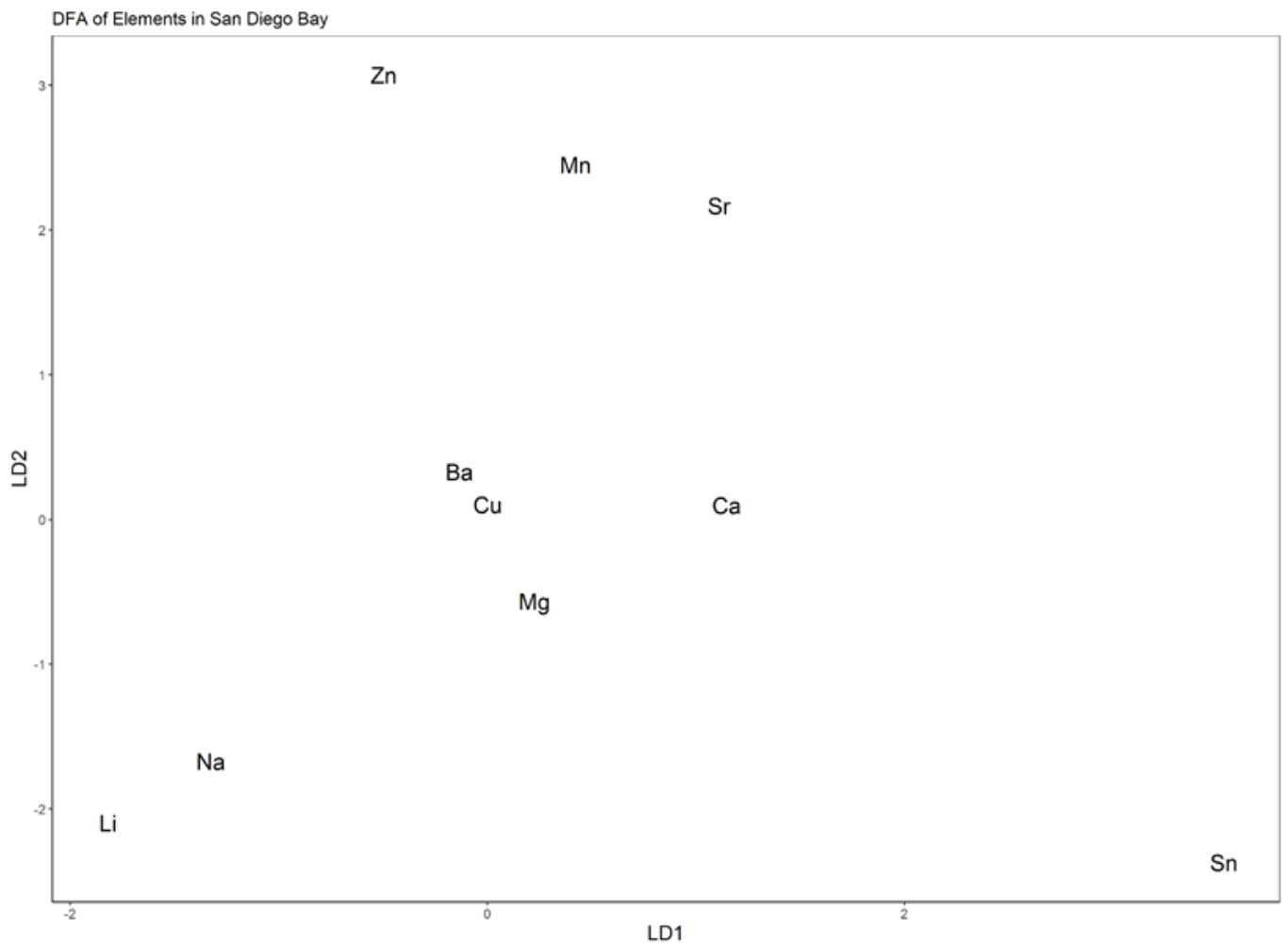


Figure 2.15 Linear discriminant function analysis scores of element:Ca ratios in 36 otoliths of adult Fundulus parvipinnis from San Diego Bay sites (SDB1, SDB2, SDB3, SDB4), by both site and element.

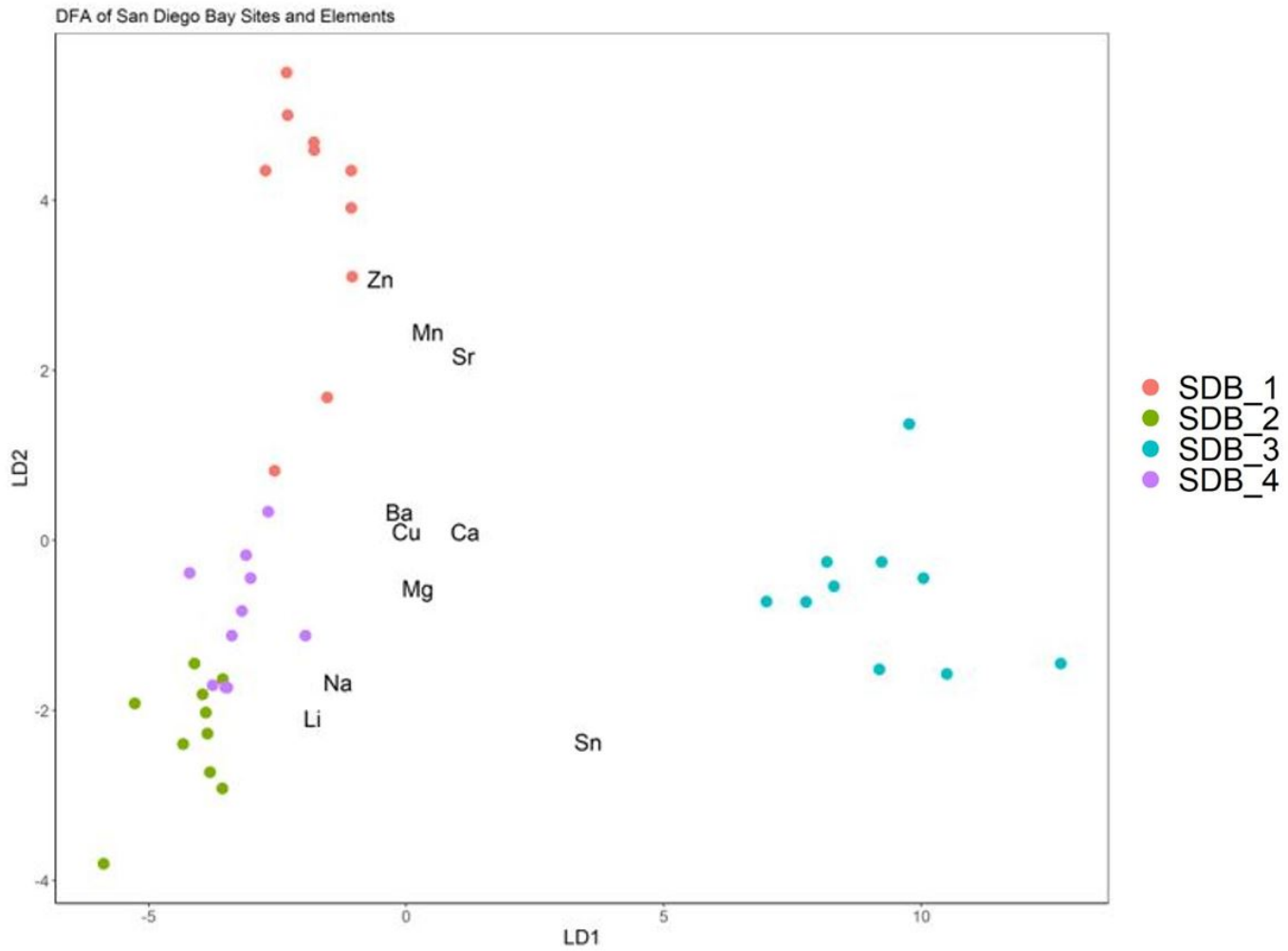


Figure 2.16 Linear discriminant function analysis scores of element:Ca ratios in 36 otoliths of adult Fundulus parvipinnis from Anaheim Bay sites (AB1, AB2, AB3), by site.

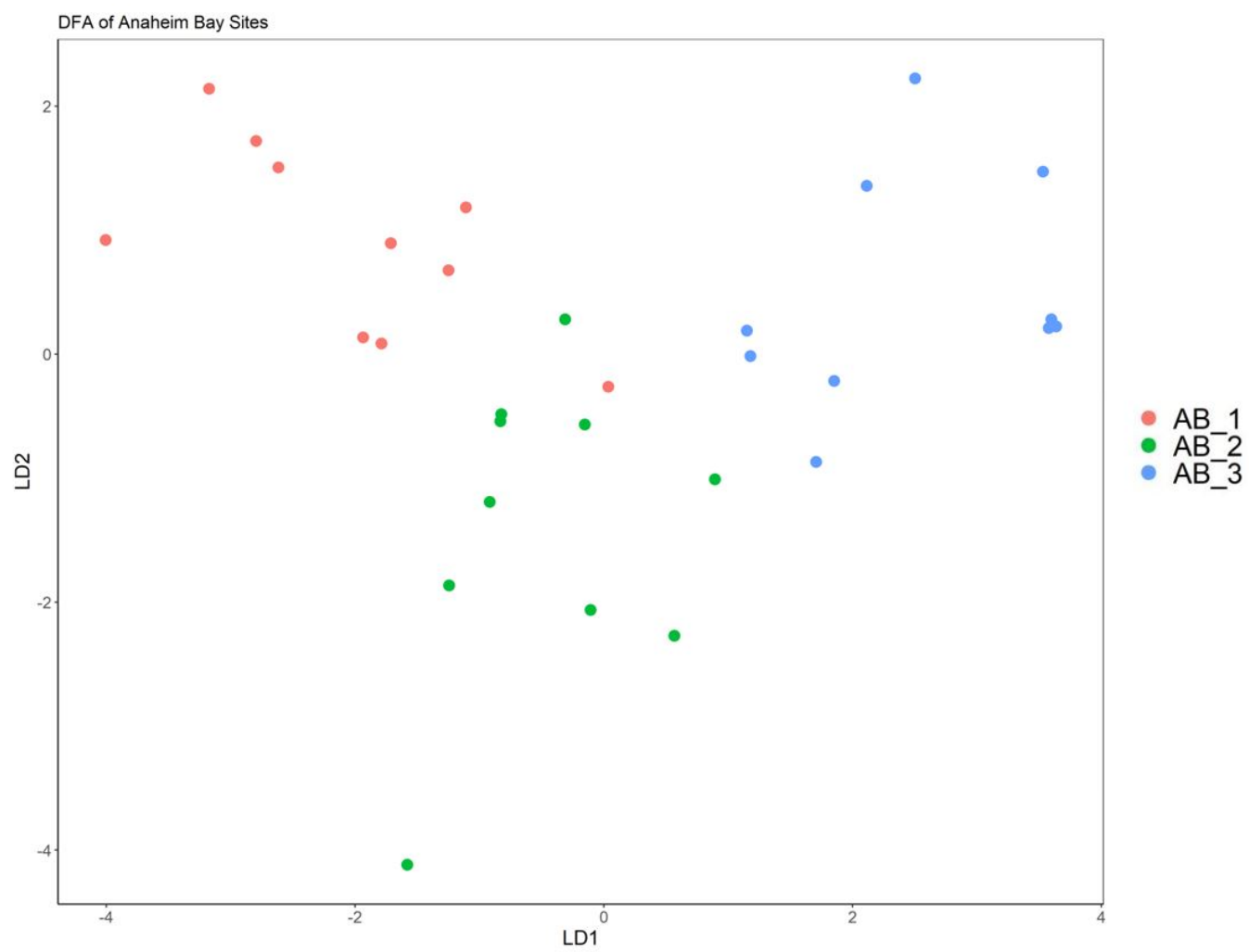


Figure 2.17 Linear discriminant function analysis scores of element:Ca ratios in 36 otoliths of adult Fundulus parvipinnis from Anaheim Bay sites (AB1, AB2, AB3), by element.

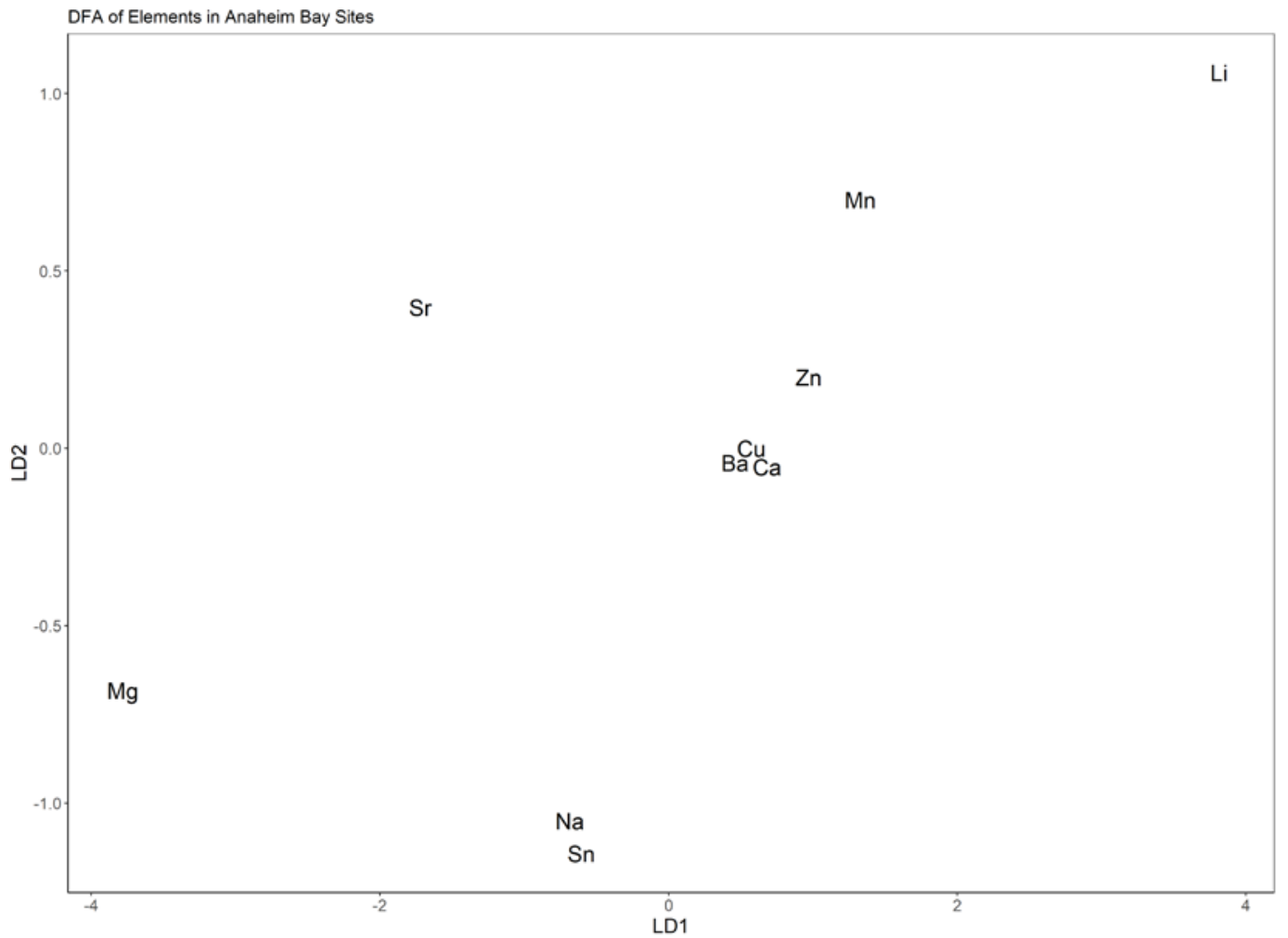


Figure 2.18 Linear discriminant function analysis scores of element:Ca ratios in 36 otoliths of adult Fundulus parvipinnis from Anaheim Bay sites (AB1, AB2, AB3), by both site and element.

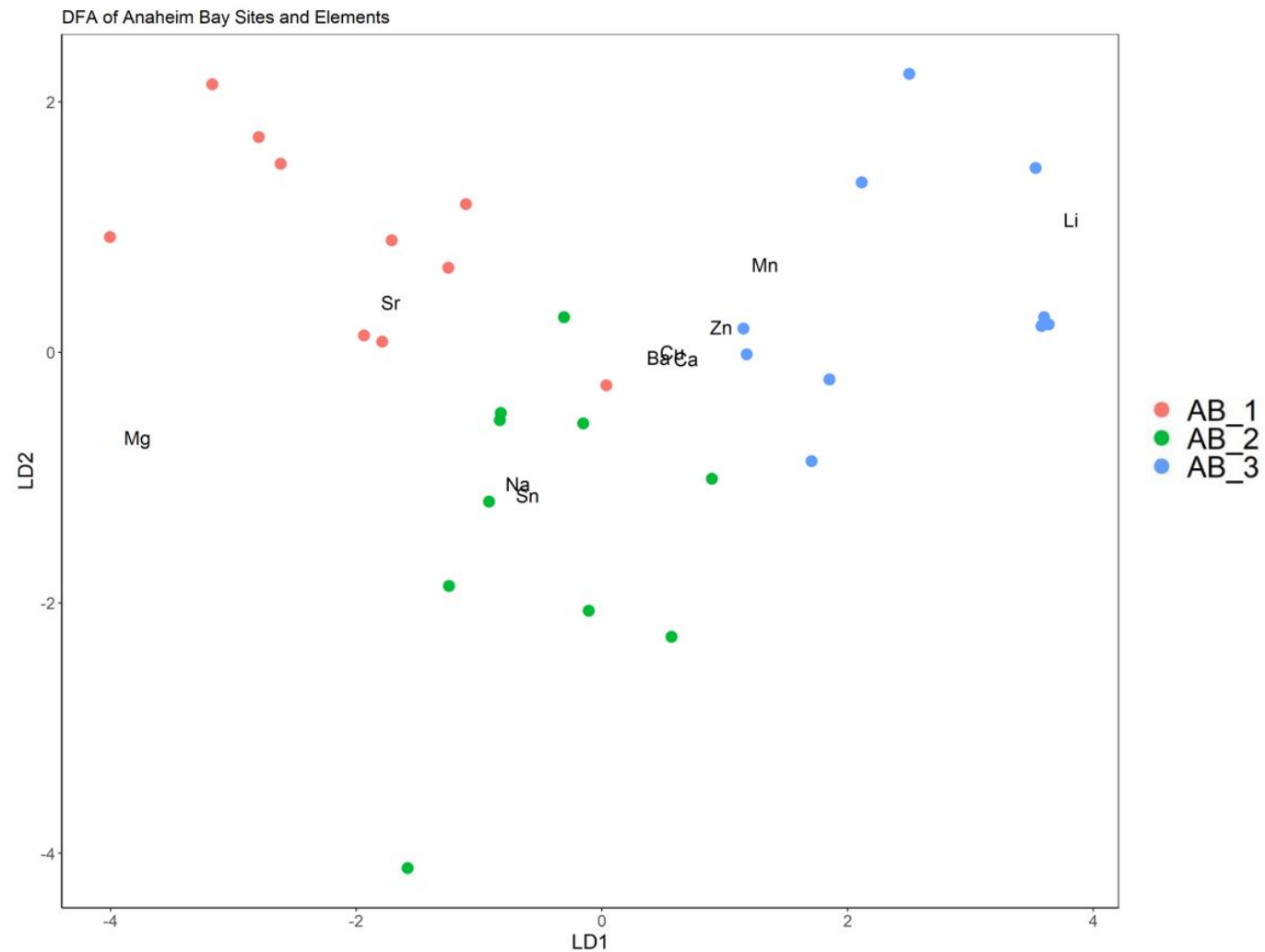




\section{REFERENCES}

Allen, L. G., Pondella, D. J., and Horn, M. H. (2006). Bays and Estuaries. P 119148. In: The Ecology of Marine Fishes: California and Adjacent Waters. University of California Press, Berkeley.

Allen, L.G., Findlay, A.M., and Phalen, C.M. (2002). Structure and standing stock of the fish assemblages of San Diego Bay, California from 1994 to 1999. Bulletin-Southern California Academy of Sciences, 101(2), $49-85$.

Bath, G. E., Thorrold, S. R., Jones, C. M., Campana, S. E., McLaren, J. W., \& Lam, J. W. (2000). Strontium and barium uptake in aragonitic otoliths of marine fish. Geochimica et cosmochimica acta, 64(10), 1705-1714.

Bernardi, G., Talley D. (2000). Genetic evidence for limited dispersal in the coastal California killifish, Fundulus parvipinnis. Journal of Experimental Marine Biology and Ecology 255: 187-199.

Bradbury, I.R., DiBacco, C., Thorrold, S.R., Snelgrove, P.V. and Campana, S.E. (2011). Resolving natal tags using otolith geochemistry in an estuarine fish, rainbow smelt Osmerus mordax. Marine Ecology Progress Series, 433, pp.195-204.

Campana, S. E. (1999). Chemistry and composition of fish otoliths: pathways, mechanisms and applications. Marine Ecology Progress Series 188: 263297.

Campana, S. E. (2005). Otolith elemental composition as a natural marker of fish stocks. Stock identification methods (pp. 227-245). Academic Press.

Campana, S. E. and Thorrold, S. R. (2001). Otoliths, increments, and elements: keys to a comprehensive understanding of fish populations? Canadian Journal of Fisheries and Aquatic Sciences, 58(1), 30-38.

Campana, S.E., Chouinard, G.A., Hanson, J.M., Frechét, A. and Brattey, J. (2000). Otolith elemental fingerprints as biological tracers of fish stocks. Fisheries Research 46, 343-357.

Campana, S.E., Thorrold, S.R., Jones, C.M., Günther, D., Tubrett, M., Longerich, H., Jackson, S., Halden, N.M., Kalish, J.M., Piccoli, P. and De Pontual, H. (1997). Comparison of accuracy, precision, and sensitivity in elemental assays of fish otoliths using the electron microprobe, proton-induced $\mathrm{X}$ ray emission, and laser ablation inductively coupled plasma mass spectrometry. Canadian Journal of Fisheries and Aquatic Sciences, 54(9), pp.2068-2079. 
Campana, Steven E. (1999). Chemistry and composition of fish otoliths: pathways, mechanisms and applications. Marine Ecology Progress Series 188: 263-297.

Childs A.R., Cowley P.D., Næsje T.F., Bennett R.H. (2015) Habitat connectivity and intra-population structure of an estuary-dependent fishery species. Marine Ecology Progress Series 537:233-245.

Connolly, S. R., MacNeil, M. A., Caley, M. J., Knowlton, N., Cripps, E., Hisano, M., ... \& Brandt, A. (2014). Commonness and rarity in the marine biosphere. Proceedings of the National Academy of Sciences, 111(23), 8524-8529.

Cowardin, L M., Carter, V., Golet, F., LaRoe, E.T. (1979). Classification of wetlands and deepwater habitats of the United States. Office of Biological Services, U.S. Fish and Wildlife Service, FWS/OBS-79/31; 131 p.

Danielson, B. J., and R. K. Swihart. 1987. Home range dynamics and activity pattern of Microtus ochrogaster and Synaptomys cooperi in syntropy. Journal of Mammalogy 68:160-165.

Day, J. W., Crump, B. C., Michael Kemp, W., and Yanez-Arancibia, A. (2013). Estuarine Ecology (2nd ed.). Hoboken, N.J: Wiley-Blackwell.

Desmond, J. S., Zedler, J. B., and Williams, G. D. (2000). Fish use of tidal creek habitats in two Southern California salt marshes. Ecological Engineering, 14(3), 233-252.

Dexter, D. M., and Crooks, J. A. (2000). Benthic communities and the invasion of an exotic mussel in Mission Bay, San Diego: a long-term history. Bulletin of the Southern California Academy of Sciences, 99(3), 128-128.

Doubleday, Z. A., Harris, H. H., Izzo, C., and Gillanders, B.M. (2014). Strontium randomly substituting for calcium in fish otolith aragonite. Analytical Chemistry 86(1), 865-869.

Elsdon, T. S. and Gillanders, B. M. (2002). Interactive effects of temperature and salinity on otolith chemistry: challenges for determining environmental histories of fish. Canadian Journal of Fisheries and Aquatic Sciences, 59(11), 1796-1808.

Elsdon, T. S., and Gillanders, B. M. (2003). Reconstructing migratory patterns of fish based on environmental influences on otolith chemistry. Reviews in Fish Biology and Fisheries, 13(3), 217-235.

Elsdon, T.S., Wells, B.K., Campana, S.E., Gillanders, B.M., Jones, C.M., Limburg, K.E., Secor, D.H., Thorrold, S.R., Walther, B.D. (2008). Otolith chemistry to describe movements and life-history parameters of fishes: 
hypotheses, assumptions, limitations and inferences. Oceanography and Marine Biology: An Annual Review, 46, 297-330

Federal Geographic Data Committee. (2013). Classification of wetlands and deepwater habitats of the United States. FGDC-STD-004-2013. Second Edition. Wetlands Subcommittee, Federal Geographic Data Committee and U.S. Fish and Wildlife Service, Washington, DC.

Fodrie, F. J. and Levin, L. A. (2008). Linking juvenile habitat utilization to population dynamics of California halibut. Limnology and Oceanography, 53(2), 799-812.

Fodrie, F. J. and Mendoza, G. (2006). Availability, usage and expected contribution of potential nursery habitats for the California halibut. Estuarine, Coastal and Shelf Science, 68(1), 149-164. DOI: 10.1016/j.ecss.2006.01.017

Fodrie, F.J. and Herzka, S. (2008). Tracking juvenile fish movement and nursery contribution within arid coastal embayments via otolith microchemistry. Marine Ecology Progress Series 361, 253-265.

Forrester, G. E., Swearer, S. E. (2002). Trace elements in otoliths indicate the use of open-coast versus bay nursery habitats by juvenile California halibut. Marine Ecology Progress Series 241, 201-213.

Frimpong, E. A. (2018). A case for conserving common species. PLoS Biology, 16(2).

Fritz, Eugene S. (1975). The Life History of the California Killifish Fundulus Parvipinnis Girard, in Anaheim Bay, California. U.S. Fish and Wildlife Service.

Froese, Rainer and Pauly, Daniel, eds. (2012). Species of Fundulus in FishBase. August 2012 version.

Garwood, J.A., Allen, D.M., Kimball, M.E. (2019) Site Fidelity and Habitat Use by Young-of-the-Year Transient Fishes in Salt Marsh Intertidal Creeks. Estuaries and Coasts 42, 1387-1396

Gillanders, B. M. Kingsford, M. J. (2000). Elemental fingerprints of otoliths of fish may distinguish estuarine 'nursery' habitats. Marine Ecology Progress Series, 201, 273-286.

Gillanders, B. M., Able, K. W., Brown, J. A., Eggleston, D. B., and Sheridan, P. F. (2003). Evidence of connectivity between juvenile and adult habitats for mobile marine fauna: an important component of nurseries. Marine Ecology Progress Series, 247, 281-295. 
Gillanders, B.M. (2005). Using elemental chemistry of fish otoliths to determine connectivity between estuarine and coastal habitats. Estuarine, Coastal and Shelf Science 64, 47-57.

Green, B.C., Smith, D.J., Grey, J. and Underwood, G.J. (2012). High site fidelity and low site connectivity in temperate salt marsh fish populations: a stable isotope approach. Oecologia, 168(1), pp.245-255.

Hanson, P. J., Evans, D. W., Colby, D. R., and Zdanowicz, V. S. (1993). Assessment of elemental contamination in estuarine and coastal environments based on geochemical and statistical modeling of sediments. Marine Environmental Research, 36(4), 237-266.

Hervé, M. and Hervé, M. M. (2020). Package 'RVAideMemoire’. See https://CRAN. R-project. org/package= RVAideMemoire.

Kent, B. J. and Mast, J. N. (2005). Wetland Change Analysis of San Dieguito Lagoon, California, USA: 1928-1994. Wetlands 25(3): 780-787.

Kneib, Ronald T. (1986). The role of Fundulus heteroclitus in salt marsh trophic dynamics. American Zoologist 26.1, 259-269.

Kneib, Ronald T. (1997). The role of tidal marshes in the ecology of estuarine nekton. Oceanography and Marine Biology, 35, 163-220.

Kneib, Ronald T. 1993. Growth and mortality in successive cohorts of fish larvae within an estuarine nursery. Marine Ecology Progress Series 94:115-127

Kramer, Sharon H. (1991). Growth, mortality, and movements of juvenile California halibut (Paralichthys californicus) in shallow coastal and bay habitats of San Diego County, California. Fish. Bull. 89: 195-207.

Kuris, A.M., Hechinger, R.F., Shaw, J.C., Whitney, K.L., Aguirre-Macedo, L., Boch, C.A., Dobson, A.P., Dunham, E.J., Fredensborg, B.L., Huspeni, T.C. and Lorda, J. (2008). Ecosystem energetic implications of parasite and free-living biomass in three estuaries. Nature, 454(7203), pp.515-518.

Kwak, T. J., and Zedler, J. B. Food web analysis of southern California coastal wetlands using multiple stable isotopes. Oecologia 110.2 (1997): 262-277.

Lafferty, Kevin D. (2005). Assessing Estuarine Biota in Southern California. Gen. Technical Report. PSW-GTR-195. United States Department of Agriculture, Forest Service.

Largier, J. L., Hollibaugh, J. T., and Smith, S. V. (1997). Seasonally hypersaline estuaries in Mediterranean-climate regions. Estuarine, Coastal and Shelf Science, 45(6), 789-797. 
Legendre, Pierre and Fortin, Marie-Josee. Comparison of the Mantel test and alternative approaches for detecting complex multivariate relationships in the spatial analysis of genetic data. Molecular Ecology Resources 10.5 (2010): 831-844.

López-Duarte, P. C., Carson, H. S., Cook, G. S., Fodrie, F. J., Becker, B. J., DiBacco, C., and Levin, L. A. (2012). What controls connectivity? An empirical, multi-species approach. 511-524.

Love, Milton. (2011). Certainly More Than You Want to Know About The Fishes of The Pacific Coast. Santa Barbara, CA: Really Big Press.

Ludsin, S. A., Fryer, B. J. and Gagnon, J. E. (2006). Comparison of SolutionBased versus Laser Ablation Inductively Coupled Plasma Mass Spectrometry for Analysis of Larval Fish Otolith Microelemental Composition. Transactions of the American Fisheries Society 135: 218231. doi:10.1577/T04-165.1

Madon, S. P., Williams, G. D., West, J. M., Zedler, J. B. (2001). The importance of marsh access to growth of the California killifish, Fundulus parvipinnis, evaluated through bioenergetics modeling. Ecological Modelling 135: 149-165.

Martinho, F., Pina, B., Nunes, M., Vasconcelos, R.P., Fonseca, V.F., Crespo, D., Primo, A.L., Vaz, A., Pardal, M.A., Gillanders, B.M. and Tanner, S.E. (2020). Water and otolith chemistry: implications for discerning estuarine nursery habitat use of a juvenile flatfish. Frontiers in Marine Science, 7, p.347.

McGrath, Patrick and Austin, Herbert A. (2009). Site Fidelity, Home Range, and Tidal Movements of White Perch during the Summer in Two Small Tributaries of the York River, Virginia. Transactions of the American Fisheries Society, 138:5, 966-974.

McLusky, D. S. and Elliott, M. (2004). The Estuarine Ecosystem: Ecology, Threats and Management. New York: Oxford University Press. ISBN 019-852508-7.

McMahon, K. W., Johnson, B. J., and Ambrose, W. G. (2005). Diet and movement of the killifish, Fundulus heteroclitus, in a Maine salt marsh assessed using gut contents and stable isotope analyses. Estuaries, 28(6), 966-973.

Miller, RR. (1943). Further data on freshwater populations of the Pacific killifish, Fundulus parvipinnis. COPEIA 1: 51-52. 
Milton, D. A. and Chenery, S. R. (2001). Sources and uptake of trace metals in otoliths of juvenile barramundi (Lates calcarifer). Journal of Experimental Marine Biology and Ecology, 264(1), 47-65.

NOAA (National Oceanic and Atmospheric Administration). (1990). Estuaries of the United States, statistics of a national resource base. Special NOAA 20th Anniversary Report, Strategic Assessment Branch, Office of Oceanography and Marine Assessment, Washington, DC.; 79 p.

Nordby, C. S. (1982). The comparative ecology of ichthyoplankton within Tijuana Estuary and in adjacent nearshore waters. M.S. California State University, San Diego.

Oksanen, Jari; Blanchet, Guillaume F.; Friendly, Michael; Kindt, Roeland; Legendre, Pierre; McGlinn, Dan; Minchin, Peter R.; O'Hara, R.B.; Simpson, Gavin L.; Solymos, Peter M.; Stevens, Henry H.; Szoecs, Eduard; Wagner, Helene (2019). vegan: Community Ecology Package. R package version 2.5-6. https://CRAN.R-project.org/package=vegan

Patterson, H. M., McBride, R. S., and Julien, N. (2004). Population structure of red drum (Sciaenops ocellatus) as determined by otolith chemistry. Marine Biology, 144(5), 855-862.

Patterson, W. P. (1999). Oldest isotopically characterized fish otoliths provide insight to Jurassic continental climate of Europe. Geology 27(3): 199-202.

Quinn, Gerry P. and Keough, Michael J. (2002). Experimental Design and Data Analysis for Biologists, Cambridge University Press.

R Core Team (2020). R: A language and environment for statistical computing. R Foundation for Statistical Computing, Vienna, Austria. URL https://www.R-project.org/.

Shaw, J. C, Hechinger, R. F., Lafferty, K. D. and Kuris, A. M. (2010). Ecology of the brain trematode Euhaplorchis californiensis and its host, the California killifish (Fundulus parvipinnis). Journal of Parasitology 96(3), 2010, pp. 482-490.

Sturgeon, R. E., S. N. Willie, L. Yang, R. Greenberg, R. O. Spatz, Z. Chen, Clancy Scriver, V. Clancy, J. W. Lam, and S. Thorrold. (2005). "Certification of a fish otolith reference material in support of quality assurance for trace element analysis." Journal of Analytical Atomic Spectrometry 20, no. 10: 1067-1071.

Sturrock, A. M., Wikert, J. D., Heyne, T., Mesick, C., Hubbard, A. E., Hinkelman, T. M., et al. (2015). Reconstructing the migratory behavior and long-term survivorship of juvenile Chinook salmon under contrasting hydrologic regimes. PLOS ONE 
Swearer, Stephen E., Forrester, Graham E., Steele, Mark A., Brooks, Andrew J., Lea, David W. (2003). Spatio-temporal and interspecific variation in otolith trace-elemental fingerprints in a temperate estuarine fish assemblage. Estuarine, Coastal and Shelf Science 56(5): 1111-1123.

Talley, D. M. (2000). The Role of Resident Fishes in Linking Habitats of a Southern California Salt Marsh. In: Scripps Institution of Oceanography, 227 pages. University of California, San Diego, La Jolla, CA Retrieved from https://escholarship.org/uc/item/1qr663x4

Talley, Drew (2000). Ichthyofaunal utilization of newly-created versus natural salt marsh creeks in Mission Bay, CA. Wetlands Ecology and Management 8, 117-132.

Teo, S.L.H and Able K.W. (2003) Habitat use and movement of the mummichog (Fundulus heteroclitus) in a restored salt marsh. Estuaries and Coasts 26:720-730

Thompson, A. R., Baskin, J. N., Swift, C. C., Haglund, T. R., and Nagel, R. J. (2010). Influence of habitat dynamics on the distribution and abundance of the federally threatened Santa Ana Sucker, Catostomus santaanae, in the Santa Ana River. Environmental Biology of Fishes, 87(4), 321-332.

U. S. Fish and Wildlife Service. (2018) National Wetlands Inventory website. U.S. Department of the Interior, Fish and Wildlife Service, Washington, D.C. http://www.fws.gov/wetlands/

Venables WN, Ripley BD (2002). Modern Applied Statistics with S, Fourth edition. Springer, New York. ISBN 0-387-954570, https://www.stats.ox.ac.uk/pub/MASS4/.

Vinagre, C., Salgado, J., Costa, M. J., and Cabral, H. N. (2008). Nursery fidelity, food web interactions and primary sources of nutrition of the juveniles of Solea solea and S. senegalensis in the Tagus estuary (Portugal): a stable isotope approach. Estuarine, Coastal and Shelf Science, 76(2), 255-264.

Vince, S., Valiela, I., Backus, N., and Teal, J. M. (1976). Predation by the salt marsh killifish Fundulus heteroclitus (L.) in relation to prey size and habitat structure: consequences for prey distribution and abundance. Journal of Experimental Marine Biology and Ecology, 23(3), 255-266.

Waltham, N. J., and Connolly, R. M. (2006). Trophic strategies of garfish, Arrhamphus sclerolepis, in natural coastal wetlands and artificial urban waterways. Marine Biology, 148(5), 1135-1141.

Walther, B. D. and Thorrold, S. R. (2006). Water, not food, contributes the majority of strontium and barium deposited in the otoliths of a marine fish. Marine Ecology Progress Series, 311, 125-130. 
Walther, B.D. and Limburg, K.E. (2012). The use of otolith chemistry to characterize diadromous migrations. Journal of Fish Biology, 81(2), pp.796-825.

Watson W. (1992). Cyprinodontidae in Moser HG, ed. The early stages of fishes in the California Current region, vol. Atlas 33 California Cooperative Fisheries Institute (CalCOFI).

West, J.M., Zedler, J.B. (2000). Marsh-creek connectivity: Fish use of a tidal salt marsh in Southern California. Estuaries 23, 699-710.

Wickham, H. (2016). ggplot2: Elegant Graphics for Data Analysis, SpringerVerlag New York. Available at: https://ggplot2.tidyverse.org.

Williams, G.D., Zedler, J.Z. (1999). Fish assemblage composition in constructed and natural tidal marshes of San Diego Bay: Relative influence of channel morphology and restoration history. Estuaries. 22: 702-716.

Wolanski, E., Brinson, M. M., Cahoon, D. R., and Perillo, G. M. (2009). Coastal wetlands: a synthesis. Coastal wetlands: an integrated ecosystem approach. Elsevier. Amsterdam, Países Bajos. p, 1-62. 


\section{CHAPTER 3: Conclusion}

Southern California wetlands, despite decades of habitat disturbance and loss, remain productive and vital environments for fishes, birds, invertebrates, insects, and plants. We found even small fragments of wetland were able to retain small spatially distinct subpopulations of F parvipinnis. This study was the first ICP-MS analysis of F. parvipinnis in Southern California, one of the few to investigate the power of otolith microchemistry on such a small spatial scale, and the first to analyze the habitat connectivity of $F$. parvipinnis within and among these three estuaries.

We conclude F parvipinnis exhibits high site fidelity and low habitat connectivity on a range of spatial scales in Southern California. Habitat connectivity depends on more than just the distance between available sites, but also on the availability of natural habitat between these nearby sites, which provide fish the possibility of movement or relocation following marsh degradation or destruction. Therefore, protection of the matrix between habitats allows for increased movement. This study improves our understanding of how $F$. parvipinnis and other important wetland fishes are connected so that we protect their ability to move freely among available habitats.

We currently have a better understanding of the applications of otolith microchemistry than the mechanisms responsible for this process. Future studies should examine the causes of these site-specific differences in otolith chemistry and how they relate to environmental variability in sediment and water. Future work should also study habitat resilience by testing how long it would take for the 
fragment of wetland at one of these study sites to recover, if all resident fish species were removed.

Lastly, we suggest future otolith studies incorporate genetic analyses when studying habitat connectivity of estuarine fishes. Recent studies that have paired the use of otolith microchemistry with genetic analyses indicate that these techniques can provide unique and complementary information on the population structure and life history of fishes (Feyrer et al. 2007, Miller et al. 2005, Patterson et al. 2004). While otolith microchemistry provides shorter resolution of events that have occurred within the time scale of an individual lifetime, genetic markers such as microsatellite DNA provide a much longer time scale resolution of fish life history of the population (Miller et al. 2005). When combined, genetic analyses and otolith ICP-MS hold the potential to provide both short-term and long-term resolution that one technique alone are unable to provide (Patterson et al. 2004). However, like the current spatial scale shortcomings of otolith microchemistry studies, combinations of these approaches have not been adequately tested for fishes at smaller spatial scales (Feyrer et al. 2007).

We suggest combining these approaches in future studies to improve the temporal resolution of habitat connectivity of estuarine fishes, better understand how populations are connected, and sustain the role of fishes in wetland food webs through appropriate management and conservation. 


\section{REFERENCES}

Feyrer, Frederick, James Hobbs, Melinda Baerwald, Ted Sommer, Qing-zhu Yin, Kevin Clark, Bernie May, and William Bennett. (2007). Otolith microchemistry provides information complementary to microsatellite DNA for a migratory fish. Transactions of the American Fisheries Society 136(2), 469-476.

Miller, J. A., Banks, M. A., Gomez-Uchida, D., and Shanks, A. L. (2005). A comparison of population structure in black rockfish (Sebastes melanops) as determined with otolith microchemistry and microsatellite DNA. Canadian Journal of Fisheries and Aquatic Sciences, 62(10), 2189-2198.

Patterson, H. M., McBride, R. S., and Julien, N. (2004). Population structure of red drum (Sciaenops ocellatus) as determined by otolith chemistry. Marine Biology, 144(5), 855-862. 


\section{APPENDIX}

Appendix A.1 - Histograms of the 12 trace metals to check for normality of distribution for Mission Bay sites (MB1, MB2, MB3). Signatures from the 36 otoliths were combined in the histograms.
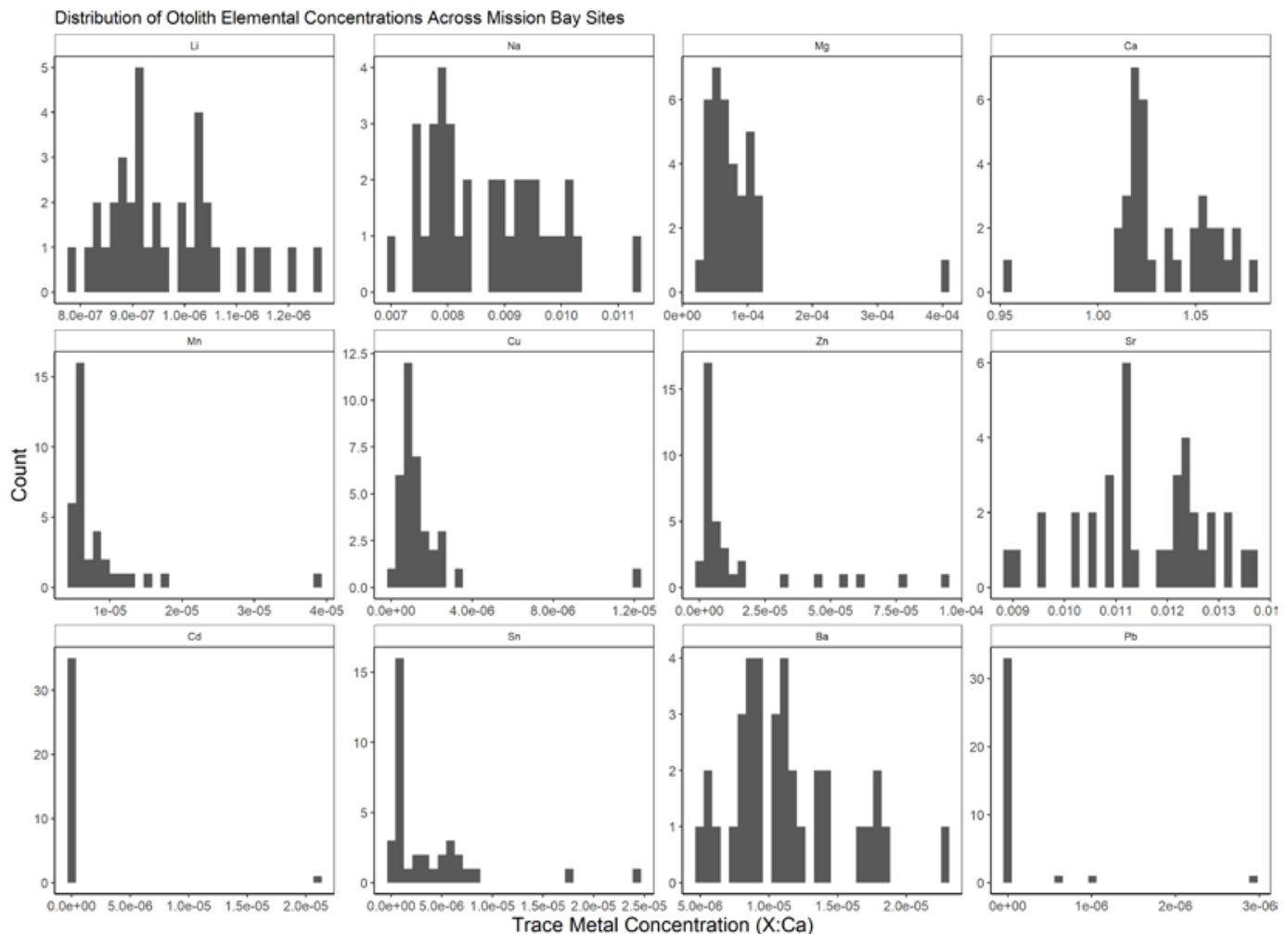
Appendix A.2 - Histograms of the 12 trace metals to check for normality of distribution for San Diego Bay sites (SDB1, SDB2, SDB3, SDB4). Signatures from the 40 otoliths were combined in the histograms.
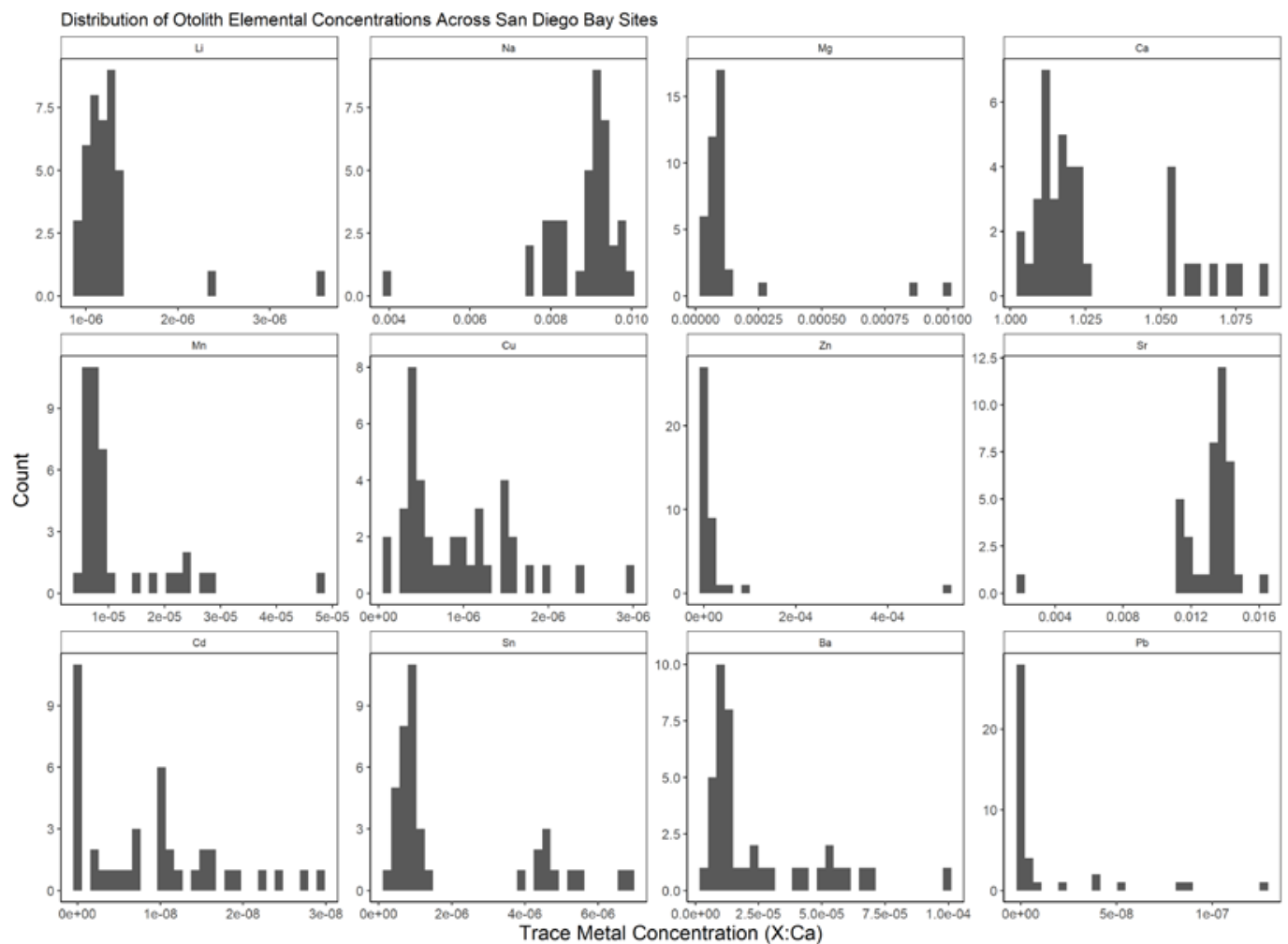
Appendix A.3 - Histograms of the 12 trace metals to check for normality of distribution for Anaheim Bay sites (AB1, AB2, AB3). Signatures from the 30 otoliths were combined in the histograms.
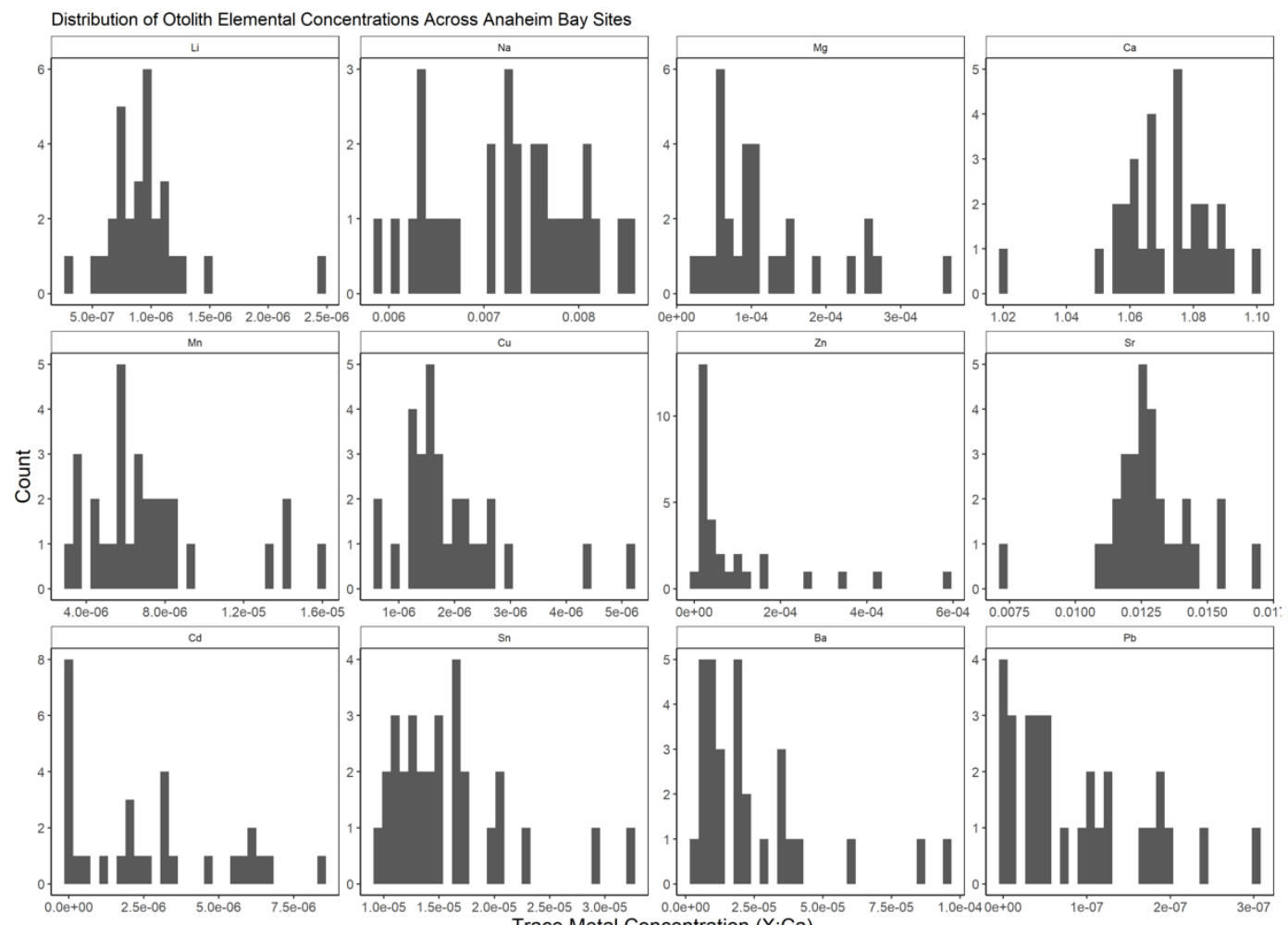